Portland State University

PDXScholar

Summer 8-7-2017

\title{
Sustaining the Human Spirit of the High School Principal Leading for Equity
}

Ryan David Richardson

Portland State University

Follow this and additional works at: https://pdxscholar.library.pdx.edu/open_access_etds

Part of the Educational Administration and Supervision Commons, and the Educational Leadership Commons

Let us know how access to this document benefits you.

\section{Recommended Citation}

Richardson, Ryan David, "Sustaining the Human Spirit of the High School Principal Leading for Equity" (2017). Dissertations and Theses. Paper 3763.

https://doi.org/10.15760/etd.5647

This Dissertation is brought to you for free and open access. It has been accepted for inclusion in Dissertations and Theses by an authorized administrator of PDXScholar. Please contact us if we can make this document more accessible: pdxscholar@pdx.edu. 
Sustaining the Human Spirit of the High School Principal Leading for Equity

by

Ryan David Richardson

A dissertation submitted in partial fulfillment of the requirements for the degree of

Doctor of Education

in

Educational Leadership: Administration

Dissertation Committee:

Deborah Peterson, Chair

Pat Burk

Dan Johnson

Margaret Everett

Portland State University

2017 
C 2017 Ryan David Richardson 


\begin{abstract}
Shrinking budgets and swelling public accountability characterize public education in the $21^{\text {st }}$ century. Pressures to increase achievement while assuring the emotional and physical safety of all students make the work of the secondary principal daunting. A leader for equity must be a symbolic, visionary, and instructional leader that creates positive change that leads to student achievement, especially for students that are traditionally underserved. The demands placed on school administrators generate leadership burnout. As we strive to meet the rigorous goals of improving academic achievement while teaching and caring for each child, we must create environments for effective administrators to thrive in their schools long enough to impact a school's culture and produce equitable outcomes.

The purpose of this dissertation is to describe and explain the issues around nurturing the human spirit of high school principals. Chapters One and Two will describe the context of the problem and a literature review. In Chapter Three, the research will be described including the methodology, instruments, and the process for data collection and analysis. Chapter Four will describe the findings of the research that examines how a clear focus on equity and relationships lead to feelings of satisfaction, self efficacy, and career/personal fulfillment for each of the leaders in this study. The study includes two groups, Principals of Color and White principals that are allies to people of color. Chapter Five synthesizes the findings and makes recommendations for future practice and policy.
\end{abstract}




\section{Dedication}

First and foremost this dedication is to my incredible family. To my wife, Julie, who has been behind me since the day I started this program, cheering me on while taking on extra work so that I may pursue this goal. Our spirits are one. I could not do this without you. My daughter, Poppy, who loves me unconditionally, even if it means I am home late and leave early. Thank you for your patience while Daddy "finishes his project." And, to the amazing administrators across the state of Oregon who are dedicating their lives to the work of nurturing every student that walks through your school doors; may your lives be filled with satisfaction, pride, and fulfillment as you connect with your own sense of meaning and purpose every day. 


\section{Acknowledgements}

I am forever grateful for the people and organizations that have supported me, encouraged me, and allowed me to pursue my own sense of meaning and purpose. As I fulfill my own human spirit through this work my hope is that in some way, their role in helping me has contributed to fulfilling their own human spirit. I know that we are forever connected thanks to the support and care that was given to me during these last four years.

I am especially grateful for the ongoing care, support, kindness, encouragement, push, and snacks that have been given to me by my incredible dissertation chair and assistant professor at Portland State University, professor Deborah Peterson. She is the reason I was inspired to pursue my dissertation, the reason I have stayed intellectually engaged during the past four years, and the reason I will continue to learn and grow as a passionate participant in the field of education.

I am also grateful for my committee members for their feedback and commitment to ensuring my research and methodology is sound and respected. Thank you Dr. Everett, Dr. Burk, and Dr. Johnson. My hope is that by supporting another student, your spirit is fulfilled knowing the incredible difference you make in the lives of others.

To my research partner and friend, Victor Vergara. You have inspired and pushed me along the way. I could not ask for a better person to go through this with. I am grateful for our friendship and future partnership on the next chapter.

I also wish to thank my incredible colleagues in North Clackamas School District. Superintendent Matt Utterback has inspired me to include equity in everything I do, 
including this research. The incredible principals that I've worked for during these 4 years: Alyson Brant and Kathy Walsh. You have put up with my demanding schedule and supported me every step of the way. I am lucky to be able to call each of you a mentor, a colleague, and a friend. Finally, the amazing staff that I've worked with during these 4 years. You have shown nothing but support, curiosity, and kindness. Our students are lucky to be supported by the best teaching and support staff there is. 


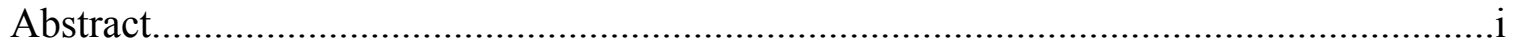

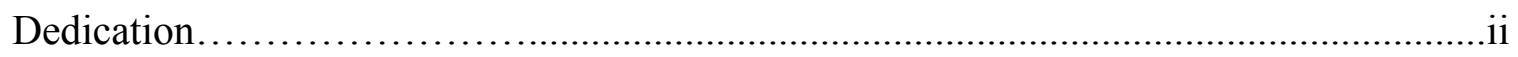

Acknowledgements......................................................

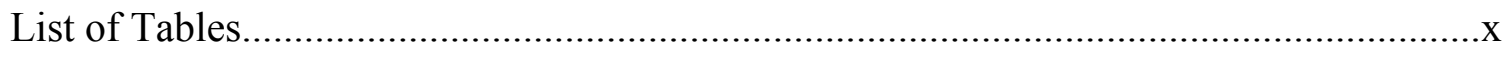

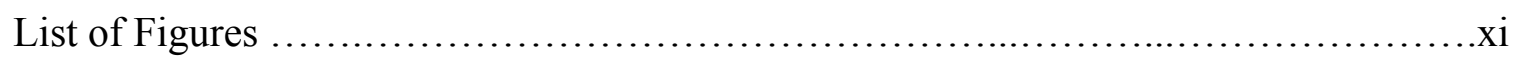

Chapter One: Problem Statement.............................................................................

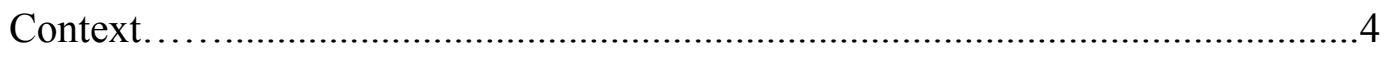

Background of Problem............................................................................ 6

Statement of Research Problem.......................................... 8

Significance of the Research Problem................................... 9

Presentation of Methods and Research Question............................. 12

Key Concepts........................................................ 13

Chapter Two: Literature Review...........................................15

Theoretical Frameworks \& Review of Literature.......................... 16

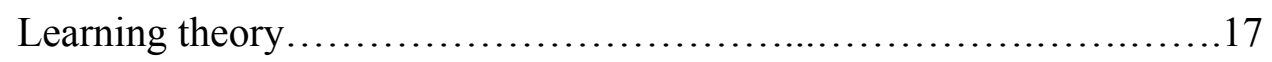

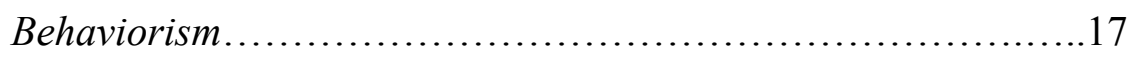

Constructivism.........................................20

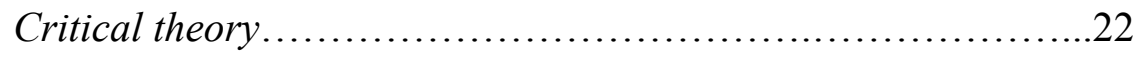

Latino race theory .........................................24

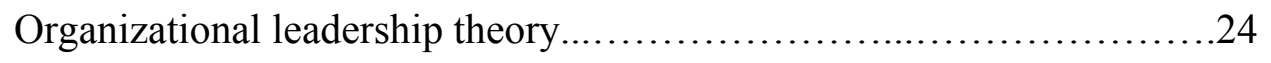




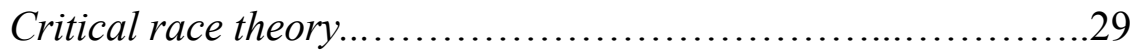

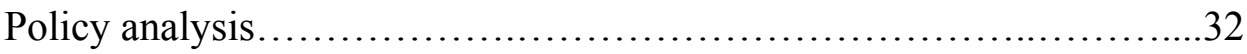

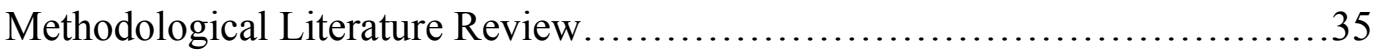

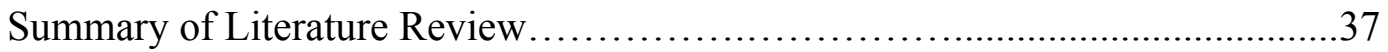

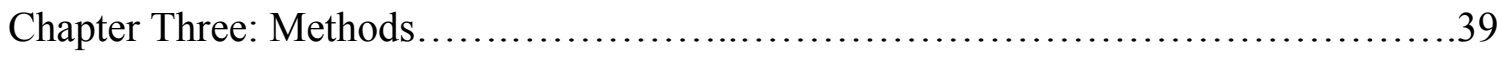

Research Methods.......................................................40

Quantitative component..........................................42

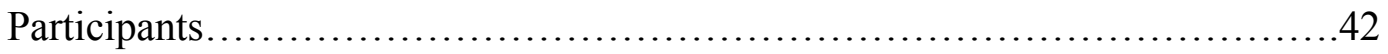

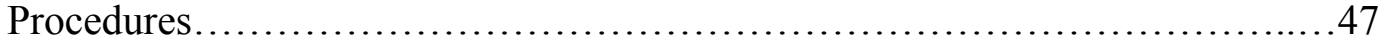

Recruitment................................................... 47

Informed consent ............................................48

Data collection.................................................... 48

Data confidentiality..........................................48

Risks...................................................... 49

Instruments and measures.............................................49

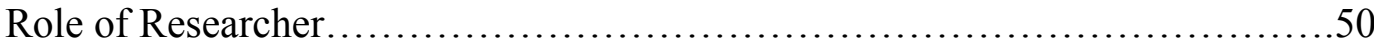

Data Collection and Analysis............................................52

Chapter Four: Results/Analysis..................................................55

Analysis of the TELL Survey...............................................57

Analysis of Qualitative Data..............................................60

Question 1: Career Pathway ..........................................61 
Question 2: Who inspired you?...................................6 62

Question 3: Did you get any resistance?.............................63

Question 4: Formal training for success w/ Latina/o students?............64

Question 5: Best advice received?................................65

Question 6: Unique leadership characteristics?..................................65

Question 7: Most important initiatives \& priorities?...................66

Question 8: Latina/o success?....................................68

Question 9: Expectations from superintendent and board?..................69

Question 10: What messages do you send?...............................69

Question 11: What advice would you give?.............................70

Question 12: Sense of meaning and purpose?..............................71

Question 13: What gets in the way of meaning and purpose?.................73

Synthesis of Data.................................................. 75

Limitations of the Study ......................................... 92

Chapter Five: Discussion/Conclusion........................................95

Synthesis of Findings.............................................. 98

Implications...................................................... 100

Implications for All Principals.................................. 100

Implications for Administrators Working with Principals of Color.......102 Implications for Principals of Color............................. 104

Implications for District Leadership...............................106

Implications for Higher Education Principal Preparation Programs......110

vii 
Conclusion

Appendix A Email to Potential Participants...................................128

Appendix B Letter to Superintendents to Request Permission to Study..........130

Appendix C Interview Questions.......................................132

Appendix D Consent for Participation in Research............................134

Appendix E SPSS Results: Shared Vision..................................137

Appendix F SPSS Results: Trust, Mutual Respect..........................138

Appendix G SPSS Results: Staff Can Raise Concerns........................139

Appendix H SPSS Results: Leadership Supports Teachers....................140

Appendix I SPSS Results: High Professional Standards.......................141

Appendix J SPSS Results: Using Data...................................142

Appendix K SPSS Results: Teacher Performance Assessed Objectively............143

Appendix L SPSS Results: Helpful Feedback for Improvement.................144

Appendix M SPSS Results: Ongoing Teacher Feedback......................145

Appendix N SPSS Results: Evaluations Consistent.........................146

Appendix O SPSS Results: Admin Uses Evaluation Tool Well.................147

Appendix P SPSS Results: School Improvement Team Leads....................148

Appendix Q SPSS Results: Recognition of Accomplishments..................149

Appendix R SPSS Results: Good Place to Work and Learn.....................150 
Appendix S Question 1 Responses.

Appendix T Question 2 Responses................................... 152

Appendix U Question 3 Responses.....................................153

Appendix V Question 4 Responses...................................154

Appendix W Question 5 Responses.................................... 155

Appendix X Question 6 Responses...................................156

Appendix Y Question 7 Responses...................................157

Appendix Z Question 8 Responses......................................158

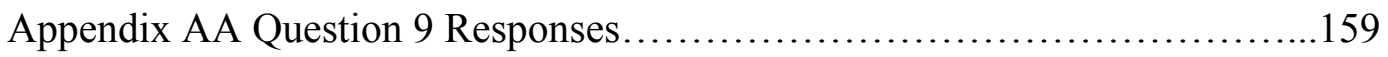

Appendix BB Question 10 Responses.................................160

Appendix CC Question 11 Responses.................................161 


\section{List of Tables}

Table

1 School Organizational Characteristics That Correlate With Bureaucratic

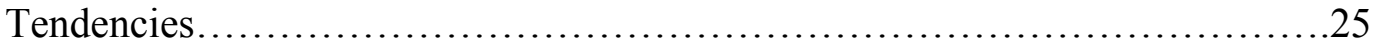

2 Participant Demographics............................................44

3 School Demographic Information...................................... 45

4 Synthesis of Participant Data by Race, Gender, and Language.................45

$5 \quad$ Location of Schools...................................................... 46

6 School-wide Percent of Latina/o Students.................................46

$7 \quad$ Size of Schools....................................................... 46

8 Graduation Rates at Each School...........................................46

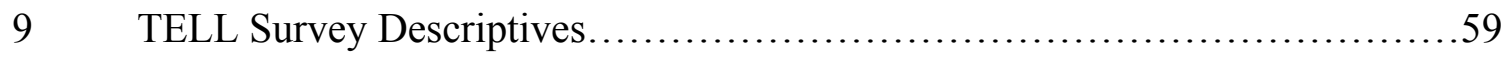

10 What Gives You a Sense of Meaning and Purpose?....................................... 72

11 What Gets in the Way of Your Sense of Meaning and Purpose?........................74

12 Quantized Data for Equity Responses..................................76

13 Quantized Data for Relationship Responses............................80

14 Quantized Data for Working Conditions Responses........................84

15 Quantized Data for the Category: Systems of Oppression......................86

16 Principals of Color: Need for Grit..................................91 


\section{List of Figures}

$\begin{array}{lll}\text { Figure } & \text { Page }\end{array}$

1 Theoretical framework.............................................. 38

2 Coding methods framework ........................................... 53

3 Coaxial coding showing how themes connected to central category or equity....78

4 Themes that connected to the category of relationships..................... 81

5 Chapter Two framework compared to new findings........................83

6 Coaxial coding for themes related to working conditions....................85

7 Coaxial coding for themes related to systems of oppression..................87

8 Comparison of findings between White principals and Principals of Color........90 


\section{Chapter One: Problem Statement}

Since the implementation of No Child Left Behind (2001) the role of school leader has become more challenging than ever (CPE, 2012; Markow \& Pieters, 2012). After scanning several media sources in which the principal's job was advertised, Copland (2001) synthesized the requirements of the job descriptions by developing his own advertisement illustrating the portrait of the much-needed principal:

Position Vacant: School Principal

Qualifications: Wisdom of a sage, vision of a Chief Executive Officer, intellect of a scholar, leadership of a point guard, compassion of a counselor, moral strength of a nun, courage of a firefighter, craft knowledge of a surgeon, political savvy of a senator, toughness of a soldier, listening skills of a blind man, humility of a saint, collaborative skills of an entrepreneur, certitude of a civil rights activist, charisma of a stage performer, and patience of Job. Salary: lower than you might $\operatorname{expect}($ p. 528).

Principals working for social justice have high turnover rates (Burkhauser, Gates, Hamilton \& Ikemoto, 2012; CPE, 2012). Leaders who focus on equity are met with greater challenges than others (DiAngelo, 2011; Theoharris, 2007). Principals often feel isolated while fighting uphill battles in order to advocate for students and families that otherwise would not have a voice. The toll this takes on leaders, especially Principals of Color, is dramatic and includes a negative emotional and physical affect (Peterson \& Vergara, 2016; Theoharis, 2007). 
One suggested cause of this phenomenon is that the human spirit of principals cannot be sustained in the midst of too many demands that come with the principalship (Alt \& Henke 2007; Gates et al., 2006; Guarino, Santibanez \& Daley, 2006). Connecting a sense of meaning to our daily work is critical in the midst of complex systems that may pull one's time and attention in many directions (Marshall, 2009; C. Mayes, P. Mayes \& Sagmiller, 2003; Miller, 2006; Palmer, 2003). Most educators who seek out administrative positions, including principalships, are motivated by a desire to engage in cultural, symbolic, and educational leadership, rather than by a desire to serve as managers or human relations experts (UCEA, 2012). To put it another way, most prospective principals are excited to make a difference in the lives of students and teachers.

While it is true that leadership activities that are technical in nature are necessary to the daily functioning of a school and its facilities and that leadership activities that deal with human relations are critical to ensuring that working relationships are functioning competently and efficiently, these activities are generally not memorable and do not make principals feel that they are making a difference (Sergiovanni, 1984; UCEA, 2012). The principal's role as manager (or technical leader) as well as the designated human relations expert often prevents them from devoting adequate time and energy to cultural, symbolic, and educational leadership - tasks most critical to student achievement (Hattie, 2009; Sergiovanni, 1984).

Building a culture that is unique to a school community, and being a visionary leader that can help push forward the mission and purpose of a school are both roles that 
will provide a connection to principals' sense of efficacy and satisfaction, which has been linked to success (Hitt, Tucker \& Young, 2012). Cultural and visionary leadership is especially challenging at the secondary level because of a multitude of responsibilities that can be viewed as obstacles that take away the focus of transforming an entire staff towards a clear mission.

The purpose of this study is to examine how successful principals sustain their human spirit while leading for equity. This examination includes what sustains them when finding themselves physically, intellectually, and emotionally drained (Bridges, 1977; Theoharris, 2007), conditions that exacerbate high principal turnover rates (National Center for Education Statistics, 2013; Wilmore, 2004).

While I have explained that technical and human relations leadership may not be what principals would choose to devote most of their time on, this kind of leadership cannot be ignored. The mandates for increased testing, data tracking, and rigorous evaluation systems for teachers brought about by NCLB have further increased the technical management demands of the principal (Cross, 2014; Fowler, 2012). Additional discussion on NCLB and the newly enacted Every Students Succeeds Act (ESSA) will follow as it relates to educational leaders' work and political theory. The human relations aspect of leadership has a direct correlation with the morale of a building and is a critical part of the job (Sergiovanni, 1984). Balancing technical and human relations demands while trying to create a culture of success with a strong social justice orientation through a clearly defined mission is a heavy responsibility given that teacher morale is at its lowest levels in 20 years (Markow \& Pieters, 2012). While NCLB has set the stage for 
high accountability and high demands, the Every Student Succeeds Act, passed in December of 2015 will only increase these demands (Mathis \& Trujillo, 2016).

\section{Context}

Principals are working at least 10-hour days (Marshall, 2004) and are still unable to adequately focus on instruction, building culture, and symbolic leadership. Their role as building manager and building-level human relations director is too time consuming (CPE, 2012). The same CPE study indicates that many principals report that the principalship is simply undoable (CPE, 2012). These demands lead to increased turnover (Burkhauser et al., 2012). Principals that remain in a single school need at least five years to fully implement teaching practices for a staff to impact higher student achievement (Leithwood, Louis, Anderson, \& Wahlstrom, 2004). However, the average tenure of a principal is only 3.5 years (Louis, Leithwood, Wahlstrom, \& Anderson, 2010). Principal tenure is especially important in more challenging settings that include lower socioeconomic status and higher proportions of Students of Color (Louis et al., 2010).

The absurdity of the job description in the introduction of this paper (Copeland, 2001 ) is palpable to many principals. The westernized approach to problem solving that breaks systems into a series of parts leaves educational leaders in a position to piecemeal solutions one at a time only adding to their many demanding tasks and never allowing opportunities to reduce the responsibilities that come with educational administration, a reduction that would lead to more focused leadership.

Fixing systemic outcomes requires deep, cultural changes that are long lasting (Deal \& Peterson, 2009). For instance, getting teachers to work together, rather than in 
isolation, across subject matter and grade levels is extremely challenging but rewarding work (AMLE, 2014; Dufour, Dufour, Eaker \& Many, 2006; Leithwood et al., 2004). Systemic changes must also account for the growing population of Students of Color, which currently in the state of Oregon, makes up $36 \%$ of our student population and has a graduation rate of just under $66 \%$, while their White counterparts have graduation rates at nearly $76 \%$ (ODE, 2015). Nationally this trend is echoed when $87 \%$ of White students graduated in four years in 2012 while only $70 \%, 72.5 \%$ and $76 \%$ of American Indian, Black, and Hispanic students graduated in the same amount of time respectively (NCES, 2014).

While the job of principal seems daunting, there are countless examples of educational leaders who have successfully carried out the mission to bring equity to schools by increasing student achievement for all and there is considerable research on those who do it well (Childress, Doyle, \& Thomas, 2009; Fullan, 1993; Fullan, Cutress \& Kilcher, 2005; Gay, 2010). Missing from the research on these successful leaders are issues that address how these leaders for equity sustain their human spirit while engaging in this complex work.

A discovery and response to one's sense of meaning and purpose is what I will refer to as the human spirit (Crowell, 2003; Marshall, 2009, Palmer, 1997). The challenge for school principals is to find meaningful work in the midst of many necessary tasks that may not align to a principal's purpose. Duties such as building a master schedule, deescalating an angry parent or student, managing a building, and dealing with a discipline issue of a staff member are all necessary tasks of the principal, but most likely 
not directly aligned to one's sense of meaning or motivation for joining education (AASA, 2007; UCEA, 2012). The combination of these necessary, yet tiresome, tasks contrasted with the educational, cultural, and visionary leadership that create successful outcomes make the demands of the principal consuming and overwhelming (Blackmore, 2001; Drago-Severson, 2012; Theoharis, 2007). Challenging working conditions creates leadership burnout. Wilmore (2004) found that, "principals must learn how to balance their job and personal time before they realize they have nothing else to give physically, mentally or emotionally" (p. 141). As we consider the human spirit of the high school principal we must remember the physical, emotional, and mental toll that is taken on these leaders. Sustaining the human spirit amidst these demands is paramount to longterm success (Drago-Severson, 2012; Marshall, 2009; Wilmore, 2004).

\section{Background of Problem}

Conversations of the human spirit are generally left for religious settings and not often considered as an integral part of educational discussions (Marshall, 2009; Mayes et al., 2003). Attention to the spirit in education deeply impacts our personal health and the health of others and therefore should not be forgotten. Historically, academia generally focuses on the mind while leaving out conversations of the spirit, or as some my call it, the heart (Palmer, 2011; Jinpa, 2015). In fact, some would argue that a missing piece of the social justice movement in education is the human spirit (Peterson, 2014).

Many cultures throughout history have considered spirituality as an integral part of life, but this critical part of humanness has been placed behind a sea of accountability, testing, and standards in public education policy in the $21^{\text {st }}$ century (Cross, 2014). While 
talks of human spirit are not brought to the forefront of westernized thoughts (Peterson, 2014), the idea of spirit is a universal and widely used term in our day-to-day lives. It would be of no surprise to hear one described as having a "lively spirit" or being involved in a "spirited debate." Often groups of friends rally around someone in mourning to "raise their spirits." There are even many theories as to why alcohol is referred to as spirits, most referring to the idea of human spirit. Many cultures and religions have more formal ideas of the spirit, including Christian and Islamic ideas of the Holy Spirit that lives within each of us (Luke 1:47, New International Version); Buddhist aspirations of reaching enlightenment for the spirit; and many Native American practices that incorporate the spirit of all living things.

If we use Crowell's (2003) definition of spirit - the discovery and response to one's sense of meaning - it seems relevant to explore educators' motivation for getting into education in the first place. Many in education became leaders because they were drawn to a profession that would lead to high levels of efficacy and satisfaction rather than for monetary gain (UCEA, 2012). It is a deep desire to help others learn and grow that pulls people into the profession (Marshall, 2009). Palmer states that spirituality is the eternal human yearning to be connected to something larger than our own egos (1997). Palmer would argue that the decision to go into the education field is a very spiritual decision. Given that the average salary for masters degree recipients between the ages of 25 - 34 years of age is nearly $\$ 60,000$ while the average starting salary for teachers is about $\$ 36,000$ nationally (NEA, 2013; US Census, 2013), it is hard to argue that people with teaching aspirations are in it for themselves. Given the income discrepancies that 
exist for teachers, one could argue that the draw, or calling, to work in schools is a discovery and response to one's own sense of meaning.

Teachers who have strong leadership traits cite working conditions as the reason for staying out of the field of administration (UCEA, 2012). Those who enter school administration must work harder to find evidence of their impact; leaders' effect on student learning is indirect through influence on other people or influence on their organizations (Hattie, 2009; Louis, et al., 2010). This is especially true in schools of higher needs, that is, schools with higher poverty levels and likely mostly Students of Color, large schools, and schools with high urbanity (Louis et al., 2010). While these settings create a more difficult leadership context to work in, leaders have a greater impact - both positive and negative - on student learning than in schools without these challenges (Louis et al., 2010). It takes a strong leader, a leader for equity, to help turn around struggling schools (Fullan, 1993; Heifetz \& Laurie, 1997; Leithwood \& Poplin, 1992; Louis et al., 2010).

\section{Statement of Research Problem}

The human spirits of principals are not being sustained in the midst of too many demands that come with the job (Alt \& Henke 2007; Gates et al., 2006; Guarino et al., 2006). While conversations around human spirit are sprinkled throughout our daily lives informally, and are more deliberately discussed and reflected upon in religious settings, the very thought of sustaining the human spirit of educational leaders is not a part of the conversation or research around successful school leadership (Marshall, 2009; Mayes et al., 2003; Palmer, 2003). With little emphasis put on the spiritual sustainment of high 
school principals, it is no wonder that turnover rates amongst principals is so high, especially new principals (Burkhauser et al., 2012; CPE, 2012). These high turnover rates have great impacts on students and teachers.

\section{Significance of the Research Problem}

We need leaders who can reduce educational disparities to stay in the profession. Instructional and transformational leadership that impacts student outcomes takes time (Deal \& Peterson, 2009; Leithwood et al., 2004). The average principal tenure is three to four years (CPE, 2012) with principal turnover rates high: 79\% of White principals stayed in their same building from 2011-2012 school year to the 2012-2013 school year while only $74 \%$ and $72 \%$ of Latino and Black principals stayed respectively (NCES, 2014). This should not be a surprise given the research supporting the fact that Principals of Color face additionally barriers not seen by White principals (Achinstein, Ogawa, Sexton, \& Freitas, 2010; Gordon, 2000; Johnson \& Hekman, 2016; Peterson \& Vergara, 2016; Theoharis, 2007). At face value these retention rates may not appear significant, however, if this trend were to continue, it is reasonable to assume that most schools would have a different leader after only two to three years. The concern here is that leadership turnover results in a lack of clear direction for students and community members, stalls the professional development of teachers, and obstructs the design or redesign of an organization (Leithwood et al., 2004). In addition, at a time when we are working to increase our Principals of Color, they are leaving the profession at higher rates than their White colleagues (NCES, 2014). 
A climate of high accountability demands and low trust fueled by media, often surrounds a school where students have earned low scores on standardized/state assessments (Blackmore, 2001). Without a connection to their work, leaders in these struggling schools can suffer from despair, apathy, and helplessness (Smith \& Williams, 1999). While such struggling schools need leaders who will promote and bring about equitable outcomes, principal retention is lowest in these underachieving settings (Gates et al., 2006; Louis et al., 2010). Strong social justice leadership leads to student success (Hattie, 2009; Leithwood et al., 2004). It is imperative that leaders find ways to sustain themselves in the midst of job duties that they do not find as meaningful as cultural and visionary leadership (Drago-Severson, 2012; Roeser, Skinner, Beers \& Jennings, 2012). Our most underserved students are those that are most impacted by high turnover rates and unsuccessful leaders (Dworkin, Haney, Dworkin \& Telschow, 1990; Fullan, 1993; Gay, 2010; Leithwood \& Poplin, 1992). Leadership for social justice is too important to ignore. Leaders that can stay in the profession for a length of time and reduce disparities are rare.

Leadership is the second biggest contributor to student success; teaching is the first (Hattie, 2009). Therefore, we must examine the effects that leadership has on teachers. While principal retention and sustainability is important, teacher retention and sustainability is equally important for student success. In schools where principal turnover is high, teacher turnover is also higher than average (Béteille, Kalogrides \& Loeb, 2012). We also know that teacher stability does have a positive impact on student achievement, in particular if those teachers are in working situations where they are 
allowed and encouraged by their leaders to work together utilizing their social capital (Leana, 2011)

Furthermore, in order to successfully reduce ineffective teachers' impact and increase effective teacher hires, it is critical for principals to remain in the same building for at least five years (Leithwood, et al., 2004). Effective teachers are more likely to stay if they are working under a leader that is supportive, even in more challenging urban settings (Dworkin, et al., 1990; Leana, 2011). Thus, in order to successfully hire and retain effective teachers, it is critical to retain principals that can do so.

This is especially important in high poverty schools where teachers are more likely to leave due to difficult working conditions (Alt \& Henke, 2007; Guarino, et al., 2006). Also, as we consider equity, we must hire and retain teachers that represent the students we are serving (Gay, 2010). Sadly, Black teachers report an expectation to teach for the remainder of their careers at about half the rates of their White colleagues; $70 \%$ of White teachers report an expectation to finish their career as a teacher while only $37 \%$ of Black teachers have the same expectation (Alt \& Henke, 2007). These high turnover rates have a reciprocal effect on the leader in these buildings. Having burnt out teachers leads to more hiring and more hiring means more demands put on the principal as training and hiring is a time consuming process.

It takes strong leadership to create an environment for culturally responsive teaching (Gay, 2010). Curriculum decisions, school culture, and student identity are all critical to reduce disparities (Gay, 2010; Tatum, 2007). Leaders need to create a culture of dialogue and collaboration rather than debate in order to change the status quo (Ferrer, 
2003; Leana, 2011). This cultural shift cannot occur overnight and, as Ferrer contends, is a very spiritual process in that one's connection to themselves and others is extremely relevant to the process of dialogue. If leaders hope to lead a staff that creates caring and meaningful interactions with students who are underserved, they must model those relationships and interactions with their staff; the relationship of the school leader and staff will be mirrored by the relationship between staff and students (Barth, 2006). This is not a new challenge for leaders to balance their position of power with a desire and need to honor the uniqueness of their students and staff (Ramsey, 1962). Principals need to implement plans and ideas that are not always well received in a way that pulls in key stakeholders rather than pushes them away.

\section{Presentation of Methods and Research Question}

The purpose of this study is to address the essential research question: How do successful high school principals sustain their human spirit while leading for equity. Implications for these answers will inform administrative preparation programs and effective professional development strategies for existing administrators. If leaders are able to find strategies to sustain themselves, retention and longevity, in addition to reducing educational disparities, could result. As schools in Oregon continue to become more diverse, it becomes more imperative that our leaders are successfully reducing disparities and that school leaders reflect our students' diversity. The researchers will identify successful leaders (as defined in Chapter Three) and interview them to gain insights into their leadership characteristics and attributes and seek connections to their sense of meaning and purpose. This will be a qualitative study using semi-structured 
interviewing (Bogdan \& Biklen, 2007, p. 9). Chapter Three will specifically outline study methods and procedures that are being proposed.

\section{Key Concepts}

Human Spirit is a discovery and response to one's own sense of meaning and purpose (Crowell, 2003). To expand on this concept, Palmer (1997) talks of the spirit as a yearning to be connected to something larger than our own egos.

Principals for equity advocate, lead, and keep at the center of their practice and vision issues of race, class, gender, disability, sexual orientation, and other historically and currently marginalizing conditions in the United States (Theoharris, 2007). These leaders strive to ensure that each student receives the resources they need in order to graduate and are prepared for life after high school (CPE, 2016).

Symbolic Leadership focuses the attention of others on important matters (Sergiovanni, 1984). In a sense, the symbolic leader helps to sustain the spirit of those around him/her by providing meaning to the behaviors of staff members. The symbolic leader provides a clear vision of purpose for all stakeholders. They also remain visible as the leader of the building.

Cultural Leadership builds a unique culture or identity to a school. The culture of the school is what sets it apart from all others and unites the students, staff, and community (Sergiovanni, 1984).

Educational Leadership or Instructional Leadership works to make teacher instruction and student achievement a priority in a school setting (Jenkins, 2009). 
Traditionally Underserved describes "groups that have a history of oppression and exploitation and are pushed further and further from the centers of power that control the shape and destiny of the society" (Curry-Stevens, Cross-Hemmer, 2010, p. 141).

Motivation is the reason for those in education to have gotten into the field. Most cite that job satisfaction and efficacy are the reasons for entering teaching and eventually administration (UCEA, 2012).

Self Efficacy is an individual's belief about what s/he can achieve in a given context. Bandura made connections between one's level of self-efficacy and their success measured by persistence and job performance (2006). Federici \& Skaalvik (2012) studied principals in Norway to find relationships between self-efficacy and job satisfaction, burnout, and motivation to quit. They found that self-efficacy was positively correlated with job satisfaction and negatively correlated with burnout and motivation to quit.

Purpose represents the why of our work. Fullan, Cuttress, and Kilcher (2005) argued that one of the eight keys to effective change was to engage in our moral purpose. When key stakeholders don't understand why change is necessary, change will not occur. 


\section{Chapter Two: Literature Review}

The sustainability of the human spirit of educational leaders for equity is critically important to the success of students and teachers, in particular, students and teachers from traditionally underserved groups. High turnover rates; toxic levels of stress and burnout; and consistent job dissatisfaction characterize the job of secondary principal for many (Blackmore, 2001; Drago-Severson, 2012; Theoharis, 2007). For this study, I will be researching high school principals that have shown success working with Latina/o students in the state of Oregon. Our Latina/o population is the largest Non-White culture in the state and the rates of Latina/o students will continue to grow in the next half century (US Census Bureau, 2012). The very success of Oregon education relies on the success of this vulnerable population.

This study will aim to answer one key question: How do successful high school principals sustain themselves spiritually while leading for equity? The following chapter will identify teaching and learning theory, organizational theory, and the impact of the Elementary and Secondary Education Act (ESEA) which, for most of the last two decades, was guided by the No Child Left Behind (NCLB) Act and as of December, 2015 is now guided by the Every Student Succeeds Act (ESSA). Each of these plays a role in the human spirit of educators and specifically, secondary principals. I will highlight important research that adds to the topic of sustainability of the human spirit while critiquing theoretical frameworks that may not apply to this study. 


\section{Theoretical Frameworks \& Review of Literature}

While I examined research related to education, I also examined studies originating primarily from the business and medical world, related to resilience and workforce retention (Hartfiel, Havenhand, Khalsa, Clarke, \& Krayer, 2011; Jackson, Firtko, \& Edenborough, 2007; Tapia \& Kvasny, 2004). Common themes include how to react to adversity, how to maintain balance of life and work, physical wellbeing, and structures that can support employees. Much of the research was employee based rather than leadership based. It also assumed that those that were experiencing a work-life imbalance or were receiving undue stress at work had the capacity or control to change their working situation. While contributing to an understanding of how stress and burnout can occur and be avoided, these articles rarely focus on the employee's sense of meaning and purpose. There was an assumption that people are working in order to live rather than responding to a sense of calling, something that is evident for those in education (Farkas, Johnson, Foleno, Duffett, \& Foley, 2000). Additionally, in Chapter One I outlined that the role of principal is uniquely challenging and simply rearranging or lightening one's load for the benefit of stress reduction or resiliency is not a reasonable premise to start from. For that reason, I am limiting my examination of research articles to an educational setting and those that focus on why educators choose the profession and their sense of meaning and purpose. The whole intent of education starts with a fundamental belief that our job is to teach and more importantly, help students learn (Marshall, 2009). Secondary leaders should also intend for their staff to be life long learners (Dufour et al., 2006; Merriam \& Cafarella, 1991) 
Learning theory. In the following sections I will discuss the frameworks relevant to the research question. The discussion of learning theory will include behaviorism, constructivism, critical theory, and Latino critical race theory.

Behaviorism. Behaviorism is the idea that extrinsic rewards or consequences motivate human behavior. Skinner (1938) found that all behavior is the result of rewards and punishment and went as far to say that humans had no freewill nor dignity. The absence of freewill originates from one of the most famous experiments of all, simply known as Pavlov's Law. Ivan Pavlov was able to cause a dog to salivate simply by ringing a bell and offering a treat. Once conditioned through behaviorist methods, the dog's reaction to the bell remained the same - salivating - even in the absence of the treat (Pavlov \& Anrep, 2003). The concept of classical conditioning grew and continues to be applied to human behavior today (Elias \& Merriam, 2005).

Behaviorist methods are duplicated in schools for students all the time. A high school student coming to class late may receive a detention. A second grader who correctly solves a math problem may receive a reward sticker. Both positive and negative consequences are being doled out in classrooms across the country every day. In fact, Positive Behavioral Interventions and Supports (PBIS) is a widely used school-wide behavior system that is rooted in behaviorist philosophy (Sprick, 2009). In a PBIS system, teachers and staff teach lessons to students on the behaviors they want to see and then reward students for showing those behaviors. The idea is rooted in behaviorist philosophies with the hope that just as the dog salivated each time it heard a bell knowing the food would be coming soon, the students will behave appropriately knowing they too 
will get some positive reward for their good behavior. According to Sprick, schools that are fully adopting PBIS extend these ideas to the adult learners in the building offering small tokens of appreciation for fellow staff members who are following the established rules of the teaching community.

Behaviorists would argue that the act of learning is a change in behavior (Skinner, 1974). This would imply that learning must be a visible act rather than an internal dialogue that a learner may go through. Behaviorists also must make clear what the objectives are, for learners to meet the criteria needed to reach the objective (Marzano, 2009). Once the objectives are known the teacher's role is to create conditions that change behavior to align with the given objective (Marzano, 2015, Sprick, 2009). Behaviorism takes an objective, isolates it from the whole system or the complex context of the school, the classroom, or the human being, essentially isolating factors that may or may not be related to the observed behavior.

Many in education believe in the value of behaviorism as an effective way to change student and adult behavior (Merriam \& Caffarella, 1991; Sprick, 2009). The idea of proficiency grading for students has been a hot topic amongst teachers for a number of years. House Bill 2220, which was proposed in Oregon and then removed in 2013 is one of many attempts from government to mandate learning. Proponents of the bill are starting with the premise that students are motivated by grades and therefore will learn if teachers are effective. While student learning is the goal, the grade is used to assess and hopefully motivate that learning. The idea of learning for a grade rather than for a deeper 
more intrinsic desire for knowledge is counter to the idea of spirituality or the discovery and response of one's sense of meaning.

While some argue that behaviorist methods can get desired results for learners, one must question the true level of behavioral change that takes place due to behaviorist practices. While detention may be a short term antecedent to being late, does this truly create life long behavioral changes for the student? When looking at adult learners, many would argue that the loss of one's autonomy would lead to despair (Smith \& Williams, 1999).

In matters of the human spirit, the very foundation that Skinner used to determine the philosophy is counter to the very definition of spirit that I am using for this paper. If we use Skinner's (1974) premise that there is an absence of free will if the conditions are set accordingly, how is it possible for a leader to feel connected to her or his work and sense of meaning? The mandates that were created by NCLB are rooted in behaviorist philosophy: if we test students, and then penalize schools that are not performing adequately, behaviors will change and students will learn. Whether one is for or against the idea of NCLB is a moot point when exploring the issue of spirit. The point here is the mandate is coming from a behaviorist philosophy of rewards and consequences.

Some argue that students and adults need to be intrinsically motivated to reach the desired performance outcome. How we do this is critical for leaders, especially in the context of high teacher and administrator burnout, high expectations with low support, and high public scrutiny of public leaders (Blackmore, 2001). Furman and Gruenewald (2004) note that even if schools and leaders must be accountable within a behaviorist 
framework, "the goals of social justice are too important to be jeopardized by preecological thinking and the too narrow focus of achievement scores as the sole measure of accountability" (p. 72). Accountability is not in the score alone. Accountability must include the response of a professional in the face of data or other information that indicates that some students have been more successful in acquiring a desired outcome than other students. This is especially true when the differences break down along gender, racial, linguistic or ableness indicators. While behaviorists believe that learning is based on an experience created by a teacher or a leader, others reject that notion and believe far differently.

Constructivism. While Skinner (1974) and other behaviorists argued that knowledge is imposed onto the learner, Piaget (1969) and other constructivists believed learning was to be determined by the learner and cannot be imposed by others. Piaget and constructivist theory maintains that learners have experiences and previous knowledge that must be accessed and used in order to facilitate learning. Constructivists reject the behaviorist notion that knowledge is derived strictly from behavioral changes (Sjoberg, 2007). The teacher or the leader does not hold the knowledge. Similarly, the leader does not hold the wisdom for the school; the community creates knowledge and wisdom.

Furman and Gruenwald (2004) argue that the creation of knowledge must be in a context, or must be place-based and is highly dependent on the learner's interaction with their past learning and experiences as it pertains to their current situation. To consider the human spirit of educational leaders and their own personal learning it is important to note that a critical part of constructivist learning theory is honoring the experience of the 
learning and by doing so, affirming the identity of the learner. The challenge is that school leaders must affirm the identities of many adult learners by honoring past experiences in the midst of trying to move an organization forward which often includes interrupting biases rooted in White privilege (Sjoberg, 2007). More discussion about White privilege will follow in the next section.

While well intentioned, many educators perpetuate the status quo that is causing achievement gaps to exist and continue. Supporting these educators is especially draining for leaders who must honor the experience of these educators even if those previous experiences are leading to misconceptions (Theoharris, 2007). Constructivists may argue that misconceptions can be warranted and accepted if established in true paradigms that can be thoughtfully explained and that trying to change them may be a lost cause. Constructivism acknowledges that knowledge is often collectively shared and may become culturally and socially accepted (Sjoberg, 2007). This is a scary outcome in a culture of achievement gaps for traditionally underserved students.

Lambert (2002) noted that collaborative, constructivist leadership is possible and stems from a deep routed belief that all students can learn and all adults can lead. There are many leaders that seem to have used constructivist methods to, as Lambert says "handle intractable problems with a lightness of spirit" (p. XV). Distributive and collaborative leadership are both based in constructivism, as teachers, family members and the leader collaboratively construct plans for student success. Student achievement is higher in schools with these leadership strategies (Dufour et al., 2006; Lambert, 2002). However, leaders for social justice must be careful when creating a distributive 
leadership plan if those involved do not hold the same set of values that the leader has (Diamond, 2013).

Teacher burnout and school leader burnout are higher in schools where people are disrespected and unsupported (Dworkin, et al., 1990). Constructivist leaders would work harder to honor the teacher's experience that they bring. In many respects, the constructivist learning theory may have a closer connection to one's spirit, but when thinking about issues of social justice, changing firmly established mindsets about traditionally underserved groups of students might require more direct approaches. Teachers truly care for the students in their classrooms. This notion of care is certainly spiritual in nature. However, some would argue that it is not enough to simply care without concomitant action that is deliberate and targeted towards traditionally underserved students (Gay, 2010).

Critical theory. When looking at issues of the spirit it is impossible to ignore critical theory for both student learning and principal learning. Issues of the spirit include care for others, a sense of service or calling, and equity (Gay, 2010; Marshall, 2009; Noddings, 2005; Tisdell, 2001). Critical theory examines situations through a social justice lens, asking who is impacted by the decisions that are made or the systems that have been created. It is quite clear that there are significant achievement gaps for many groups of students in education (National Urban League, 2015). As we consider how students and adults learn and thrive, we have to ensure that we are affirming the identity of learners and leaders before simply applying a learning theory to everyone involved (Delpit, 2012). 
As we apply critical theory to leaders we cannot ignore the underrepresentation of Principals of Color. In the 2012-13 school year, 80 percent of principals in the United States were White while only 10 percent were Black and 7 percent were Latino compared to 51 percent of students were White, 16 percent were Black and 24 percent were Latino. (Bitterman, Goldring \& Gray, 2013). Our Students of Color are not seeing themselves in leadership roles. This may not be an internalized self-view, but a realistic perception of whether the profession is open to leaders of color. Recruiting and retaining Principals of Color is imperative for the success of our Students of Color (Hitt et al., 2012).

Sadly, Principals of Color are leaving their schools at higher rates than their White colleagues (NCES, 2014). These leaders are facing unique challenges daily that White colleagues do not deal with (Peterson \& Vergara, 2016; Theoharris, 2007). White colleagues may misinterpret the actions of Principals of Color as blame or resentment. White leaders do not need to face any of these difficulties and often choose to walk away from difficult conversations involving race (DiAngelo, 2011; Theoharris, 2007). The culture of an entire staff is likely rooted in White privilege, and to interrupt that culture as a Principal of Color takes a significant toll (Peterson \& Vergara, 2016; Theoharris, 2007). Fortunately, there are many that say that closing the achievement gap must be the highest priority for teachers and leaders, and NCLB has put a spotlight on the problem of equity in America's schools (Gay, 2010; Noguerra, 2008) and ESSA will keep it shining. Exploring student and adult behavior without a critical lens may be an exercise in futility. 
Latino critical race theory. While critical race theory sets the stage for us to question practices and systems that are rooted in a history of oppression for Non-White cultures, Latino race theory examines how race impacts Latina/o people specifically. Latino critical theory requires that education acknowledge that the dominant ideologies of alleged color blindness in practice only serve to benefit majority White students while further disadvantaging Latina/o students and other Students of Color (Villalpando, 2004). By adopting an attitude of color blindness we are ignoring the history of overt oppression that America and Oregon has placed on the Latina/o community (Oregon Center for Educational Equity, 2014). Color blindness makes community building among the Latina/o community, and empowerment to those in the community, superfluous rather than necessary components to successful Latina/o students (Anguiano, Milstein, De Larkin, Chen, \& Sandoval, 2012).

Organizational leadership theory. There is no doubt that schools are complex organizations that can be taxing to manage and lead. When looking at organization theory I will frame the conversation in bureaucracy theory as it relates to schools. I am not suggesting that bureaucracy theory is the best lens to use when leading a school, however, there is a strong correlation to this theory in the business world and its connection to schools. Without understanding the current bureaucracy of schools, it may be difficult to understand the sustainability of the spirit amidst the system in which principals are working in. Clegg shows that the tendencies of schools are rooted in bureaucratic tendencies that cannot be ignored (1990). Bureaucracy is not connected to one's sense of meaning and some refer to it despairingly as "jumping through hoops." 
Table 1 below shows correlates between some of those tendencies and some of

the organizational characteristics of schools.

Table 1

School Organizational Characteristics That Correlate With Bureaucratic Tendencies

\begin{tabular}{|c|c|}
\hline Bureaucratic Tendencies & School Organization Correlates \\
\hline Specialization of personnel based on tasks & Administration, Licensed Staff, Support Staff \\
\hline Authorization of organizational action & $\begin{array}{l}\text { Functions of each personnel role have specific } \\
\text { levels of authority commensurate with their } \\
\text { duties }\end{array}$ \\
\hline $\begin{array}{l}\text { Hierarchization, stemming from tasks and personnel } \\
\text { being functionally separated }\end{array}$ & $\begin{array}{l}\text { Hierarchy of functions ranging from } \\
\text { administrative, to teaching, to classified, etc. }\end{array}$ \\
\hline $\begin{array}{l}\text { Contractualization of organizational relationships } \\
\text { that specifies duties, rights, obligations and } \\
\text { responsibilities }\end{array}$ & $\begin{array}{l}\text { Each employee unit has precise contracts of } \\
\text { employment }\end{array}$ \\
\hline $\begin{array}{l}\text { Credentialization that is used to measure } \\
\text { qualifications }\end{array}$ & $\begin{array}{l}\text { Administrators, teachers, specialists and } \\
\text { paraprofessionals have licenses or credentials } \\
\text { commensurate with their contracts }\end{array}$ \\
\hline $\begin{array}{l}\text { Careerization is based on differentially stratified } \\
\text { credentials }\end{array}$ & $\begin{array}{l}\text { Career structure and promotion from one rung } \\
\text { of the hierarchy to another is based on } \\
\text { appropriate credentials and experience }\end{array}$ \\
\hline $\begin{array}{l}\text { Stratification of status among personnel in the } \\
\text { organization. }\end{array}$ & $\begin{array}{l}\text { Pay and compensation differentials are } \\
\text { structured through contracts and define } \\
\text { employee status }\end{array}$ \\
\hline Specific rights of control are held by superordinat & $\begin{array}{l}\text { Specific configurations of authority maintain } \\
\text { various layers of subordinates- } \\
\text { Superintendent to District Office Personnel, to } \\
\text { Principals, to Teachers, etc. }\end{array}$ \\
\hline $\begin{array}{l}\text { Formalization of rules that justify and produce } \\
\text { legitimate action. }\end{array}$ & $\begin{array}{l}\text { Functional separation of roles/tasks and } \\
\text { hierarchical relations within district and } \\
\text { schools are rule-bound (State regulations, } \\
\text { Board Policy, Administrative Regulations) }\end{array}$ \\
\hline Standardization & $\begin{array}{l}\text { Files of written documents are held in } \\
\text { administrative offices with access limited for } \\
\text { others based on role }\end{array}$ \\
\hline Centralization & $\begin{array}{l}\text { Communication, co-ordination and control are } \\
\text { routed through the administrative offices, } \\
\text { forming a central hub for the school } \\
\text { organization }\end{array}$ \\
\hline
\end{tabular}

Source: Clegg (1990)

Bureaucracy has turned into a negative idea in today's working environment as

people often view bureaucracy as hoops to jump through in order to get desired

outcomes. The extra hoops can devalue the elemental humanness that exists within

organizational structures (Sergiovanni, 1990). Others argue that the complexity that 
humans bring to an organization leads to a necessity for bureaucracy (Swedberg \& Agevall, 2005).

In addition to the complexity that exists from the many humans that exist within an organization, Bolman and Deal (2011) identify four distinctive frames from which leaders view their world - structural, human resources, political, and symbolic. While no one uses all four frames at the same time, Bolmon and Deal argue that most seem to gravitate towards one or two of these frames. There may be a growing challenge for leaders to be able to navigate all four frames at different times. Fullan (1999) notes that the best organizations are those that have a connection with their wider environments, further acknowledging that changes in school cultures may require more sophisticated leadership than has existed before in schools.

Bolman and Deal (2011) identify four key characteristics of organizations and the challenges that leaders may face: 1) organizations are complex, they are populated by people, whose behavior is notoriously hard to predict; 2) organizations are surprising and what you get is often not what you expect; 3) organizations are deceptive and they camouflage their mistakes and surprises; and 4) complexity, unpredictability, and deception generate rampant ambiguity creating a dense fog that shrouds what happens from day to day.

Educational organizations can be thought of metaphorically using a variety of symbols to best understand and analyze the working parts of the school system. Many schools can be thought of as a machine, a collection a parts working independently for a common goal (Morgan, 1980). There is a clear connection of Morgan's (1980) machine 
metaphor with Clegg's (1990) idea of a bureaucratic educational system. Human resource departments deal with contracts and certifications, student management offices deal with discipline, counseling offices deal with academics, bookkeepers deal with funds, and more often than not, those offices are working in isolation in the hopes that the machine of the whole school is working smoothly as a result of their functioning "cog." Those interested in sustainability would argue that the Morgan's organism metaphor is a more desired approach to caring for each student, where the whole organization is working together rather than in isolation. One could compare this culture of care to that of a family unit $-\mathrm{a}$ unit of support and connection to one another. Some pockets of schools have tried, through the use of small schools, or professional learning communities, to work more organically and cohesively to support the goals put forth by the larger organization (AMLE, 2014; Dufour, et al., 2006).

The bureaucracy and complexity make it challenging for leaders to stay connected to their sense of meaning. To further understand the challenging nature of organizations and leadership a discussion of transformational leadership and critical theory will follow.

Transformational leadership. Transformational leaders are motivational role models that are out to inspire innovation and creativity by coaching and mentoring those around them (Bass, 1996). Transformational leadership is needed to get to important changes of culture and vision rather than staying stuck in the technical management of a school (Leithwood \& Poplin, 1992). This style of leadership is key, especially in struggling schools that need to make major changes. One of the keys to transformational leadership is developing people and redesigning organizations in ways connected to 
student performance (Leithwood et al., 2004). The principal's impact as a transformational leader will come to fruition through their impact on others. Therefore, their impact on student achievement is critical but is indirect (Hattie, 2009; Leana, 2011; Leithwood, et al., 2004). This could benefit or hinder one's sense of meaning and purpose. The transformational leader has the potential to create positive change for students which is likely connected to the sense of meaning, however, the disconnect that they have with students could render the positive change unnoticed or unrecognized therefore diminishing one's sense of meaning.

Adaptive leadership is similar to transformative leadership in that it galvanizes those working within an organization and includes people in the solutions to problems rather than being the authority on all (Heifetz \& Laurie, 1997; Bass, 1996). Some argue that good leadership is about having the knowledge and expertise to solve problems. Heifetz \& Linsky (2004) argue that good leadership requires problem solving when the experts cannot come up with solutions themselves. This reliance or collaboration supports the ideas of the human spirit and a connection to something greater than oneself (Palmer, 1997). These problems are referred to as adaptive problems that require solutions that lie in people and not technical fixes (Heifetz \& Linsky, 2004).

Given these contexts, leaders must fight against the machine metaphor to understand how all the working parts of an organization work in cohesion rather than isolation. Or, rather than fighting against the machine, they must understand the organization that they are working in to best unite key stakeholders in a common mission 
and cause. Heifetz and Laurie, (1997) described it as going back and forth between the field of action and the balcony to understand the whole context of a problem.

Transformative leaders must stay connected to their sense of meaning. In order to create inspiration and motivation for others, they have to exude energy, enthusiasm, and hope (Fullan, 2002). These characteristics are directly connected to the spirit of the leader. In contrast, a leader that lacks energy, seems apathetic, and has no hope that true change can occur will find one's self facing burnout and little job satisfaction (Federici \& Skaalvik, 2012). Their lack of enthusiasm will be equally contagious to those working around them (Shapiro, 2009).

Transformational leadership also solicits solutions from its followers, which has implications connected to equity. Without recognition of privilege, followers will not be able to identify equity issues and thereby, followers may replicate systems of oppression for others. If transformational leaders are to interrupt the further oppression of traditionally underserved groups, they may face scrutiny and judgment from their followers making it more difficult to instill inspiration and hope in their buildings.

Critical race theory. Previously I examined critical race theory as it pertains to learning theory. Here, I will apply it to organizational leadership theory. It is impossible to recognize leadership for equity without acknowledging the idea of a psychic prison, where individuals have grown up in a society so engrained in institutional racism that their conscious and unconscious biases continue the cycle of educational disparities for traditionally underserved students (Ladson-Billings \& Tate, 1995; Morgan, 1980; Tatum, 
2007). This plays out for the non-white culture, which has experienced stereotypes, lowered expectations, and even hostility in learning environments (Gay, 2010).

Critical Race Theory (CRT) plays such a vital role in looking deeply into organizations. CRT starts with the premise that the world is "rife with contradictions and asymmetries of power and privilege" (McLaren, 2003). This is especially true for our Principals of Color. Principals of Color report feeling extra pressure to prove themselves to their White community members (Theoharris, 2007). Centuries of oppression for nonWhite cultures are playing a key role into our schools today (Oregon Center for Educational Equity, 2014).

CRT is a lens to examine organizational and human behavior including structures, attitudes, beliefs and cultural norms that maintain the underperformance of Students of Color. For social justice principals, issues of equity are driven by a moral obligation to interrupt the patterns of oppression that exist in educational settings (Theoharris, 2007). The idea of moral obligation is closely connected to a principal's spirituality. Without this moral purpose, principals' may struggle to have true compassion for Students of Color. Issues of inequity need to come from a place of morality and compassion rather than a place of job completion and frustration. Reducing achievement gaps is challenging work and can be emotionally exhausting, and the slow process can result in reduced levels of a sense of self-accomplishment, leading to physical exhaustion and burnout (Maslach, Schaufeli, \& Leiter, 2001). This is why compassion must take the place of frustration. Compassion can lead to happiness, reduced stress, and a healthier lifestyle (Jinpa, 2015). 
As I discuss connections between one's sense of meaning and one's daily work experiences, CRT is an important aspect of my examination. Our local, state, and national educational data indicates that race is a predictor of academic outcomes. I would contend that changing this trend needs to start with changing the hearts and minds of teachers and leaders working with Students of Color.

Some may argue that a focus on race is too narrow; our students with disabilities are also underperforming. Looking at National Assessments of Educational Progress (NAEP) reports, students with disabilities are scoring an average of 50 less points on the NAEP than those that are not disabled at the age of 17 (NCES, 2015). Students living in poverty and English Language Learners (ELLs) experience similar educational disparities. Gaps based on poverty on the NAEP are 23 points while ELLs are performing at almost 60 points less than non-ELLs at the age of 17 (NCES, 2015).

Thus, applying a critical lens to all educational issues is appropriate. Principals can apply a critical lens to all groups of students especially those who are traditionally underserved. This understanding of critical theory in general means the principal must move from the balcony of leadership to the playing field (Heifetz \& Laurie, 1997). Paulo Freire (2000) writes about this type of leader:

This individual is not afraid to confront, to listen, to see the world unveiled. This person is not afraid to meet the people or to enter into dialogue with them. This person does not consider himself or herself the proprietor of history or of all people, or the liberator of the oppressed; but he or she does commit himself or herself, within history, to fight at their side (p.39). 
Being a leader of equity in a system of bureaucracy can be a daunting, frustrating job. Referring back to Bolman \& Deal (2011), one must think politically while also considering the human relations part of leadership. This will take a rare set of skills and places a lot of pressure on the leader to make organizations work more fairly. If the leader does not stay connected to their sense of meaning, and maintain a feeling of compassion, it will become easy to succumb to a wide range of pressures from the community, students, parents, district, and school board that could result in burnout and maintain the status quo (Allison, 1997).

Policy analysis. Education has been influenced tremendously by policy for the entirety of the United States history. In recent year, levels of accountability have risen while support has stayed the same at best - a recipe detrimental to the human spirit of educators (Marshall, 2004). No Child Left Behind (NCLB) brought about greater bureaucracies for educators to work through in an effort to hold schools accountable for learning through the use of standardized testing with the goal that all students will reach proficiency in math and reading assessments by 2014 (Cross, 2014). The waiver process was created by the U.S. Department of Education, and approved by Congress under the Johnson Administration in 1965. President Obama could not get Congress to move on his proposals to reauthorize ESEA, contained in a document titled the "Blueprint for Reform" (United States Department of Education, 2010). Instead, the Obama Administration offered flexibility to states to alter how they would define their target outcomes for the use of federal funds. This coincided with work underway by Governor Kitzhaber in Oregon to provide a more comprehensive integration of educational services 
in Oregon by bringing together, under one jurisdiction, early childhood education, K-12 programs, higher education (both community colleges and 4-yr institutions), and youth service programs. These four areas were brought together under a new management structure known as the Oregon Education Improvement Board (OEIB) and the Governor successfully worked with the Legislature to change Oregon law to make the governor the state's Chief Education Officer. This continued until the Governor was forced to resign from office in early 2015. During this brief period, the OEIB established an agenda for school reform that included SB253 as a component to focus overall system outcomes on college and career readiness, thus the "40-40-20" target language as the overall system objective (ODE, 2011). It also included SB290, a revision of the state's teacher and administration evaluation procedures that broadened teacher evaluation outcomes beyond student performance data as outlined in NCLB. At the same time, the U.S. Department of Education and the Obama administration developed a waiver process for states interested in applying for Race to the Top grants which provided relief from some of the requirements in NCLB, as long as evidence of student proficiency was a component of teacher and administrator evaluation procedures. The creation of the Oregon Matrix Model for teacher and administrator evaluation was the result of this effort in Oregon. However, the Matrix model to many did not go far enough in focusing on teacher ability to improve student performance and it was delayed in getting passed by the Oregon Legislature. As a result, Oregon applied for but was never awarded a Race to the Top Grant except for one small grant in Early Childhood education. 
Most recently the Every Student Succeeds Act replaced the NCLB and was signed into law on December $10^{\text {th }}, 2015$ (USDE, 2015). The bill is still too new to know its impact on education. One of the major changes that will result from this bill is that it gives more decision making power to the state level rather than federal level, including assessment that will be used and standards that will be taught. While many are excited about the control coming back to state levels, the levels of accountability will still exist and the government will still be a major driving force for practicing principals (Mathis \& Trujillo, 2016).

These radical shifts in governance result in societies of high accountability and low trust and create very challenging working environments for principals and others (Blackmore, 2001). NCLB put a high priority on rigorous content, but focusing on content to the exclusion of the student's emotional needs, may be detrimental to the spirit of those working in schools (Noddings, 2005). Some may argue that NCLB's focus on test scores and students' academic growth lack the emotional component that Noddings was advocating for as it pertains to educating school aged children.

The culture of data tracking and assessments may overshadow the need to nurture a culture of care, which may be more important than anything else in education (Noddings, 2005). Nieto (2009) argues that the content and social emotional needs of students cannot be separated, in essence endorsing a culture of care. Gay (2010) argues that teachers must work harder to be fully present in a culture of care. I would agree and add that principals must set the tone to allow teachers to do so. If all of the focus is put on the academic gains of losses of students, it is natural to lose focus on the whole child and 
hone in on content while putting care of the student on the backburner of education. However, NCLB has brought to light the educational disparities that have existed for as long as education has existed and may support the culture of care more than ever, especially for traditionally underserved students. Because of NCLB and the ESSA, principals can no longer ignore these disparities and rely on their schools overall data to highlight success or failure. Given the challenging complexity of the modern principalship —including high-stakes testing, standards-based reform, increased accountability, and severe budget cuts - practitioners and scholars emphasize the urgency of supporting principals' stress-relief and renewal (Drago-Severson, 2012).

\section{Methodological Literature Review}

Several research articles have been highly influential to my own study. Theses studies have been qualitative and have relied upon interviews to reveal phenomenon regarding issues connected to the human spirit. Theoharis (2007) interviewed leaders to articulate the challenges that leaders are faced with. His study revealed that Principals of Color undergo extra stress and dismay that their White colleagues don't deal with. One limitation of this study was that he used a snowball selection of participants, which allows participants to identify other fitting participants, so there was no way of vetting the actual success of participants. Vergara and Peterson (2016) examined how leaders thrived. They, too, utilized qualitative research in a phenomenological study. While rich in findings, some could argue that there are not enough participants to justify generalizability. Our proposed study will have a similar sample size. Strauss and Corbin (1998) would argue that 10 participants are enough to conduct a study worthy of 
grounded theory analysis, which is our intended strategy for analysis. Saldaña, (2016) used grounded theory in one of his studies with 15 participants and found that there was sufficient variability to construct core categories and its properties and dimensions from a study he conducted in 1995. Grounded theory is a research methodology that is inductive, allowing for participants to create their own themes and categories that are shared by other participants in the study. These themes and categories become findings that support a theoretical or conceptual framework.

Marshall (2009) asked participants about why they entered the profession and deliberately used the term "spirit." In this study participants all came from a Catholic institution. The questions that included the term spirit were misinterpreted by the participants who assumed spirituality was connected to the religion of the institution of which they were in school. Drago-Severson (2012) used a qualitative approach interviewing principals across the nation. From the responses she relied on grounded theory to determine themes from each of the interviews. She study revealed the need for renewal through reflection and collegial conversation that was a regular occurrence.

In 1997, Donald Allison applied a large-scale quantitative approach to studying stress and stress reduction linking participants coping mechanisms to their level of stress using a measurable tool. While my study seeks to discover what sustains the human spirit, it is important to note that stress reduction is not synonymous with a thriving human spirit, but it may be a barrier to sustaining the human spirit. While this article revealed what some of the strategies are for people to reduce stress, one of the findings was that activities that connect to participant's "spiritual growth" is a strong coping 
activity. The problem with this quantitative study is that I intend to hone in on what those activities are for principals. This requires a story, or a deeper conversation, which could not be revealed using Allison's data-collection tool.

\section{Summary of Literature Review}

Leading a complex organization is extremely challenging. Long hours (10 to 17 per day), narrow salary gaps between administrators and teachers, lack of support, new accountability requirements, the scapegoating of principals, changing characteristics of the principalship, declining respect, the need for full-service schools, and the negative media focus make administration less attractive (Marshall, 2004) and sustaining one's human spirit difficult amidst these challenging working conditions. Sustaining principals in the midst of this kind of environment is critical if we hope to find leaders of equity that can stay in challenging schools long enough to make an impact on student achievement.

The problem of sustaining the principal could be resolved by changing the conditions listed above, however, the likelihood of such changes is little, and will take a significant amount of time. To reduce the hours, increase the salaries, increase support, lessen accountability, stop the blame, increase respect, reduce the need for full-service schools and have positive media focus on schools sounds ideal, but nearly impossible. While other studies may seek to find schools where these positive conditions exist, this study will focus on solutions that lie in the principals themselves rather than a change of the social, political, and organizational structures that are causing the current conditions of the principalship. My research question is: How do principals sustain their human spirit while leading for equity? 
In Chapter Two I've shown how learning theory, leadership theory, and policy intersect to play a key role in the sustainability of human spirit of principals. Using these frameworks, I summarize my theoretical framework for this study as shown in Figure 1 below.
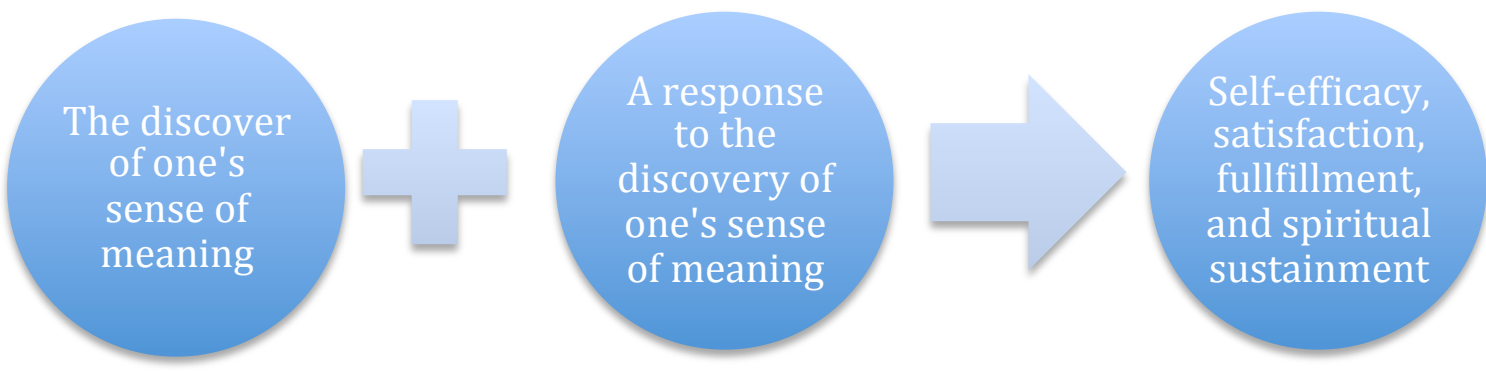

Figure 1: Theoretical framework

The impact of a principal with a strong sense of meaning and responding to this meaning will result in successful principals staying in buildings long enough to create a culture conducive to the elimination of achievement gaps. Principals that are closely connected with their sense of meaning and that are successful in reducing achievement gaps for Latina/o students will be more likely to duplicate the actions that caused the success given the reflective practices one needs to have in order to discover and respond to one's own sense of meaning (Roeser et al., 2012). 


\section{Chapter Three: Methods}

\section{Ryan Richardson and Victor Vergara}

\section{Collaborative Dissertation Using a Common Data Set: Approved 01/15/2013 GSE Doctoral Program Council}

The purpose of this study is to examine how high school principals successful with Latina/o students sustain their human spirit while leading for equity. We have used school data to identify leaders that are having successful results thus we are identifying them as principals that are leading for equity. Two problems that school leaders successful with reducing educational disparities are facing are not enough time and too many responsibilities to sustain their sense of purpose and meaning. This is leading to increased burnout, job dissatisfaction, and turnover (Allison, 1997; Federici \& Skaalvik, 2012; Gates, et al., 2006; Markow \& Pieters, 2012).

In Chapter One I examined the problems associated with educational leaders who have lost their sense of meaning or purpose, essentially, whose spirits are not thriving. A discussion of the human spirit and its connection to successful educational leadership has been examined. I have defined the human spirit to mean the discovery and response to one's own sense of meaning and purpose (Crowell, 2003; May, Gilson, \& Harter, 2004; Miller, 2006). Chapter Two has outlined the need for continued research on the issue of the human spirit of educational leaders leading for equity and includes a literature review of the research connected to issues of leadership, organizational, and political contexts connected to the topic of the human spirit of the educational leader for equity. 
In Chapter Three I will explain the purpose of this study, which is to explore how high school principals successful with Latina/o students sustain their human spirit. I will also describe the methods employed to investigate and analyze my findings. The chapter is organized into six sections: (a) research methods, (b) participants, (c) procedures, (d) instruments and measures, (e) role of researcher, and (f) data collection and analysis.

\section{Research Methods}

This study is a phenomenological qualitative study that investigates the phenomenon of how successful Principals of Color and White principals sustain their human spirit while leading for equity (Creswell, 2013). Phenomenological studies seek to "understand the lived experience" through a detailed description of a situation (p.13). This study purposively chose 10 successful school principals (Maxwell, 2012). Successful school principals were identified as those with four-year graduation rates higher than the state average of $72 \%$ and, at the same time, have nearly closed the achievement gap between White and Latina/o students. All of the leaders chosen have led schools that have a graduation gap of less than $3 \%$ which is significant given the state average gap is $9.3 \%$ between their Latina/o graduation rates and White graduation rates. I have referred to these leaders as leaders for equity because of the remarkable results of their Latina/o students. In Chapters Four and Five, through analysis and interpretation of the data, I will provide a clear picture of the role, or lack thereof, that a focus on equity from the principal has on Latina/o student success in high school.

My research question is how do high school principals sustain their human spirit while leading for equity? This study is a qualitative study that allows the researcher to 
compare the sustainability of Principals of Color and White leaders in successful high schools with a significant population of Latina/o students. In this study, I compared data from Principals of Color and White principals using note writing (Saldaña, 2016), and subsequently using inductive coding to find themes and categories, an approach that lends itself towards qualitative research (Merriam \& Tisdell, 2015). Qualitative research is "the kind of research that produces findings arrived from real-world settings where the phenomenon of interest unfold naturally" (Patton, 2002, p. 39). In this study, the phenomenon of interest was exploring and understanding how individuals create meaning and purpose for themselves, which is very conducive to qualitative research (Creswell, 2009). Examining participants' responses to questions regarding how they engage in a complex system within our world and identifying themes common among the participants is fitting for a qualitative research study (Creswell, 2009).

Examining culturally responsive leadership resulting in success of Latina/o students in high schools (Cummins, 2005; Gay, 2010) and how the spirit of those leaders is sustained (Marshall, 2009; Theoharris, 2007) sets an action agenda for reform that impacts the lives of the research participants, the schools where the participants work, and the lives of Latina/o children in the State of Oregon. As a researcher who is deeply engrossed in the work of equity in education, I consider myself a passionate participant as a facilitator of this research study (Lincoln, Lynham, \& Guba, 2011). I will address researcher bias later in this paper. For years the world of education has been subjectively articulated and shaped by specific stakeholders. White educators have been tailoring education to White students, asking minority students to simply adapt to the dominant 
culture (Barnes, 1989; Gay, 2010; Ladson-Billings \& Tate, 1995). The findings of this study inform this cultural approach. Therefore, the purpose of the study is to examine how successful educational leaders sustain themselves spiritually while leading for equity.

Quantitative component. While this study is a phenomenological qualitative study, my research partner and I have added an additional examination of data from the Oregon TELL survey (Oregon TELL, 2016), a survey administered by the New Teacher Center (NTC) regarding the working conditions in Oregon schools. Our hope is to identify any correlations between the TELL survey results and interview outcomes regarding school leadership. While this study is a qualitative study, we believed an inquiry regarding potential correlations would provide insight to our findings and offer opportunities for further research.

\section{Participants}

My research partner, Victor Vergara, and I used purposive selection to identity 10 high school principals who have been successful with Latina/o students (Maxwell, 2012). There are a variety of ways to identify success in schools (Leithwood, Day, Sammons, Harris, \& Hopkins, 2006). Some argue that we have placed too high an importance on standardized test scores and rigorous content (Nieto, 2009). For the purposes of this research study, we define "successful school leaders" as those who lead schools with graduation rates higher than the state average and where the achievement gap that exists between Latina/o students and their White peers is nearly eliminated. While looking at achievement gaps across all underserved groups is important, it is estimated that the 
Latina/o population in the US will more than double in the next 50 years; thus, serving this critical population is imperative for the future of our nation (U.S. Census Bureau, 2012). Currently the state of Oregon's gap between White graduates and Latina/o graduates is at 9.3\% (Oregon Department of Education, 2016). We have found 10 principals of schools who have less than a 3\% gap in graduation rates between their White and Latina/o students. In half of these schools, the Latina/o students are outperforming their White peers. We also considered the length of the tenure of the principals at the selected schools. Studies indicate that it takes three to five years to make a significant impact on a school culture, thus, we chose principals that have led their schools for at least three years (Leithwood, Seashore Louis, Anderson \& Wahlstrom, 2004; The Wallace Foundation, 2007).

Table 2 indicates the demographic data of participants. All participants are 18 years of age or older, hold an administrator license and have obtained tenure as school administrators. A synthesis of Table 2 presents a synthesis of participants, with 5 identifying a White and 5 as Principals of Color. Four participants identified as Female and 6 identified as Male. 
Table 2

Participant Demographics

\begin{tabular}{lll}
\hline Participant \# & Race & Gender \\
1 & POC & F \\
2 & POC & M \\
3 & POC & M \\
4 & POC & M \\
5 & POC & F \\
6 & W & F \\
7 & W & F \\
8 & W & M \\
9 & W & M \\
10 & W & M \\
\hline Notes: W = White, & POC = Person of Color \\
F = Female, M = Male, O = Other
\end{tabular}

Table 3 presents the demographic data of the selected schools, with 3 schools identified as urban, 6 schools as rural, and 1 school as suburban (OHSU, 2016). All numbers of participant schools are presented in such a way that the data will maintain confidentiality of the school. The graduation rates ranged from $72 \%$ to $98 \%$. The state graduation rate is $73.8 \%$ (Oregon Department of Education, 2016). Six schools graduated Latina/o students at the same rate or better than White students. 
Table 3

School Demographic Information

\begin{tabular}{lllll}
\hline Area & Total & \% Latina/o & Graduation Rate & Graduation Gap \\
$\mathrm{R}$ & $<400$ & $20-50 \%$ & $80-90 \%$ & No gap \\
$\mathrm{R}$ & $<400$ & $>75 \%$ & $90-100 \%$ & No gap \\
$\mathrm{R}$ & $<400$ & $>75 \%$ & $90-100 \%$ & No gap \\
$\mathrm{R}$ & $400-700$ & $20-50 \%$ & $80-90 \%$ & No gap \\
$\mathrm{R}$ & $400-700$ & $50-75 \%$ & $80-90 \%$ & No gap \\
$\mathrm{R}$ & $700-1000$ & $10-20 \%$ & $80-90 \%$ & $<3 \%$ \\
$\mathrm{~S}$ & $1100-1400$ & $10-20 \%$ & $80-90 \%$ & $<3 \%$ \\
$\mathrm{U}$ & $700-1000$ & $20-50 \%$ & $80-90 \%$ & No gap \\
U & $1100-1400$ & $10-20 \%$ & $70-80 \%$ & $<3 \%$ \\
U & $>1500$ & $50-75 \%$ & $70-80 \%$ & $<3 \%$ \\
\hline
\end{tabular}

Notes: $\mathrm{R}=$ Rural; $\mathrm{S}=$ Suburban; $\mathrm{U}=$ Urban; Total = Total student body

Graduation Gap $=$ White graduation rate - Latina/o graduation rate

Source: Oregon Department of Education, (2016)

Table 4 presents a synthesis of participants, with five participants identifying as

White and five as Principals of Color. Six participants are male and four are female.

Three participants are bilingual.

Table 4

Synthesis of Participant Data by Race, Gender, and Language

\begin{tabular}{llll}
\hline Race & Female & Male & Bilingual \\
People of Color & 2 & 3 & 1 \\
White & 2 & 3 & 2 \\
\hline Total & 4 & 6 & 3
\end{tabular}

Table 5 presents the data regarding school location, with the majority of the schools in rural location. 
Table 5

Location of Schools

\begin{tabular}{lll}
\hline urban & rural & suburban \\
\hline 3 & 6 & 1
\end{tabular}

Table 6 presents the data regarding the percent of Latina/o students, with a range of three schools with more than $75 \%$, one school with $50-75 \%$, three schools with 20 $50 \%$, and 3 schools with $10-20 \%$ of the population identifying as Latina/o.

Table 6

School-Wide Percent of Latina/o Students

\begin{tabular}{llll}
\hline $\mathbf{1 0 - 2 0} \%$ & $\mathbf{2 0 - 5 0 \%}$ & $\mathbf{5 0 - 7 5 \%}$ & $\mathbf{7 5 \%}$ \\
\hline 3 & 3 & 1 & 3
\end{tabular}

The schools also represent a range of sizes, with three schools under 400 students and one school more than 1400 as shown in Table 7.

Table 7

Size of Schools

\begin{tabular}{lllll}
$<<\mathbf{4 0 0}$ & $\mathbf{4 0 0 - 7 0 0}$ & $\mathbf{7 0 0 - 1 0 0 0}$ & $\mathbf{1 0 0 0 - 1 4 0 0}$ & $>\mathbf{1 4 0 0}$ \\
\hline 3 & 2 & 2 & 2 & 1
\end{tabular}

Table 8 shows that the majority of schools graduate more than $80 \%$ of the Latina/o students, well above the state average of $73.8 \%$ (Oregon Department of Education, 2016).

Table 8

Graduation Rates at Each School

\begin{tabular}{lll}
\hline $\mathbf{7 0 - 8 0 \%}$ & $\mathbf{8 0 - 9 0 \%}$ & $\mathbf{9 0 - 1 0 0 \%}$ \\
\hline 1 & 5 & 3
\end{tabular}

My research partner and I interviewed school administrators, half of whom are White and half of whom are Principals of Color in order to identify differences or similarities in their responses. All participants were 18 years or older, hold an administrator license, and have obtained tenure as school administrators. 


\section{Procedures}

The following section will describe the procedures the researchers used during the study. This section will include the recruitment, informed consent, data collection and confidentiality, risks, and instruments and measures used.

Recruitment. We sent an invitation email to leaders of schools who have been recognized as successful based on their higher than state average graduation rates and low graduation gaps among Latina/os and White students to request their participation in this study (see Appendix A \& B for emails to participants and superintendents). We told participants that we are inviting them to participate because they have demonstrated successful academic results. We did not share the specific reasons for being selected.

The participants were given the option of being interviewed outside their geographical area of work (see Appendix C for interview questions). The meetings were conducted in a private space identified by the participants as a space where they could not be observed and their confidentiality would be preserved. In these cases we came to the school simply to meet with the principal but did not identify ourselves as researchers. All information that could link the subject to the study (names of people, schools, districts, communities, years of service, demographic data, or other identifiers connecting a respondent to the data) were de-identified and presented in a range and then confirmed with participants; confidentiality will be guaranteed to all subjects (see Appendix D for consent form). We conducted a member check prior to publishing our findings to ensure confidentiality. 
Informed consent. Participation in this study was voluntary. A consent form was shared with participants prior to the interview by email (see Appendix D for consent form). Upon receipt of the form, the participants thoroughly reviewed the consent form and had the opportunity to contact the researcher in case of questions. When the participant decided to participate, then they signed the form and gave it to the researcher prior to the interview. The participant was given a copy of the consent form, which included information on how to contact the researcher should questions arise.

Data collection. The data collection methods include individual semi-structured interviews with the 10 participants (Bogdan \& Biklen, 2007, p. 9). According to Bernard (1988), semi-structured interviews are best used when the researcher will not have another opportunity to interview the participant or when more than one interviewer collects data. We used open-ended questions in order to allow the interviewee to share their perspective without any indication of our desired responses. In some cases, we used additional prompts to gain more insight from participants. One researcher transcribed the interviews while the other conducted the interview; this avoided the distraction of note taking and the risk of missing out on vital information. In addition, the rapport between interviewer and interviewee was enhanced, an essential component of semi-structured interviews (Cohen \& Crabtree, 2006). Interviews were analyzed by using inductive reasoning centered in grounded theory, seeking themes and categories that eventually revealed a conceptual framework (Glaser \& Strauss, 1967).

Data confidentiality. Confidentiality was guaranteed for all study participants and data collected. Pseudonyms were used for any information that could identify 
participants. All names or characteristics that were potentially compromising to the confidentiality of the participant were immediately de-identified. All information shared was anonymous. All interview materials and notes collected in the course of this study were stored on a password-protected computer stored in the locked office of the researcher. The records will be stored for a period of three years from the time of completion of the study.

Risks. There was no expected physical or mental discomfort for participants. Corbin and Morse (2003) recommend several steps to ensure the emotional safety of those who exhibit discomfort during any type of data collection, which the researcher will apply to the study: 1 . The researcher remains with participants until the participant reaches a stable emotional state; 2 . The researcher assembles a list of local counselors to give to participants should "distress arise during or after" the survey. Corbin and Morse (2003) found that volunteer participants react positively and are grateful for opportunities and are happy to discuss even unpleasant experiences. The researchers are administrators licensed by the Teacher Standards and Practices Commission (TSPC) who have more than 30 years of experience teaching and leading schools, who have completed Institutional Review Board training, and who will follow all Human Subjects Review Board (HSRB) expectations.

Instruments and measures. For this study, the researchers were seeking to discover characteristics and beliefs regarding the leadership priorities and spiritual sustainment of the participants. These are matters that cannot be easily seen or observed in practice. Glesne (2006) states, “The opportunity to learn about what you cannot see 
and to explore alternative explanations of what you do see is a special strength of interviewing in qualitative inquiry" (p. 81).

The interview is a prime method of studying complex individuals in the midst of complex social structures (Krathwol, 2009; Steiner, 1996). We prepared questions prior to interviewing the participants, and were prepared to develop new questions and follow unexpected leads that arose in the course of each interview. The main idea of using the interview instrument was to learn from each high school principal about their leadership practices that help Latina/o students to be successful in schools, reducing the educational disparities between White and Latina/o students and to seek to find a connection, if any, to their sense of meaning and purpose.

Some argue that structured interviews are best when comparing two or more groups of data, while unstructured interviews are the best for discovering a phenomenon (Maxwell, 2013). We did both: compared the experiences of successful Principals of Color and White principals while discovering a phenomenon. Glesne (2006) argues that questions that emerge or change during the interview are more ideal in qualitative research. That being said, we recognize the need to remain somewhat consistent in our interview practices, as we wanted to ensure a level of trustworthiness and consistency throughout our findings and rule out diversions that could compromise the validity and trustworthiness of our study (Maxwell, 2013).

\section{Role of the Researcher}

As a researcher for this study, I approach this work from a critical and constructivist paradigm (Lincoln, Lynham \& Guba, 2011). As a White, middle class, 
male from an educated family, I am aware of the unearned privileges afforded me by virtue of my characteristics. Currently serving as a high school administrator, it is fair to say that my colleagues of color have barriers that I do not face. I am a passionate participant in this research and believe that I could not create my own findings but needed to work with participants to co-create findings that may be generalizable (Lincoln, Lynham, \& Guba, 2011).

While examining how individual social justice leaders sustain themselves is critical in this study, I believe I have also have a moral obligation to conduct research that changes a culture rooted in racism and oppression for people of color, a belief rooted in a critical paradigm (Lincoln, Lynham, \& Guba, 2011). I believe that this study shines a light on the challenges that Principals of Color face as well as the experience of White allies. As a White male, I realize the privilege that I have as a researcher and will need to be conscious of this privilege, especially when interviewing and interpreting the responses of Principals of Color. Relationship building will be very important in order to elicit honest responses from participants (Maxwell, 2013).

I conducted this study with my co-researcher and colleague, a principal of a high school, Victor Vergara. Victor is a recent immigrant, bilingual, first generation college graduate from Chile. Victor grew up in Chile before coming to the states. He, too, brings a constructivist and critical lens but has a much different background. We researched together, following the principles of the Carnegie Project on the Educational Doctorate (CPED, 2017). Together we conducted the interviewing process and calibrated our 
questioning strategies to ensure common interview practices. We also double coded all of our data, providing multiple viewpoints of interpretation.

\section{Data Collection and Analysis}

Conducting interviews with our 10 participants resulted in a comprehensive data set to analyze. While we double coded all data and generated themes and categories to increase the trustworthiness of our findings, I will present the data and findings related to the human spirit and my research partner Victor Vergara will present the data and findings related to other characteristics of the leaders.

Because my research question elicited complicated responses that are heuristic in nature, my research was guided by grounded theory when coding and analyzing the data (Glaser \& Strauss, 1967; Saldaña, 2016; Strauss \& Corbin, 1994). Grounded theory was appropriate for this research study because its purpose is to demonstrate the relationship between conceptual categories and to specify the conditions under which theoretical relationships emerge, change or are maintained (Charmaz \& Belgrave, 2002).

To analyze our data, my research partner and I first set out to find themes through a cycle of coding rounds interspersed with further data collection and thoughtful reflection, which Saldaña (2016) refers to as analytic memo writing. Figure 2 shows the framework of our coding methods, drawing from previous researchers (Glaser \& Strauss, 1967; Maxwell, 2012; Saldaña, 2016; Strauss \& Corbin, 1994). 


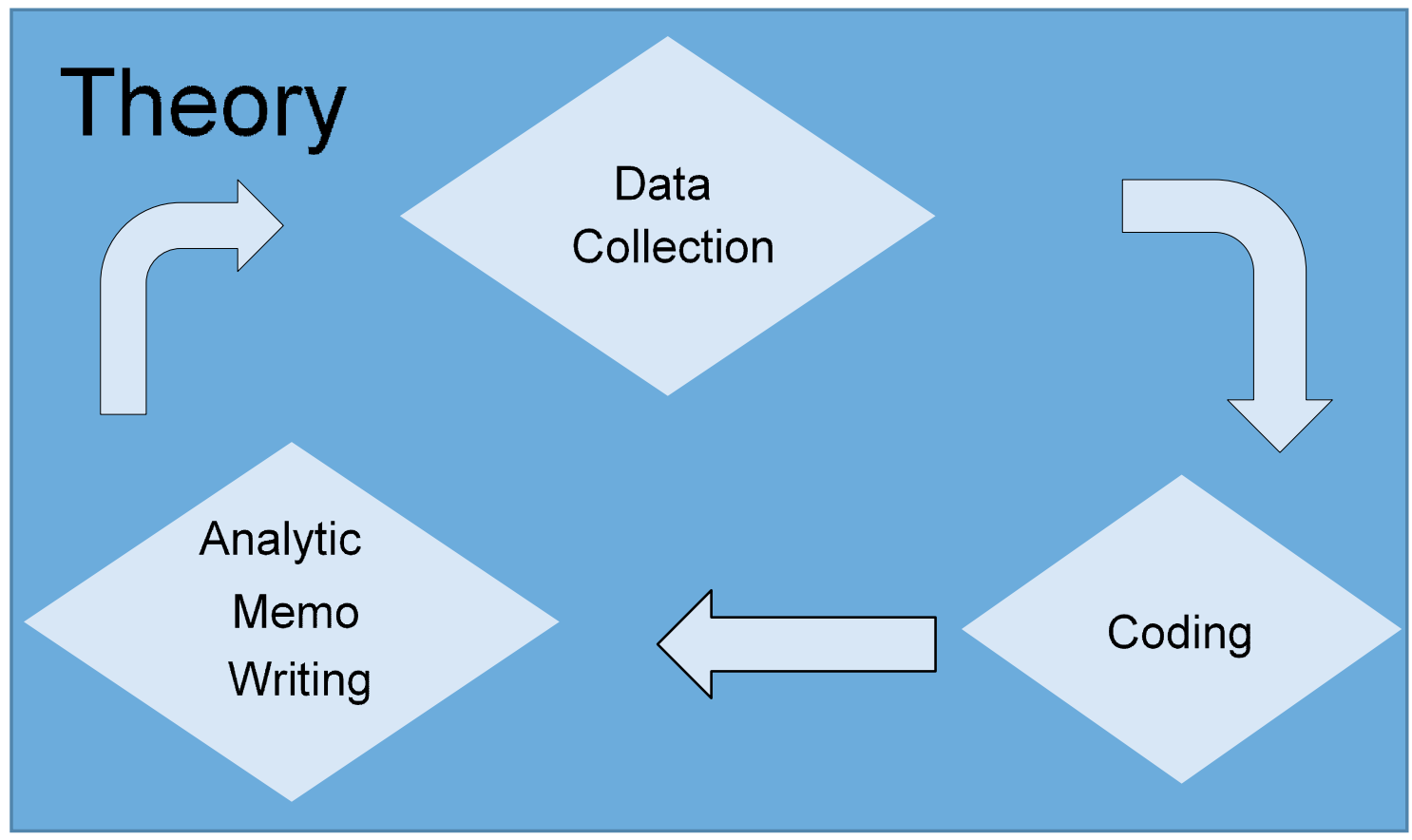

Figure 2.Coding methods framework

In the following paragraphs, I will describe the coding methods and procedures. The analytic memo writing and reflective dialogue between my research partner and me were key to interpreting the data and proposing a theory of action for the recruitment, retention and professional development of future leaders (Maxwell, 2013). As Saldaña (2016) says, "memo writing is the engine of grounded theory, not coding" (p. 164).

Memo writing and subsequent conversations about our memos guided our next steps of interpretation of the data.

For this study, we collected the data from the first four participants, all of whom are Principals of Color. We coded the data individually. In the first round, the technique of In Vivo and initial coding were combined (Saldaña, 2016). In Vivo coding allowed participants' own words to be used as guides to potential themes, and initial coding was incorporated to categorize what was said. Each researcher coded each interview and then 53 
reflected and compared one another's coding through analytic memo writing and dialogue. This technique let researchers reflect on their coding process and code choices; how the process of inquiry is taking shape; and the emergent patterns, categories and subcategories, themes, and concepts in the data (Saldaña, 2016, p. 41). Double coding ensured a process that permits data to be segregated, grouped, regrouped and relinked in order to consolidate meaning and explanation (Grbich, 2007). Next, we each wrote an analytic memo based on our coding of the data from the Principals of Color and then discussed our memos prior to conducting additional coding. We then repeated the steps above with the White participant data.

The second round of coding combined focused coding and coding (Saldaña, 2016) in which categories were identified. In this round, themes were placed into categories, although it is important to note that some themes had varying levels of fit into each category (Dey, 1999). Axial coding was also used to help the researchers find similarities between themes that were initially split into different categories or questions during the first round of coding (Saldaña, 2016). Searching for synonyms and eliminating redundant themes helped the researchers understand and articulate the findings of this study.

Using analytic memo writing, discussions of the memos and a series of coding rounds, we found that themes emerged among Principals of Color and White principals. Utilizing analytic memo writing, discussion, and several rounds of double coding allowed us to mitigate any possible bias and increase the trustworthiness in the study. The results of multiple rounds of coding revealed themes and categories that contributed to a conceptual framework to be described in Chapter Four. 


\section{Chapter Four: Results/Analysis}

In Chapter Three I described the process of analyzing the interview data and the TELL survey data, following the Graduate School of Education's CPED-inspired dissertation process. The CPED-inspired dissertation develops the doctoral candidates' collaboration and communication skills - skills that are critical to their practice as professionals in education (CPED, 2017). For this dissertation, I collaborated on data collection and analysis with my research partner, Victor Vergara. As stated in previous chapters, my research question is: How do successful high school principals sustain their human spirit while leading for equity? For this study, I am defining "human spirit" as the discovery of and response to one's sense of meaning and purpose; a definition informed by educational researchers who examined work conditions and experiences that cause educators to have a sense of fulfillment and satisfaction (Crowell, 2003; Jones, 2005;May et al., 2004; Miller, 2006; Palmer, 1996; Roeser, 2014; Tisdell, 2001). In Chapter Four I will re-state the purpose of this study, analyze and present the data, interpret the findings, and reveal limitations of this study and data analysis.

The purpose of this study was to understand how successful leaders for equity are sustaining themselves and their human spirit while engaging in complex work. It is clear that the current climate for high school principals is leading to high turnover rates, high levels of stress, and continued achievement gaps for our Students of Color (Alt \& Henke 2007; Gates et al., 2006; Guarino et al., 2006). This is especially true for women and Principals of Color (Johnson \& Hekman, 2016; Peterson \& Vergara, 2016; Theoharris, 2007). Thus, while it is not common for educators to focus on their issues of what 
sustains their spirit, it is critical that we discover what causes some leaders to be effective leaders for equity while staying in the profession.

For this study, we selected 10 high school principals whose high school graduation rates were higher than the state average and who had eliminated or nearly eliminated the graduation achievement gap between White and Latina/o students. Selected participants responded to 13 questions regarding their path to the principalship; the priorities and initiatives that they deemed to be important to the success of Latina/o students; the barriers that impede their progress; and their sense of meaning and purpose. These questions revealed their deeper beliefs about what is important to each of them, how their beliefs connect to their sense of meaning and purpose, and concomitant decisions and actions.

In Chapter Two I examined the research on leaders for equity and how those leaders are sustained when their sense of meaning and purpose is discovered and aligned with their ability to respond to that discovery. Because the subjects in this study were purposively selected due to their success with Latina/o students (as defined in Chapter Three), it is not a surprise that these principals revealed a focus on equity. However, it is important to note that all respondents spoke about equity throughout their entire interview, regardless of the question, with Principals of Color more likely to reference equity than White principals. This study did not reveal that principals' discovery of and response to their sense of meaning guided their work. Instead, principals revealed a broader connection to a greater good, specifically related to helping others and increasing student achievement, constructs that are closely connected to the human spirit (Miller, 
2006, Noddings, 2005; Palmer, 2003). Further, the Oregon Tell Survey did not reveal any correlations or significant findings related to successful high school principals.

In this next section, I will first provide an analysis of the Tell Survey results followed by an analysis of each question and a synthesis of the findings. I will also propose a revised conceptual framework for what sustains high school principals who are successfully leading for equity.

\section{Analysis of the Tell Survey}

The Teaching, Empowering, Leading and Learning (TELL) Oregon survey is an anonymous statewide survey of licensed school-based educators to assess teaching conditions at the school, district, and state level (Oregon Tell Survey, 2016). Results have been published from 2014 and 2016. The survey examined perceptions regarding eight constructs that have been linked to educator retention and student achievement (Oregon Tell Survey, 2016). For this study, I hoped to ascertain the connection between the construct entitled "school leadership" for the 10 successful principals in this study and the state average for the same construct. I also looked at one additional data point from the TELL survey: teachers' response to the prompt, "overall my school is a good place to work and learn."

Data are available for schools that have at least a $50 \%$ response rate. It is for this reason that I have data from seven of the 10 schools in our study rather than all 10 . The section on school leadership includes data from 13 themes. Teachers are asked if they agree or disagree with each prompt. The themes from the construct of school leadership are shown in Table 9. The numbers in the table represent the percentage of teachers that 
agreed to the theme. For example, the first theme is that teachers and leadership have a shared vision. The range in row two for the theme of shared vision shows that the school in our sample with the lowest percentage of teachers that agreed to this theme is $27 \%$ while the school in our sample with the highest percentage of teachers agreeing to the shared vision theme is $94 \%$. In addition to the range, the table includes the median, standard deviation, $\mathrm{p}$-value, average of our sample size, and the state average for all high schools in the state of Oregon. 
Table 9

TELL Survey Descriptives

\begin{tabular}{|c|c|c|c|c|c|c|c|}
\hline Question \# & Theme of Question & Range & Median & SD & $\begin{array}{l}\text { Sig. (2- } \\
\text { tailed) } \\
\text { or } p \\
\text { value }\end{array}$ & $\begin{array}{l}\text { Subject } \\
\text { Average }\end{array}$ & $\begin{array}{l}\text { State HS } \\
\text { Average }\end{array}$ \\
\hline Q7.1a & Shared vision & $27-94$ & 66.7 & 22 & .59 & 66 & 71 \\
\hline Q7.1b & Trust, mutual respect & $\begin{array}{l}45.6- \\
94.1\end{array}$ & 69.2 & 18 & .75 & 69 & 72 \\
\hline Q7.1c & Can raise concerns & $\begin{array}{l}45.5- \\
94.1\end{array}$ & 68.4 & 15 & .59 & 68 & 72 \\
\hline Q7.1d & $\begin{array}{l}\text { Leadership supports } \\
\text { teachers }\end{array}$ & $\begin{array}{l}54.5- \\
100\end{array}$ & 73.7 & 17 & .98 & 76 & 76 \\
\hline Q7.1e & $\begin{array}{l}\text { High professional } \\
\text { standards }\end{array}$ & $\begin{array}{l}54.5- \\
100\end{array}$ & 92.3 & 16 & .93 & 92 & 88 \\
\hline Q7.1f & Using data & $\begin{array}{l}72.7- \\
96.8\end{array}$ & 88.9 & 9 & .63 & 86 & 84 \\
\hline Q7.1g & $\begin{array}{l}\text { Teacher performance } \\
\text { assessed objectively }\end{array}$ & $70-93$ & 81 & 8 & .41 & 83 & 81 \\
\hline Q7.1h & $\begin{array}{l}\text { Helpful feedback for } \\
\text { improvement }\end{array}$ & $46-90$ & 81 & 15 & .63 & 77 & 74 \\
\hline Q7.1i & $\begin{array}{l}\text { Ongoing teacher } \\
\text { feedback }\end{array}$ & $20-96$ & 61 & 24 & .64 & 58 & 63 \\
\hline Q7.1j & $\begin{array}{l}\text { Evaluations } \\
\text { consistent }\end{array}$ & $60-94$ & 76 & 10 & .67 & 76 & 74 \\
\hline Q7.1k & $\begin{array}{l}\text { Admin uses } \\
\text { evaluation tool well }\end{array}$ & $54-94$ & 90 & 15 & .78 & 80 & 79 \\
\hline Q7.11 & $\begin{array}{l}\text { School improvement } \\
\text { team leads }\end{array}$ & $20-100$ & 77 & 26 & .98 & 70 & 70 \\
\hline Q7.1m & $\begin{array}{l}\text { Recognition of } \\
\text { accomplishments }\end{array}$ & $63-90$ & 75 & 11 & .91 & 78 & 79 \\
\hline Q10.7 & $\begin{array}{l}\text { Good place to work } \\
\text { and learn }\end{array}$ & $64-100$ & 90 & 14 & .93 & 86 & 86 \\
\hline
\end{tabular}

Note: Statistical significance at the $\mathrm{p}<.05$ level. 
It is important to note that none of the themes resulted in statistically significant results. We can conclude the null hypothesis given the results from the One Sample tTest. The null hypothesis represents that the sample mean is the same as the mean for the entire state of Oregon. The null hypothesis is true for every theme connected to school leadership as well as the final theme: my school is a good place to work and learn.

These results are not surprising due to the large range and standard deviations among our sample size. Every question had a relatively large standard deviation, which ranged from eight to 24 . With a sample of only seven schools, and such large standard deviations it is no surprise that any difference in the mean of the sample and the mean of the state would be deemed statistically insignificant. In fact, with the lowest $p$-value at .41 , none of the results were even close to statistically significant. What is surprising is that the means of the sample of successful schools are better than the mean of the state average on only six of the 14 themes that were explored. Given that the data from the TELL survey has no connection to the success of these principals compared to principals from all of the high schools across the state, I will rely on interview data to find themes that are relevant to my research question which is, how do successful high school principals sustain themselves while leading for equity. For a more in depth look at each question's results from SPSS see appendices E-R.

\section{Analysis of Qualitative Data}

To answer the research question of how successful high school principals sustain their human spirit while leading for equity, we first analyzed the data related to each interview question; synthesized the themes related to each question (Appendices $\mathrm{E}-\mathrm{O}$ ); 
provided quotations to support each theme; and then, through more rounds of focused and axial coding, identified major categories that led to key findings (Saldaña, 2016). Each question elicited themes from the participants that were identified through the process of double coding to ensure validity. Many of the themes were taken from the participants' own words, also known as In Vivo coding (Maxwell, 2012; Saldaña, 2016).

Question 1: Career pathway? In the first question, in which participants described their career pathway, clear themes emerged. Seven comments by three of the five Principals of Color indicated an adverse childhood experience or experience that led to a commitment to equity as a part of their career pathway. Only one White administrator revealed either of these themes: "I was raised by a single mom, poor, welfare, in the projects, where everyone was poor and there was alcohol and drugs (all around me.)" That experience led to their equity focus. Responses from Principals of Color included one woman who stated, "I think [my career pathway] [was due to] coming from a family where people didn't graduate. I don't know if I would've gotten through that first year (of college) without the support of my cohort." This helped contribute to her focus on equity and supporting students with similar experiences of being the first in their family to achieve academically. Another Principal of Color noted that they went into education because, "we thought (growing up) that if we had influence we could help more kids like us and eliminate barriers to success."

Four of the Five Principals of Color described a struggle to get their first job as an administrator but all five were promoted to their principalship without a formal interview process. One Principal of Color was told, "we think you can do this" by leaders in the 
district office when he had doubts about himself. Another Principal of Color stated that, "the staff asked the superintendent to promote me to the principal position." White leaders didn't discuss the process for how they got their jobs or mention advancements or struggles with the exception of one White leader who mentioned it was his third interview that got him hired.

Another clear theme was that all five Principals of Color shared the experience of someone seeing something in them. They remember who gave them their first chance or encouraged them to join the profession. No White leaders revealed this same theme during question one. One Principal of Color described an encounter with a hiring administrator who insisted they apply: “She told me, 'I noticed you didn't apply' and I told her I didn't intend to. She said, 'I'll see your application today and the position closes at 4pm.’ I got my application in.” For a chart displaying all emerging themes on Question One, see Appendix S.

Question 2: Who inspired you? The second question asked respondents who, helped, inspired, and motivated you along the way. Interestingly, three White principals described getting positive encouragement that inspired them. One White leader described "getting lots of positive feedback and encouragement as a teacher, which made me think about administration." Another White leader shared about his experience as a teacher on special assignment (TOSA) and being told to "keep doing what your doing." Only one Principal of Color mentioned mentors who had encouraging words: "He [hiring administrator] believes and trusts me. At that point I had no experience in secondary education but for some reason he gave me a chance and that motivated me." Given that 
all Principals of Color in question one noted that someone "saw something in them" and that it was a memorable encounter that contributed to their career trajectory, the absence of inspiration and support is worth further exploration.

Only two Principals of Color had a mentor of the same race and of those, only one shared the same gender. Another Principal of Color had "mentors (of color) from afar" but only had White mentors that worked directly with him. Every White leader had White mentors but some did note that they also had mentors who were Principals of Color as well. See Appendix T for all emerging themes on Question Two.

Question 3: Did you get any resistance? Question Three asked if respondents encountered any resistance when they became leaders in education. The differences in themes between White leaders and Principals of Color were dramatic. Principals of Color shared 27 different comments regarding the resistance they experienced. White leaders shared three comments, and two of those were from a White woman who experienced resistance due to her gender. Comments from Principals of Color included:

- "Someone told me this school is where all the (Principals of Color) go."

- "I remember a teacher that told me there is nothing I could teach them."

- "When I approached my superintendent and told him I'd like the opportunity to be an administrator he told me, 'you aren't ready.'"

This layer of resistance was a theme throughout the entire interview for Principals of Color, not just for Question Three. Further discussion on the impact of this active resistance on the sense of purpose of respondents will follow later in Chapter Four. For a chart displaying all emerging themes on Question Three, see Appendix U. 


\section{Question 4: Formal training for success with Latina/o students? Question}

Four asked participants about their formal training and how it prepared them to work with Latina/o students. All five Principals of Color noted that they had no positive formal training to help them be successful with Latino students; three White leaders made the same observation. Interestingly, four Principals of Color noted a multicultural class that attempted to prepare future administrators to work with a diverse population, but they found the course to be a negative experience, one that they remembered. One Principal of Color said that after learning from a professor in his class, "I was ready to go home." Another Principal of Color said that she was "appalled" by the content of the class. On the other hand, a White leader shared that he learned to "celebrate the differences we have" in his multicultural class.

Seven leaders did share that they had informal trainings outside of the principal preparation programs that did support their work as they led a school with a significant population of Latina/o students. Two participants shared that "continuing classes" helped them be ready to work with Latina/o students. Two other participants shared that the "district offers good professional development" which helped them.

One final point of interest was that two Principals of Color mentioned their life experiences that helped them and three White leaders spoke about their life experience. One White leader said that growing up poor and in the projects helped him realize that "bad decisions didn't mean they were made by bad people." He spoke about how this helped him support all students, in particular, students that were in gangs (not necessarily Latina/o). Another Principal of Color spoke openly about her own experience as a female 
Leader of Color. "I had my own struggles as a (Student of Color) and teacher and the struggle is the same." For a chart displaying all emerging themes on Question four, see Appendix V.

Question 5: Best advice received? Question five asked participants to identify the best advice they received, as they became a leader. An important difference between the Principals of Color and White leaders was the nature of the advice they described. Four Principals of Color received advice that added pressure to their work. The nature of the advice could be described as warnings rather than advice. One Principal of Color shared that the best advice they received was to get ready because "this work is hard." Another Principal of Color shared that he was told to "go the extra mile to show that we (Principals of Color) can do the job." Only one White leader shared advice that also put pressure on them. They said they were told to "model for the teachers in the building." No other White leaders received any advice that would have added pressure to their work. For a chart displaying all emerging themes on Question Three, see Appendix W.

Question 6: Unique leadership characteristics? Question Six asked participants to identify their unique leadership characteristics that made them successful. Both White leaders and Principals of Color gave numerous responses that fell into themes connected to relationship building or equity. In fact, nearly every answer eventually fell into one of these two categories. Leaders spoke about relationship building strategically. One Principal of Color shared, "they have to know we care, particularly, families of color." Another Principal of Color spoke about intentional actions to build relationships. "There are kids that won't go to the office so I find a bench out there (in the halls) and start 
working. Students or adults will find me. They realize I won't bite and start talking to me." White leaders shared similar themes around relationships. One White leader spoke about connecting to Latina/o youth and families. "You win people over when you keep going and are real and stay in there. You can’t quit if you run into resistance.” Another White leader talked about "loving kids to death."

Both White leaders and Principals of Color spoke about equity as well. A White leader attributed his success to understanding the culture of his Latina/o students. " Sit and watch movies and listen to music and have those cultural references. Those bond us." Another White leader was more humble, but direct, in her response about her commitment to equity. She said, "Our numbers go up and down a little every year and I don't know exactly why each year, but I know we are committed to keep trying (to eliminate gaps for underserved students)." Two Principals of Color shared the importance of hiring staff that reflected the students. Another Principal of Color said, "I try to share my cultural experiences and kids know I'm real and not benevolent and I've been there before." For a chart displaying all emerging themes on Question Three, see Appendix X.

\section{Question 7: Most important initiatives and priorities?}

Question Seven asked participants about their most important priorities. Major themes emerged quickly. Equity was explicitly stated and many also shared stories around cultural sensitivity. A Principal of Color answered immediately, “An important priority is building equity. Building equity from a policy standpoint but in terms of awareness and paradigm too. Also transformative equity procedures." Another Principal of Color brought up hiring just as they did on the previous question. "Students must see 
others in positions they aspire to. They have to see people that look like them." One Principal of Color spoke about a specific program that they had adopted to help ensure that their Students of Color were getting into advanced placement options.

While each White leader spoke about equity during the interview, only two White leaders shared a focus on equity when talking about their important initiatives. One shared about the importance of creating choice in the classroom as it connected to equity. "I ask my social studies teachers to teach things that are relevant. As a class, we can choose to learn about the Mexican or Russian revolutions. Students need to see themselves as part of the curriculum.” Three White leaders discussed initiatives that could potentially be implemented without an equity focus. These leaders shared answers that included a focus on graduation rates, attendance, tardies, PLCs, relationships, and instructional strategies. These three leaders didn't specifically exclude equity, but the answers given couldn't be coded into themes connected to equity while the other seven leaders clearly named equity by explicitly saying "equity" or describing actions that promoted the achievement for Students of Color.

This question also brought out the idea of being culturally sensitive. One White leader spoke about the work it took to "cultivate a culture (that reflected our kids of color)." Another White principal spoke about meeting with families of color that were intentionally planned to bring people together. The Principals of Color also spoke of being culturally sensitive. One Principal of Color spoke about his students who are migrant workers that sometimes go away for over a month. He said, "We need to share how important it is to be in school but not ask them to give up their culture... that is 
always something we are looking at." Another Principal of Color spoke about "the whole child." He added, "We talk about specific students and their life. We are trying to make sure that we are sensitive to minorities and other cultures." (For a chart displaying all emerging themes on Question seven, see Appendix Y.

Question 8: Latina/o success? Question Eight asked participants to what they attribute their success with Latina/o students. In this question, every participant spoke about a theme that connected back to relationships. Three Principals of Color and one White leader spoke about making themselves accessible in order to eliminate barriers to relationships. One spoke about their experience with the Latina/o culture. "They can always walk in (to my office) but they didn't because of the culture. The culture said, we don't just walk into my door even though I say my door is always open." He went on to share how he created opportunities to hear from those families. A White leader shared about his intentionality with getting into the halls and classrooms to talk to students.

Others spoke about relationships as well. A Principal of Color said, "We build on relationships. We get to know them and they get to know us. I spend hours and hours with students talking about transcripts, grades, scholarships, and plans." A White leader spoke about the atmosphere of relationships. "We have created an atmosphere that all students belong to everyone." He went on to use students in the English Language Development (ELD) program as an example saying, "those kids don't just belong to the ELD teacher." Another White leader spoke about the importance of feeling safe and included in the school environment. "A contributor (to our success) is relationships which helps create safe and inclusive environments." 
For a chart displaying all emerging themes on Question eight, see Appendix Z.

Question 9: Expectations from the superintendent and board? Question Nine asked participants about the leadership expectations that are placed upon them from the superintendent and school board. Seven participants, four of them Principals of Color, generalized the expectations to be high and that they were expected to work hard. A Principal of Color listed many expectations and summed it up this way, "They expect me to do a whole lot. I don't even know how to summarize everything they want us to do on a daily basis." Two other Principals of Color put it simply, both saying without much expansion that they were given high expectations.

Three other participants shared that there were no real expectations. An interesting finding that will be discussed in later in Chapter Five is that four of the five Principals of Color also shared, without being asked, that they follow all expectations. In contrast, no White leaders revealed this theme; one White leader shared that he is likely to challenge expectations if they do not align with his goals. One Principal of Color explained, "I never challenge the expectations. I just grew up doing it, just like all the other jobs like when I was in landscaping. I don't ask why.” Another Principal of Color shared, "I believe in following orders." These findings and their implications will be continued in the implications section in Chapter Five. For a chart displaying all emerging themes on Question nine, see Appendix AA.

Question 10: What messages do you send? Question Ten was about the messages that our participants gave to students, staff, and families. The consistent response to this question was a focus on teachers and showing appreciation for the work 
they do. Both White leaders and Principals of Color responded with praising the work of their teachers and staff. Four Principals of Color and four White leaders shared this sentiment. One Principal of Color said, "I try to recognize staff and the good things they are doing." Another Principal of Color shared, "Teachers' work is the most important work we can do. They aren't paid enough.” White leaders shared similar sentiments. One White leader explained their comments to staff saying, "You are performing amazingly complex tasks while engaging students in relevant discourse.” Another White leader explained it this way, "I know teachers come every day to do the best they can possibly do. I always start there. All of us not only do the best we can but we've made sacrifices to be here." The messages to students and families varied but included students working hard and families believing in themselves. Some of the participants focused on messages to teachers without addressing the messages they send to students and families. For a chart displaying all emerging themes on Question Ten, see Appendix BB.

Question 11: What advice would you give? Question Eleven asked leaders to provide advice to future administrators. The exact question was: As a member of the (i.e. White, Latina/o, etc...) culture, what else should future (i.e. White, Latina/o, etc...) leaders know about becoming a leader in schools with high populations of Latina/o students? The responses to this question were very different depending on the race of the respondent. Every White leader gave advice that was connected to equity and being culturally sensitive. A White leader said, “Always use a lens of equity. Remove your biases, which is hard." Another talked about creating opportunities for Latina/o families to connect. "We need to not be afraid to know them and be with them. Reach out 
to them. Set up visits. Talk, listen, and ask questions." One White principal boldly gave some specific advice to future White administrators. "Every White ass administrator should spend at least three hours reading about the cultures in their school."

Advice from Principals of Color was much different. Two Principals of Color gave advice around being culturally sensitive but even more interesting was that four of the five Principals of Color shared advice that would really be classified as warnings to future administrators. One Principal of Color spoke about the difficulty of the work and it being a lonely job. When he heard that the researcher had been an administrator for 12 years he laughed. 'No lunch break. I think it's crazy. You haven't had a lunch break for 12 years...half eaten sandwich on your desk...it's crazy. You have to network with people because this work can get lonely." Another Principal of Color had this warning for future Principals of Color, "Get ready to be judged. First thing people see is (my race). You'll be judged by what you look like and then the body of work comes next." For a chart displaying all emerging themes on Question 11, see Appendix CC.

Question 12: Sense of meaning and purpose? Question 12 specifically asked what gives these principals a sense of meaning and purpose, or in other words, what motivates them to do the work that they're doing. This was an important question for this study as the previous questions were designed to reveal what subjects would talk about when not explicitly prompted on their sense of purpose and meaning whereas, questions 12 and 13 explicitly asked about what I had defined in previous chapters around the human spirit. Participants spoke to the higher calling of the profession; helping students achieve. The comments from this question were placed into themes as shown in Table 10. 
While four principals, two White and two Principals of Color, spoke about reducing barriers, six made no direct connection to equity in this response. However, when principals were asked about their sense of meaning, they responded directly to the idea of helping others or student achievement. In fact, all ten participants discussed at least one of these themes. "Helping students" and "student achievement" are the same ideas that many first year teachers cite for getting into education. Respondents in this study, former teachers and now seated administrators, also referenced this motivation. Diving deeper into subject responses, we find that all ten principals use equity as the driving force behind helping others and student achievement.

Table 10

As a high school principal, what gives you a sense of meaning and purpose? In other words, what motivates you to do the work that you're doing?

\begin{tabular}{|c|c|c|}
\hline Themes for Question 12 & Administrators of Color & White Administrators \\
\hline Helping others & 5 & 2 \\
\hline Reference to a feeling or emotion & 3 & 4 \\
\hline Relationship with students & 3 & 3 \\
\hline Student success & 1 & 5 \\
\hline Liking work & 2 & 3 \\
\hline Being fulfilled & 3 & 1 \\
\hline Reducing barriers & 2 & 2 \\
\hline Respect from others & 1 & 0 \\
\hline \multicolumn{3}{|c|}{ Thus, responses to Question 12 were highly focused on students. Themes around } \\
\hline \multicolumn{3}{|c|}{ helping others, student success, relationships with students and reducing barriers were all } \\
\hline \multicolumn{3}{|c|}{ connected to students. There was a litany of generalized student centered comments from } \\
\hline \multicolumn{3}{|c|}{ many participants such as, "I like the people and kids," "It's about kids," "We care so } \\
\hline
\end{tabular}


participants didn't have specific language around their sense of meaning and purpose. For example, no participant spoke about achievement on a specific test, raising poor grades, graduating all students, preventing dropouts, or preparing students for college at a 4-year university. Instead each participant said that they want to help others and see student achievement.

Another interesting theme that emerged from question 12 was that every principal either spoke about liking their job or spoke about a feeling or emotion. They were asked what gives them a sense of meaning and purpose but included in the responses was the impact of being connected to their meaning and purpose. It was as if they were asked what their favorite food was and instead of just naming the food, they described the taste. One Principal of Color described the sense of pride when looking at the building they led and let out a huge sigh, with their shoulders releasing any tension and with a smile stated simply, "I made it." Another Principal of Color said it made them "feel good (knowing) that I helped." A White principal described the feeling of coming to work at the high school being "jazzed" and "feeling like I've won the lottery." Table 10 below reveals the themes that were revealed by the respondents.

\section{Question 13: What gets in the way of meaning and purpose? Question 13} asked principals about the barriers that get in the way of their sense of meaning and purpose. Table 11 below shows the themes that emerged with the most prevalent theme connecting to the idea of managerial work or managing things or people. One White principal said, "Being asked to do things that are a waste of time," and went on to describe state mandates and reports that had to be written. Another Principal of Color 
said, "The (rival team) basketball game, lunch duty, citations for truancy...the busyness of this job...you can find yourself in the deep end trying to swim back to the shallow end. It can be so overwhelming”

Table 11

Question 13: As a High School Principal, What, if Anything, Gets in the Way of You Connecting to Your Sense of Meaning and Purpose?

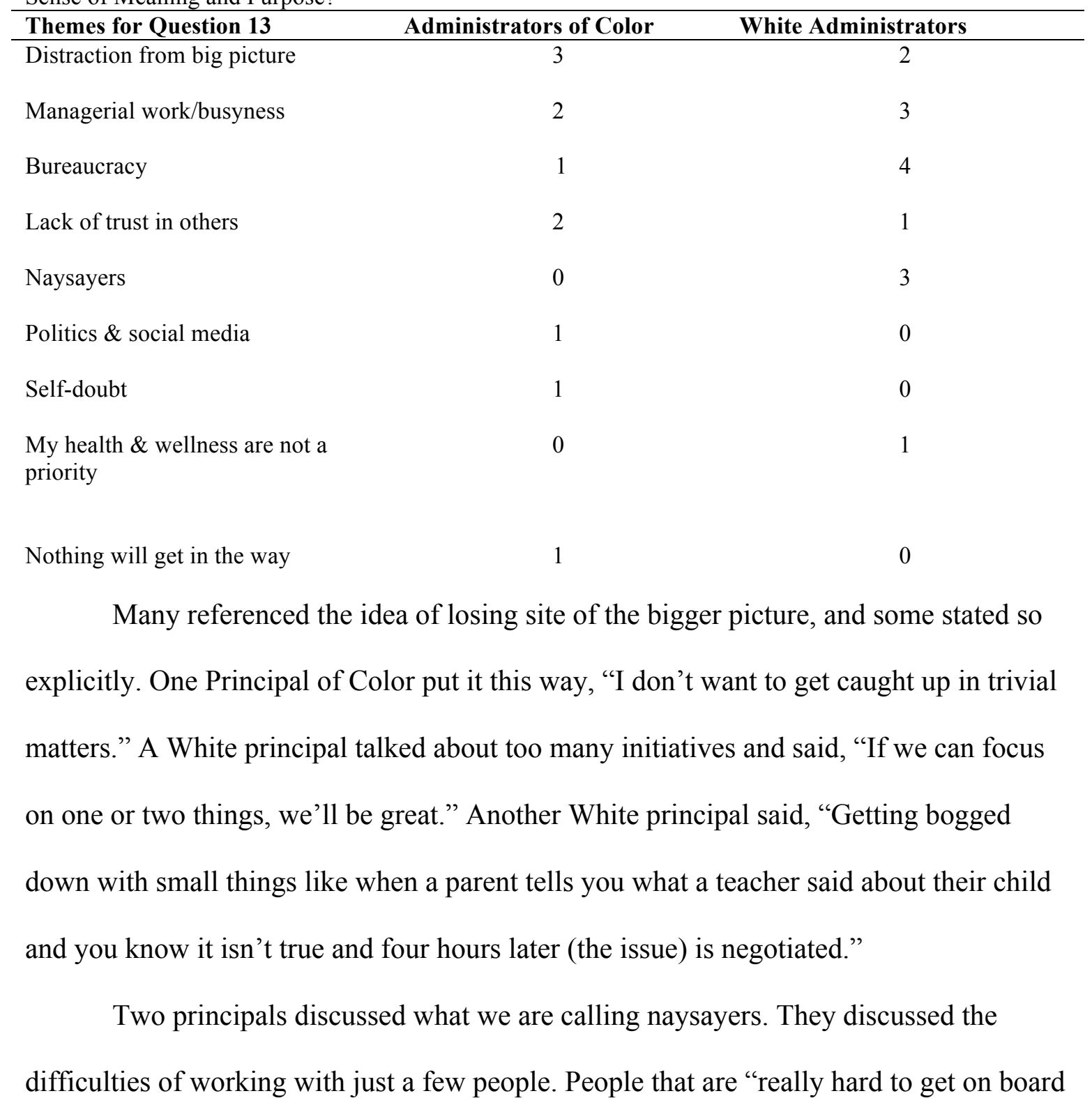


and motivate" or "people that do things in education that are really hard to defend" both being descriptions from White principals.

\section{Synthesis of Data Analysis}

While the literature review in Chapter Two presents research supporting the theory that school leaders have a clear sense of meaning and purpose, the respondents in this study shared general ideas about their sense of meaning, even when asked about the topic explicitly. Each principal shared that it was their ability to help others and see students succeed that gave them a sense of meaning and purpose; these ideas could be described as broad or vague. Instead of a close connection with an identifiable or specific sense of meaning and purpose, it was their discovery or recognition of inequities that emerged as a major category. Equity themes came up in nearly every question and every respondent brought up equity multiple times. The success of students and the people that these principals refer to when they discuss helping others, were clearly defined with an equity lens based on the evidence collected from the entire interview. The equity data has been quantized (Saldaña, 2016) in Table 12 below showing the number of times themes that were connected to the category of equity. These themes have been quantized for each question and each participant. All themes from interview questions can be found in Appendices S-CC and Tables 10 and 11. 
Table 12 Equity Focus

Quantized data for equity responses throughout the entire interview.

\begin{tabular}{|c|c|c|c|c|c|c|c|c|c|c|c|c|c|c|}
\hline Participants & Q1 & Q2 & Q3 & Q4 & Q5 & Q6 & Q7 & Q8 & Q9 & Q10 & Q11 & Q12 & Q13 & Total \\
\hline $1 \mathrm{POC}$ & 1 & 1 & - & 1 & - & 2 & 2 & 1 & - & - & - & - & - & 8 \\
\hline $2 \mathrm{POC}$ & - & 1 & - & 1 & 1 & 1 & 2 & 1 & 1 & - & - & - & - & 8 \\
\hline 3 POC & - & - & - & - & 1 & - & 2 & 1 & - & - & 1 & - & - & 5 \\
\hline $4 \mathrm{POC}$ & 1 & 1 & - & 1 & 1 & 3 & 2 & 1 & 1 & 1 & 1 & 1 & - & 14 \\
\hline 5 POC & - & - & - & - & - & 1 & 2 & 1 & - & - & - & 1 & - & 5 \\
\hline Total POC & 2 & 3 & - & 3 & 3 & 7 & 10 & 5 & 2 & 1 & 2 & 2 & - & 40 \\
\hline $6 \mathrm{~W}$ & - & - & - & 1 & - & 3 & 2 & - & - & - & 2 & 1 & - & 9 \\
\hline $7 \mathrm{~W}$ & - & - & - & - & 1 & - & - & 1 & - & - & 2 & - & - & 4 \\
\hline $8 \mathrm{~W}$ & - & - & - & 1 & 1 & 1 & - & - & 1 & - & 1 & - & - & 5 \\
\hline $9 \mathrm{~W}$ & - & 1 & - & 1 & 1 & - & - & 1 & - & - & 2 & - & - & 6 \\
\hline $10 \mathrm{~W}$ & - & - & - & 1 & 1 & - & 1 & - & - & - & 2 & 1 & - & 6 \\
\hline Total W & - & 1 & - & 4 & 4 & 4 & 3 & 2 & 1 & - & 9 & 2 & - & 30 \\
\hline Total POC \& W & 2 & 4 & - & 7 & 7 & 11 & 13 & 7 & 3 & 1 & 11 & 4 & - & 70 \\
\hline
\end{tabular}

Notes: Q1 = Question 1... POC $=$ Principal of Color. $\mathrm{W}=$ White

The number of times Principals of Color referred to equity was 40 while White principals referred to equity 30 times. These statements were not always explicitly said, but were referred to in the context of a conversation or story. For example, one White principal shared that part of their success came from "Building a culture of accepting one another" when she was asked about Latina/o student success. Another White principal noted an inequity that other principals may not had noticed if they were in a similar situation. He told a story: "Prom court. Everyone was White. We are __ \% Latino but even Latinos were voting for White kids. It was crazy. 'After a while they picked the 
right kids.' Latino, White, church kids, you name it...that took a while and you empower them (Latina/o students) and encourage them and things change." In a different instance, a Principal of Color spoke about her role as a mentor. "I spend more time with (a Person of Color) in terms of mentoring and it is to give advice and make them better because they will be held accountable for things that others won't be. When one Person of Color fails, it impacts everyone." These are examples of how equity was brought up in every question.

Figure 3 shows the coaxial coding that displays how equity emerged as a category after analyzing themes and incorporating focused coding. These themes were collected during the entire interview, not just during the question focused on what gives respondents a sense of meaning and purpose. 


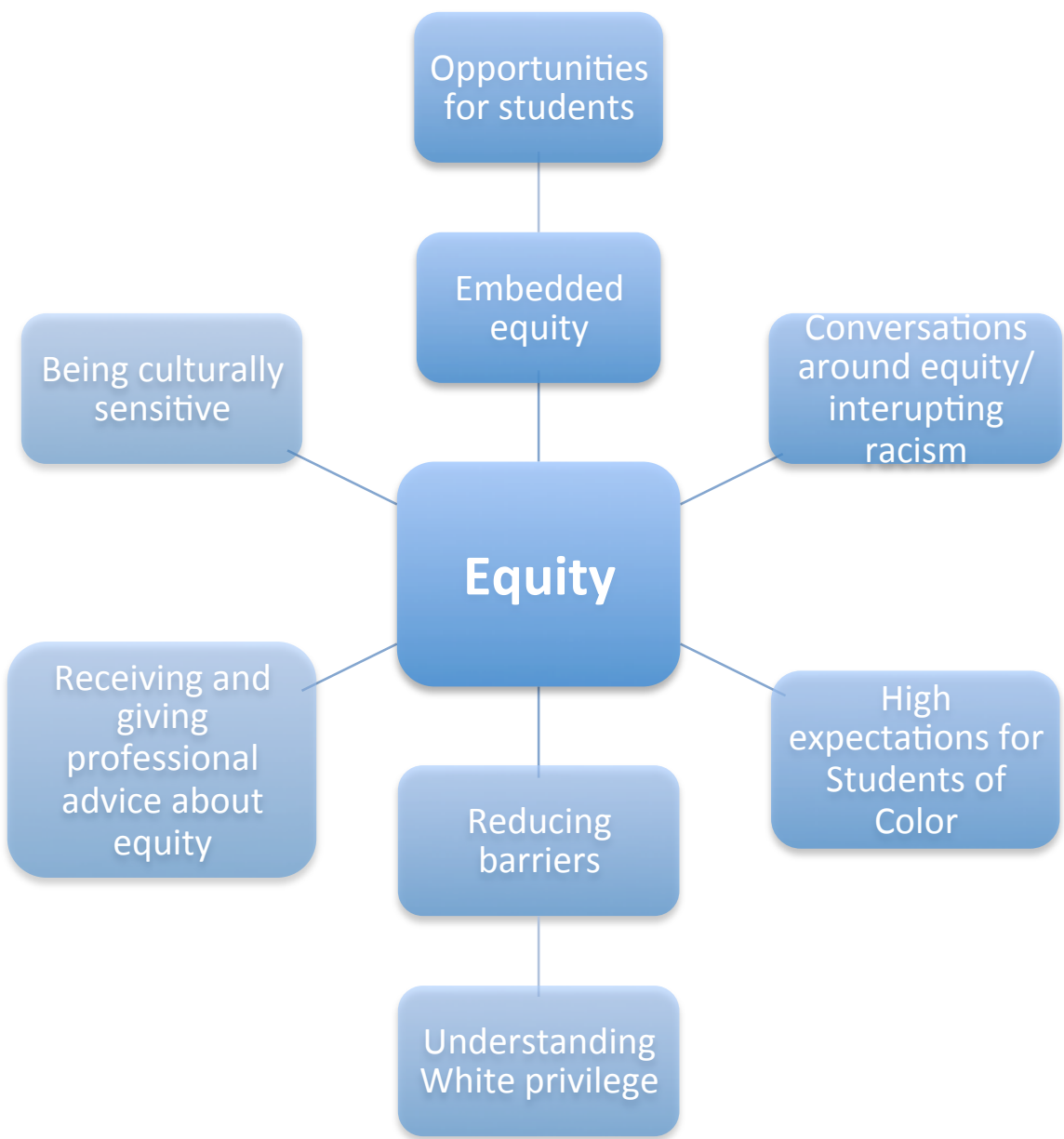

Figure 3: Coaxial coding showing how themes connected to central category of equity.

In Chapter One I made the case that sustaining the human spirit is closely tied to self-efficacy and satisfaction and the principals in this study described deep fulfillment through equity work. A White principal described the feelings that occurred when their spirit was not sustained. "I remember the kids that I lost. It angers me." Still another Principal of Color said, "I'm afraid at the thought of leaving these kids. I'm reenergized when I see some kid and I know I'm impacting them and making a difference in their life." 
While I clearly understood the outcome of what it looked like when these 10 principals were fulfilled, I didn't get specific responses about what the sense of meaning and purpose was, simply by asking the question. They chose not to specifically articulate what motivated them. Instead, participants focused on what it felt like.

Again, we looked at the themes that emerged from our interviews. While equity was the most consistent category that emerged throughout nearly every question of the interview, relationships were mentioned the most out of all categories found. Every principal spoke about the importance of relationships as a leader. Relationships with students, teachers, colleagues, and communities were a key thread that was referred to throughout the interviews. A Principal of Color even spoke of ensuring that students know that "you are loved, every day." The data is quantized in Table 13 showing the number of times relationship themes emerged per participant and per question. The last column totals the number of relationship responses for each participant and the final row totals the number of relationship responses for each question. 
Table 13

Quantized Data for Relationship Responses Throughout the Entire Interview.

\begin{tabular}{|c|c|c|c|c|c|c|c|c|c|c|c|c|c|c|}
\hline Participants & Q1 & Q2 & Q3 & Q4 & Q5 & Q6 & Q7 & Q8 & Q9 & Q10 & Q11 & Q12 & Q13 & Total \\
\hline $1 \mathrm{POC}$ & 2 & - & 1 & - & 1 & 2 & - & 1 & - & 3 & 2 & 1 & - & 13 \\
\hline $2 \mathrm{POC}$ & 1 & - & - & - & - & 1 & - & 1 & - & 1 & - & 2 & - & 6 \\
\hline $3 \mathrm{POC}$ & 1 & - & - & - & - & 1 & 1 & 2 & - & 2 & 1 & 3 & - & 11 \\
\hline 4 POC & 1 & - & - & - & - & 2 & - & 2 & - & - & 1 & 2 & - & 8 \\
\hline 5 POC & 1 & - & - & - & - & - & - & 2 & - & 2 & 2 & 2 & - & 9 \\
\hline Total POC & 6 & - & 1 & - & 1 & 6 & 1 & 8 & - & 8 & 6 & 10 & - & 47 \\
\hline $6 \mathrm{~W}$ & - & - & - & - & - & 1 & 2 & 1 & - & 2 & - & 3 & - & 9 \\
\hline $7 \mathrm{~W}$ & - & - & - & - & - & 1 & 2 & 2 & - & 1 & 1 & 2 & - & 9 \\
\hline $8 \mathrm{~W}$ & - & - & - & - & - & 1 & 1 & 1 & - & 2 & 1 & 2 & - & 8 \\
\hline $9 \mathrm{~W}$ & - & - & - & - & - & 3 & 1 & 1 & - & 1 & - & 2 & - & 8 \\
\hline $10 \mathrm{~W}$ & 1 & - & - & - & - & - & - & 2 & - & 2 & 2 & 2 & - & 9 \\
\hline Total W & 1 & - & - & - & - & 6 & 6 & 7 & - & 8 & 4 & 11 & - & 43 \\
\hline Total POC \& W & 7 & - & 1 & - & 1 & 12 & 7 & 15 & - & 16 & 10 & 21 & - & 90 \\
\hline
\end{tabular}

Principals of Color spoke about relationships 47 times while White principals spoke about relationships 43 times. The most common question regarding relationships was question 12: What gives you a sense of meaning and purpose? In other words, what motivates you to do the work that you're doing? This is a key finding. Relationships are critical in responding to equity related issues and addressing inequities. Relationships also, for these participants led to many feelings and emotions of satisfaction and selfefficacy. If equity was the destination, relationships provided to path to equitable schools for Latina/o youth. 
Figure 4 shows how the different themes were revealed through a series of coaxial and focused coding identifying relationships as the most referred to category in our study.

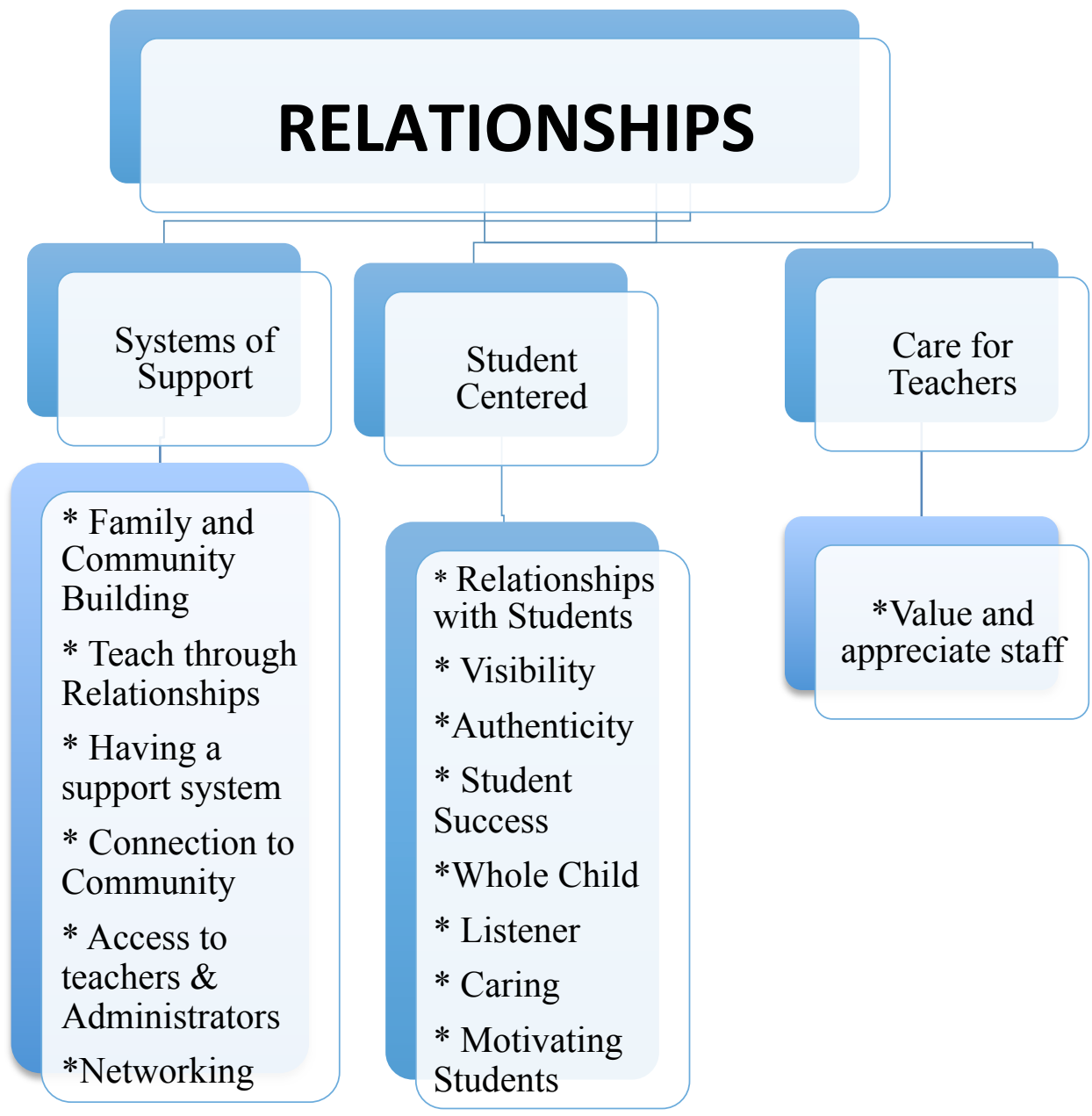

Figure 4: Themes that connected to the category of relationships

When relationships were described, it was usually in the context of a concomitant action attached to an idea. One Principal of Color said, "We were really focused on building relationships. It taught me what's most important which is to teach through relationships and relationship building." Another White principal described relationships through action. 'I'm in classes and hallways saying 'how are you' and 'how you doing.' If a kid says not so good, I turn around and start walking with them. They know we are 
invested." A Principal of Color spoke about systems for creating relationships after using data to identify students that didn't have relationships with staff. She said, "Come hell or high water we'll create systems to make sure these kids are being checked in on." She then went on to discuss what her school tried. A White principal put it quite simply. "We would just play and they (students) knew we were in this together."

In addition to sharing what principals described it is also important to note the nonverbal cues that further describe the emotions connected to these statements. One Principal of Color laughed as she described kids the kids that "crack me up" every day. A White principal smiled as he spoke about playing with students every day. Another White principals eyes welled up as she described the caring relationship she witnesses in classrooms between teachers and students. These principals did more than describe relationships. They felt them, as evidenced by their emotional responses as they talked about relationships.

These two key categories, relationships and equity, seemed to go hand in hand. One statement would be around relationships and the very next comment would bring the focus back to equity. A Principal of Color spoke of a powerful relationship they had. “(My mentor) was incredible. We had fascinating conversations that were eye opening. They were around discipline and leadership and how to lead the dominant culture as a person of color." In one breath they moved from the incredible relationship to an equity conversation.

While the researcher in Chapter One proposes that the discovery of one's sense of meaning and purpose was critical to the principals' sustainability of their human spirit, 
this study revealed it was actually the discovery of inequities and their response to those inequities through relationships that led to a sustained human spirit. Figure 5 shows the differences between my theoretical framework outlined at the conclusion of Chapter Two and the findings of my study of these 10 successful principals.

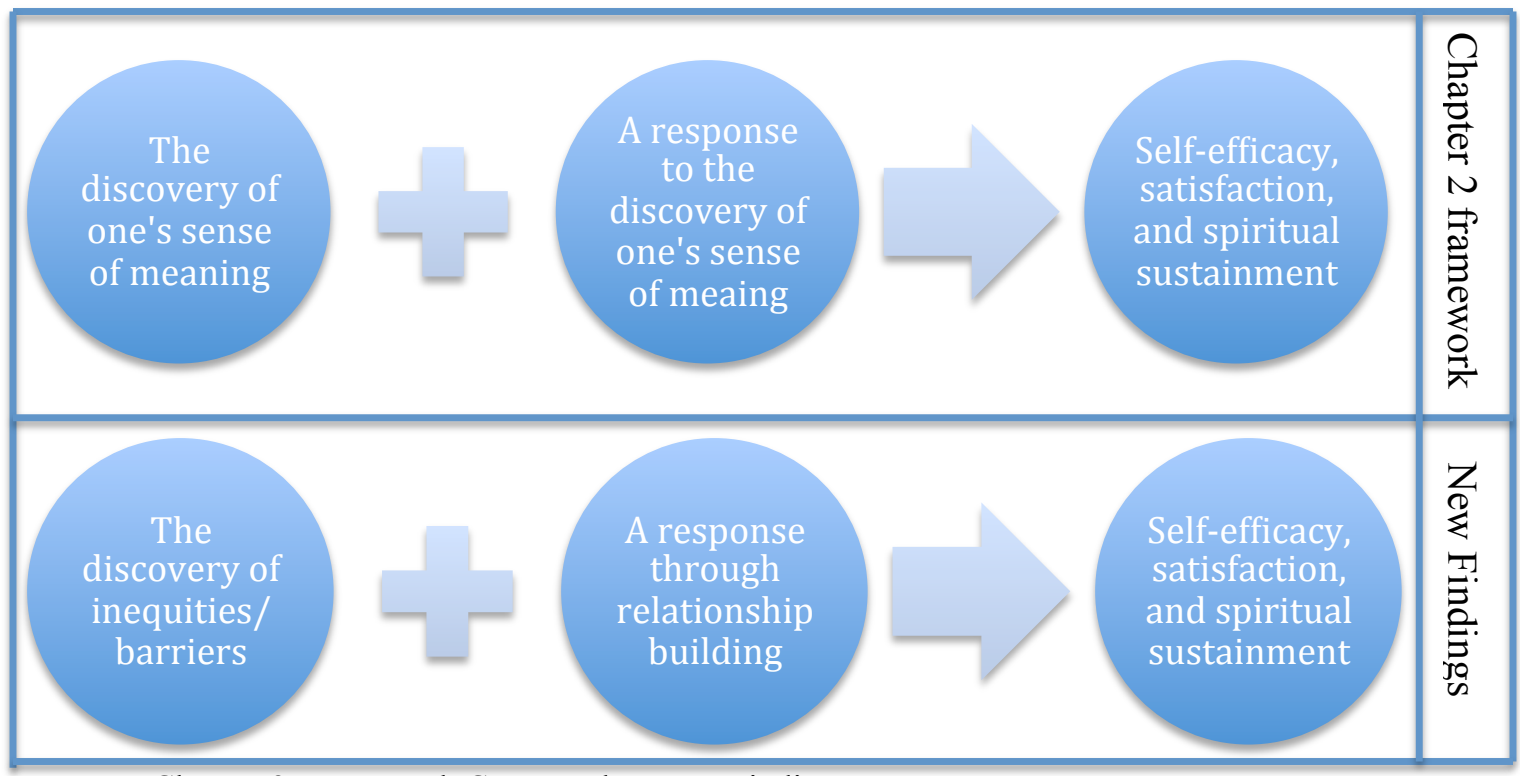

Figure 5: Chapter 2 Framework Compared to New Findings

In this revised conceptual framework, negative working conditions impacted principal self efficacy and satisfaction. Managerial tasks, distractions from the big picture, naysayers, and bureaucracies were named multiple times by respondents addressing what it is that impede the connection to their sense of meaning and purpose. These themes closely connected to two other categories that were noted during the study: working conditions and systems of oppresion. Also important to note, neither equity or relationships came up once as a barrier to one's sense of meaning shown previously in Table 12 and Table 13. 
In Table 14 below I have quantized the number of times that working conditions came up during the interviews for each participant.

Table 14

Quantized Data for Working Condition Responses

\begin{tabular}{llllllllllllllllll}
\hline Participants & Q1 & Q2 & Q3 & Q4 & Q5 & Q6 & Q7 & Q8 & Q9 & Q10 & Q11 & Q12 & Q13 & Total \\
\hline 1 POC & - & - & - & - & - & - & - & - & 1 & 1 & 1 & - & 1 & 4 \\
2 POC & 1 & - & - & - & - & 1 & - & - & - & - & 1 & - & 1 & 4 \\
3 POC & - & - & - & - & - & - & - & - & - & 1 & - & 1 & 1 & 3 \\
4 POC & - & - & - & - & - & - & - & - & 1 & - & - & - & - & 1 \\
5 POC & - & - & - & - & 1 & - & - & - & - & - & - & - & - & 1 \\
POC Total & 1 & - & - & - & 1 & 1 & - & - & 2 & 2 & 2 & 1 & 3 & 13 \\
6 W & - & - & - & - & - & - & - & 1 & - & 1 & - & - & 2 & 4 \\
7 W & - & - & - & - & - & - & 1 & 1 & 1 & - & - & - & 2 & 5 \\
8 W & - & - & - & - & - & 1 & 1 & - & - & - & - & 1 & 1 & 4 \\
9 W & - & - & - & - & - & - & 1 & 1 & 1 & 2 & - & - & 2 & 7 \\
10W & - & - & - & - & - & - & - & - & - & - & 1 & - & 1 & 2 \\
W Total & - & - & - & - & - & 1 & 3 & 3 & 2 & 3 & 1 & 1 & 8 & 22 \\
Total & 1 & - & - & - & 1 & 2 & 3 & 3 & 4 & 5 & 3 & 2 & 11 & 35
\end{tabular}

One might expect Question Three (resistance) and Question 13 (what got in the way) to reveal themes of negative working conditions. As we look at Table 14, difficult working conditions were revealed on multiple questions $(1,4-13)$.

Figure 6 reveals the themes that were connected to the category of difficult work conditions. 


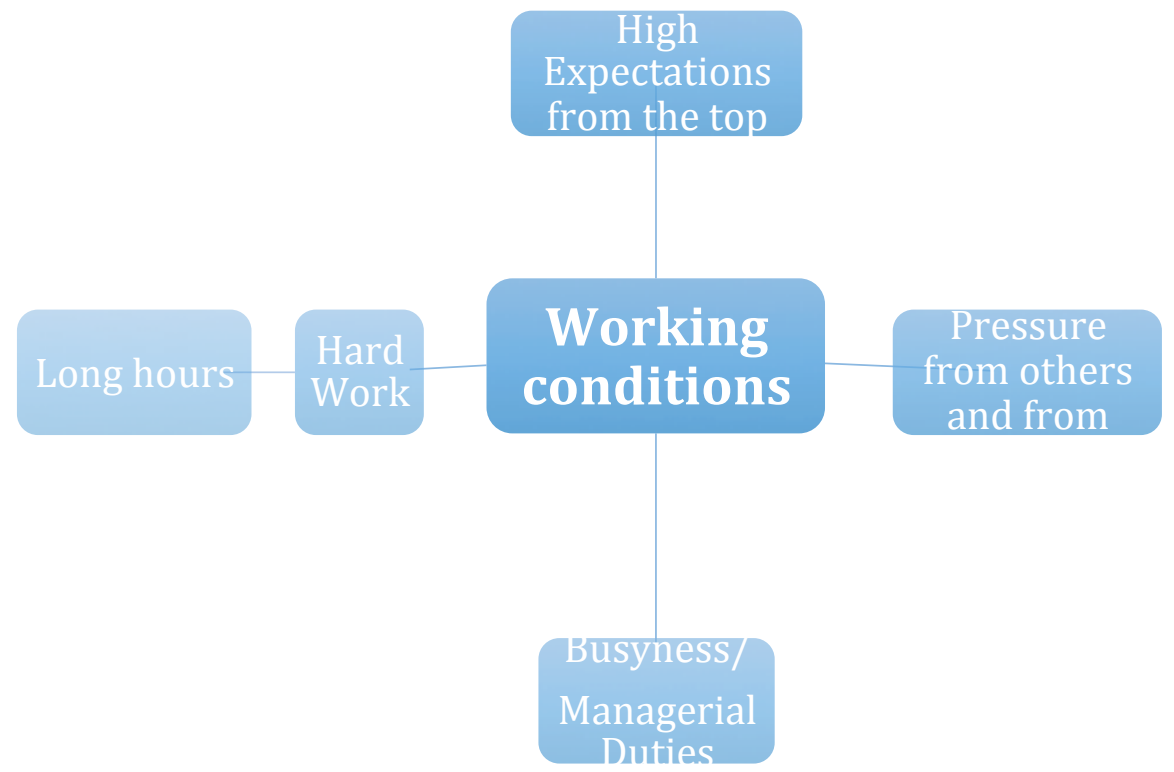

Figure 6: Coaxial coding for themes related to working conditions

Many of these came without solicitation. In question 10 regarding the messages given to students, staff, and families a White principal declared, "It is lonely at the top." Another Principal of Color during the first question regarding their career path couldn't help but add on, "This job is very demanding." The themes that contribute to negative working conditions are key to the sustainability of the human spirit and have implications that will be discussed in Chapter Five.

Finally, when asked about barriers that impede their ability to connect with their sense of meaning and purpose, some participants referred to a lack of trust in others, self doubt, and negative people in the building. One Principal of Color said, "I wish they would trust us to do our job and just treat us as professionals." While one Principal of Color doubted others to trust him, another Principal of Color seemed to doubt herself 
saying, "I get in my own way. I worry. Am I letting down people of color? Am I pushing too much or too little?" A White leader described the frustration of "getting some people on board. They can be hard to motivate."

Few participants directly spoke about other barriers around equity but it came up often throughout the interview in other questions. Table 15 quantizes the times that themes were revealed that connected to the category I called "system of oppression." This was a category that was too prevalent to ignore and was overwhelmingly telling when comparing the responses of the White principals and Principals of Color.

Table 15

Quantized Data for the Category: Systems of Oppression.

\begin{tabular}{|c|c|c|c|c|c|c|c|c|c|c|c|c|c|c|}
\hline Participants & Q1 & Q2 & Q3 & Q4 & Q5 & Q6 & Q7 & Q8 & Q9 & Q10 & Q11 & Q12 & Q13 & Total \\
\hline $1 \mathrm{POC}$ & - & - & 3 & - & - & - & - & - & - & - & - & - & - & 3 \\
\hline $2 \mathrm{POC}$ & - & - & 4 & - & - & - & - & - & - & - & 2 & - & 1 & 7 \\
\hline $3 \mathrm{POC}$ & - & - & 4 & - & - & - & - & - & - & - & 2 & - & - & 6 \\
\hline $4 \mathrm{POC}$ & - & - & 4 & - & - & - & - & - & - & - & 3 & - & - & 7 \\
\hline $5 \mathrm{POC}$ & - & - & 3 & - & - & - & - & - & - & - & - & - & - & 3 \\
\hline POC Total & - & - & 18 & - & - & - & - & - & - & - & 7 & - & 1 & 26 \\
\hline $6 \mathrm{~W}$ & - & - & - & - & - & - & - & - & - & - & - & - & - & - \\
\hline $7 \mathrm{~W}$ & - & - & - & - & - & - & - & - & - & - & - & - & - & - \\
\hline $8 \mathrm{~W}$ & - & - & - & - & - & - & - & - & - & - & - & - & - & - \\
\hline $9 \mathrm{~W}$ & - & - & 1 & - & - & - & - & - & - & - & - & - & - & 1 \\
\hline $10 \mathrm{~W}$ & - & - & - & - & - & - & - & - & - & - & - & - & - & - \\
\hline W Total & - & - & - & - & - & - & - & - & - & - & - & - & - & 1 \\
\hline Total & - & - & 18 & - & - & - & - & - & - & - & 7 & - & 1 & 27 \\
\hline
\end{tabular}

Notes: Q1 = Question 1...POC = Principal of Color. $\mathrm{W}=$ White 
The system of oppression impacted Principals of Color while White principals nearly avoided it all together. This is a key finding with important implications which will be discussed in Chapter Five. Themes that emerged were unveiled by a variety of comments all shared by Principals of Color as shown in Figure 7 below.

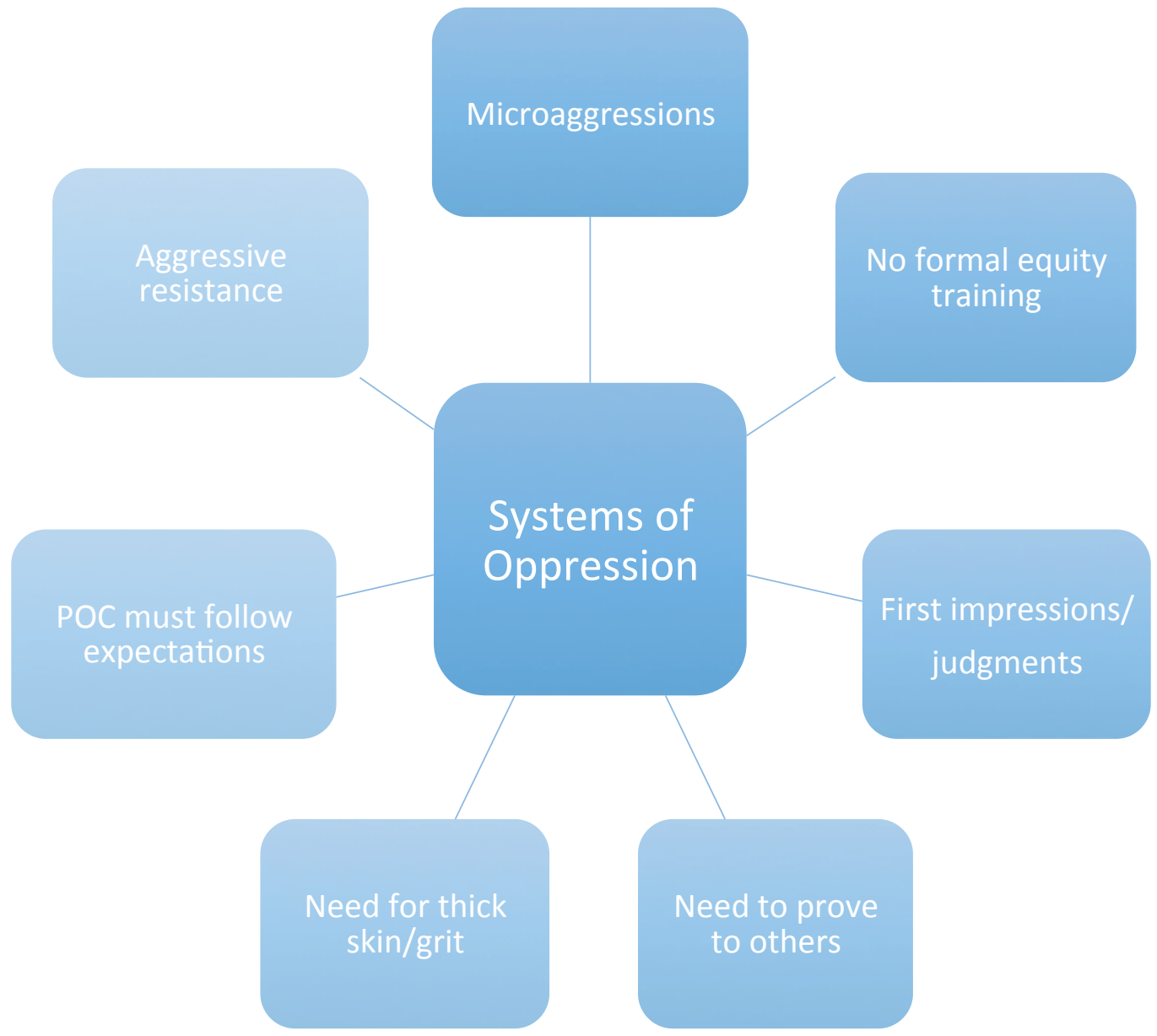

Figure 7: Coaxial coding for themes related to systems of oppresion

Principals of Color revealed far more instances of these barriers and resistance than the White principals. In fact, the number of comments that connected to one of the themes related to the category we called System of Oppression was 26 from Principals of Color while only 10 came from White principals. When asked if they had faced any 
resistance when becoming a principal, every Principal of Color explained the need to have thick skin or grit while no White principals mentioned the same need. One Principal of Color stated, "I have to prove it and I do the 11 hours a day, 6 days a week to prove it. Another said, "When there was resistance, I didn't pay attention to it." Still another spoke of, "not letting things get to me."

Every Principal of Color talked about micro-aggressions and one White female principal mentioned or described it. One Principal of Color shared that they were told, "I speak too academically. Somebody's way of saying you don't know your place. Then I get told (by someone else) you speak too informally." Another principal of color said, "I was told early that I shouldn't even think about administration. They said I wasn't ready... Maybe someday."

All five Principals of Color shared that they had been pre-judged during first impressions. Only one White male made the same observation. A Principal of Color shared a story: "I remember going to my first principal meeting. I just walked in and people said, 'no, this is just for principals' the VP meeting was down the hall." One Principal of Color described a common occurrence throughout their career. "During my first wave of any new position there is a lot of vetting and hyper questioning of any decision and my judgement."

It should be noted that two of the four women described being marginalized as a woman. One stated that when she was first hired by her principal she was walking down the hall when she was told from a teacher that the principal must really like tall women. Another woman spoke honestly about perceptions of others that she had come to learn. 
"When you are straightforward, they see you as a bitch or maniputlative rather than being transparent." Another woman used the same language stating, "Strong women are called a bitch" as she described the delicate walk of being a leader as a woman.

Earlier in this chapter I presented my findings after interviewing the 10 participants. My study aimed to find what sustains the human spirit of successful educational leaders. Participants were selected purposively with the intent to compare Principals of Color with White principals revealing any commonalitites or differences. Both sets of principals shared the construct outlined in the beginning of this chapter in Figure 5, that it was their discovery of inequities and their response to these discoveries that seemed to gain outcomes that led to feelings of satisfaction, self-efficacy, and fullfillment. Principals response to inequities was largely described through relationships. However, there is a missing component for the Principals of Color. It was a component that all 5 Principals of Color spoke about and no White principals discussed. The added component that must be included in the equation for Principals of Color is a need for what some are calling "grit" (Duckworth, Peterson, Matthews, \& Kelly, 2007). Principals of Color showed a perservence and passion for long term goals. In this study, grit can be connected to these principals overcoming racism in the midst of a system of oppression. Figure 8 shows the difference in findings between White principals and Principals of Color. 


\section{White Principals}

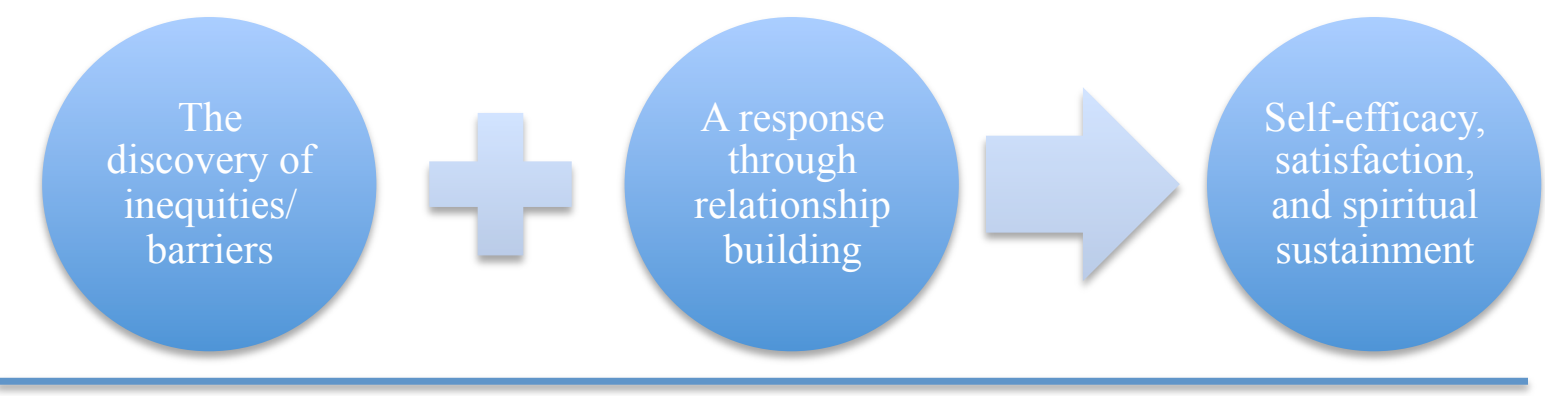

\section{Principals of Color}
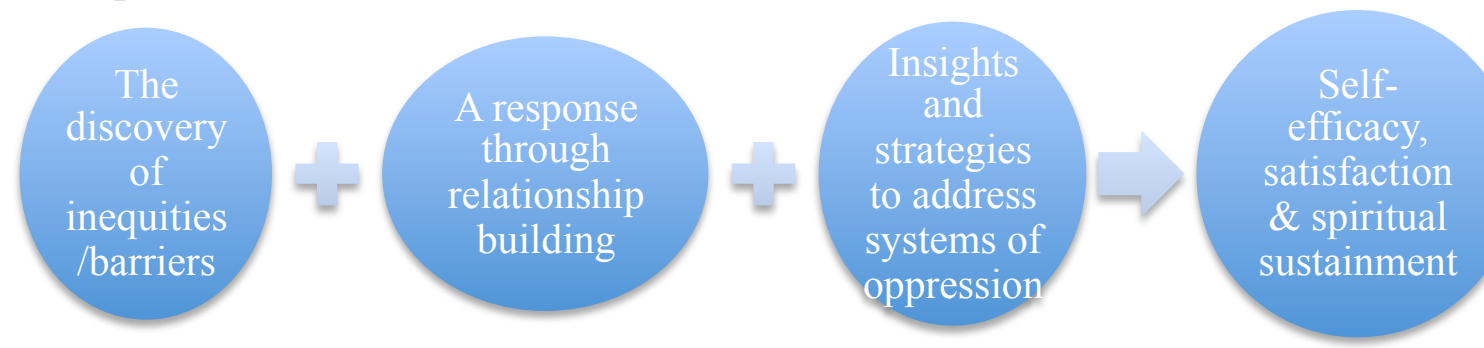

Figure 8: Comparison of findings between White principals and Principals of Color

To further highlight their need for grit (Duckworth, et. al., 2007) Table 16 shows each Principal of Color's comments that connect to perseverance and passion for long term goals. While some White leaders seemed to share long-term goals, none of them referred to needing perseverance to reach them. 
Table 16

Principals of Color: Grit

\begin{tabular}{lll}
\hline \multicolumn{2}{l}{ Long Term Goal } & Passion and perseverance \\
\hline \#1 & I knew I wanted to break the cycle of poverty & $\bullet \quad$ I lost a lot of friends when I focused on school. \\
and get out. & $\bullet \quad$ Now (as principal) I have to prove it. \\
& $\bullet \quad$ I'll prove you wrong (referring to the naysayer).
\end{tabular}

\#2 I think about coming from a family that didn't graduate. I have a passion for bringing equity into education.

- You have to speak your truth and stay the course.

- When I had resistance, I didn't pay attention to it.

\#3 I always wanted to grow up and influence kids like us and eliminate barriers.

- $\quad$ Even when things get hard and despondent, I have a soft spot for the underdog.

- You can't let things get to you.

\#4 My (mission) is to impact kids and make a difference in their life.

- I tell others to stay open to your purpose. Don't get mad or angry if your path (to leadership) is different (or takes a while).

- I stay obedient (to God) and wait for my chance.

\#5 My motivation is to lead and expand my sphere of leadership to positively impact students and families.

Note: Source Duckworth, et. al., (2007)
- It became difficult. After four or five interviews I knew it would be really hard to get to the next level.

- I've learned to work through that (doubt from others) and prove that me and other minorities can do this.

To further highlight the need for grit there are a few more findings that

differentiate the responses of the Principals of Color from those of the White principals.

Each of the Principals of Color spoke about when somebody saw something in them.

Some said it as if they were surprised. Only one of the White administrators noted the

same instance. These principals have all proved to be successful yet they look back still

with surprise that they were given a chance. Only one White principal made the same

observations. Their inherent surprise that someone saw something in them would infer 
that they expected to be viewed with doubt. Despite these beliefs, they continued to pursue leadership roles until they achieved their goal of the principalship.

The work of any principal comes with a high level of pressure. There was a higher level of pressure that four of the Principals of Color spoke about. They talked about the pressure they put on themselves. There was a desire to pave the way for future Principals of Color, or to represent their race in order to overcome stereotypes that existed. One principal said, "We have to be exceptional and go beyond what is expected in order to open the door to a future Principals of Color." Another said, "I need to be a role model for my students. I believe there is a misunderstanding that (students with the same race as me) are lazy or don't do the work, so I go the extra mile and show that we (our race) can do the job." Another Principal of Color talked about putting in extra hours saying, "I have to prove it and I do the 11 hours a day, 6 days a week just to prove it. I have to put in an extra 2-3 hours to stay above water." This idea of pressure put on oneself was only true for Principals of Color. It is no surprise that these same principals described some instance of having grit (Duckworth, et. al., 2007) in order to be successful.

\section{Limitations of the Study}

Given the researcher's desire to keep the context of the study to Oregon and the researcher's rigorous criteria for meeting what was determined to be successful, the sample size of this qualitative study was only 10 participants. While other studies have had similar numbers (Theoharris, 2007; Marshall, 2009) it would be desirable to have a larger sample size. Ten participants are sufficient but not ideal for utilizing grounded theory (Saldaña, 2016; Strauss \& Corbin, 1998). 
Additionally, while the questions were open ended, some of the questions explicitly requested information regarding the participant's success with Latino youth. While it was necessary to ask about specific students and their success, this may have led the participants to have a focus towards equity in their responses.

Another limitation is that as a White male, I brought that perspective to the research process from beginning to end. I strive to be an ally for People of Color, which means both being aware of my privilege while trying to check my biases as a White male, but many biases go unidentified despite my best intentions. Therefore, I was fortunate to work with a research partner who is an immigrant from Chile and brings a significantly different perspective to our research. A significant part of my White privilege is being unaware of the barriers that others face. As a White male, it can be easy to explain away the barriers that others explain as unique or circumstantial utilizing a variety of detours common to many White people, especially White males like myself that fit into every category of our societal norms: able bodied, hetero sexual, North Western European decent, Christian upbringing, and a high socio-economic status. I have never experienced oppression of any kind and therefore may not recognize it when it is described to me. It was important to be aware of my privilege, not just my White privilege, but also privilege I have when it comes to many forms of oppression that many groups of people face in our context of Oregon.

In Chapter One I described the importance that leadership has on school success but I also recognize that the role of a leader may not be the sole reason that a school is having success. In this study we focused our attention on the leader but left out other key 
stakeholders such as students and staff. We did hope to include teacher input through the TELL Survey but found no statistically significant data that added to our study, although that is a finding worth further study and will be addressed in Chapter Five. Our low sample size reduced the likelihood of achieving statistically significant results from Tell Survey analysis.

Another limitation of this study is that we did not include focus groups or interviews of teacher leaders, family members of the principals, or students. Students, principal family members, and teachers may have a different concept of what sustains the principals and why they are successful. Pulling in these stakeholders would have addressed those issues more directly and possibly revealed further answers to support or refute the key findings of this study. 


\section{Chapter Five: Discussion/Conclusion}

High school principals are working under extremely challenging conditions resulting in high turnover rates (Gates et al., 2007), high rates of stress (Roeser et al., 2012) and increased scrutiny regarding reducing educational disparities for students (Blackmore, 2001). The complex nature of job, the extended responsibilities that fall outside the school day, and the expectations from senior leadership, families, and the community for leaders to be available day or night seven days a week, make the need to care and nurture principals a necessity if we hope to prevent burnout and encourage principal sustainability (Whitaker, 1996). The challenging work conditions and increased scrutiny are magnified for Principals of Color (Achinstein, Ogawa, Sexton, \& Freitas, 2010; Gordon, 2000; Johnson \& Hekman, 2016; Peterson \& Vergara, 2016; Theoharis, 2007). This study included interviews with 10 principals who reduced or eliminated educational disparities in an effort to surface their values, identify their priorities, unveil their beliefs, reveal their sense of meaning and purpose, and name the barriers that impede their ability to connect to their sense of meaning and purpose. This study's research question is: How do successful educational leaders sustain their human spirit while leading for equity? While many studies focus on management strategies that cause the work to be sustainable, this study specifically focuses on the principals' sense of meaning and purpose that leads to self-efficacy, job satisfaction, and fulfillment. Jones (2005) referred to the human spirit, or the connection to issues of meaning and purpose, as something that nourishes us and allows us to flourish. Others have studied the human spirit as it connects to teachers (Marshall, 2009; Mayes et al., 2003; Palmer, 2007; Roeser 
et al., 2012) and educational leaders (Haffner \& Capper, 2005; Theoharis, 2007). This study revealed what sustains the leaders whose schools have successful outcomes for Latina/o students, with graduation rates exceeding the state average and with no disparities between Latina/o and White graduation rates. These are leaders embracing the moral imperative of serving all students, especially those that are underserved. These are imperatives that have already been researched by many (Fullan, 1993; Gay, 2010; Grogan \& Andrews, 2002; Noguera, 2008).

In Chapter Two I identified a theoretical framework to guide my research study. This theoretical framework identified the discovery and response to one's sense of meaning and purpose that led to sustainment of the human spirit as displayed in Figure 1 (copied from Chapter Two, p. 38).
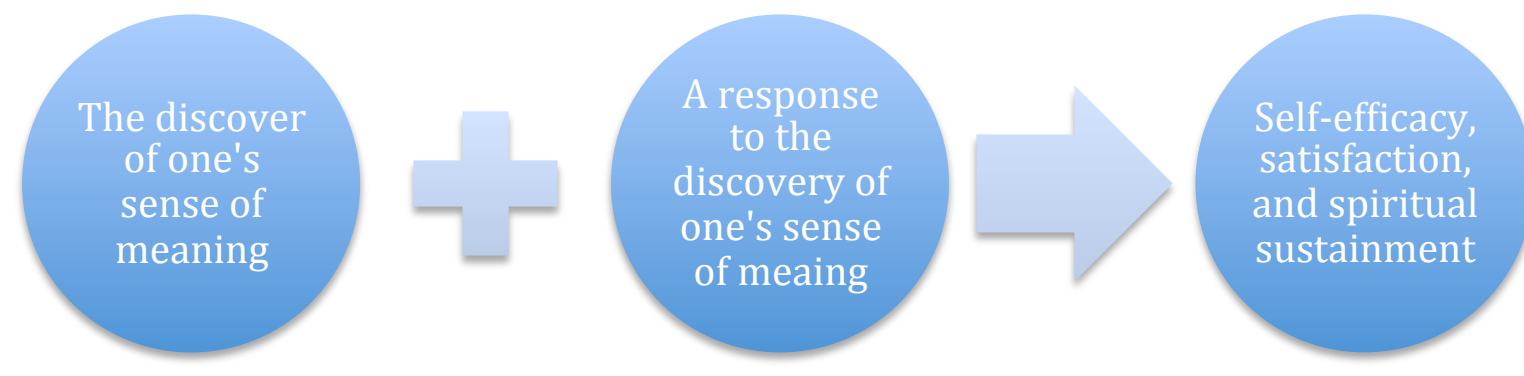

After examining 10 participants' responses from 13 questions regarding their key career path, motivations, reasons for success, barriers to success, and connections to their sense of meaning and purpose, I analyzed the data using grounded theory (Saldaña, 2016). My research partner Victor Vergara and I double coded the data to ensure the trustworthiness of my findings. My analysis of the data revealed the following characteristics related to a sense of meaning and purpose of leaders successful with Latina/o students: equity focused, relationship focused, and a strong desire to help 
students succeed. These findings do not support the theoretical framework I proposed in Chapter Two. Thus, in Chapter Four I proposed a new framework to address my research question (see Figure 8, copied from Chapter Four, p. 90). Because many responses of White principals were considerably different from the responses of Principals of Color, the data suggest two conceptual frameworks.

\section{White Principals}
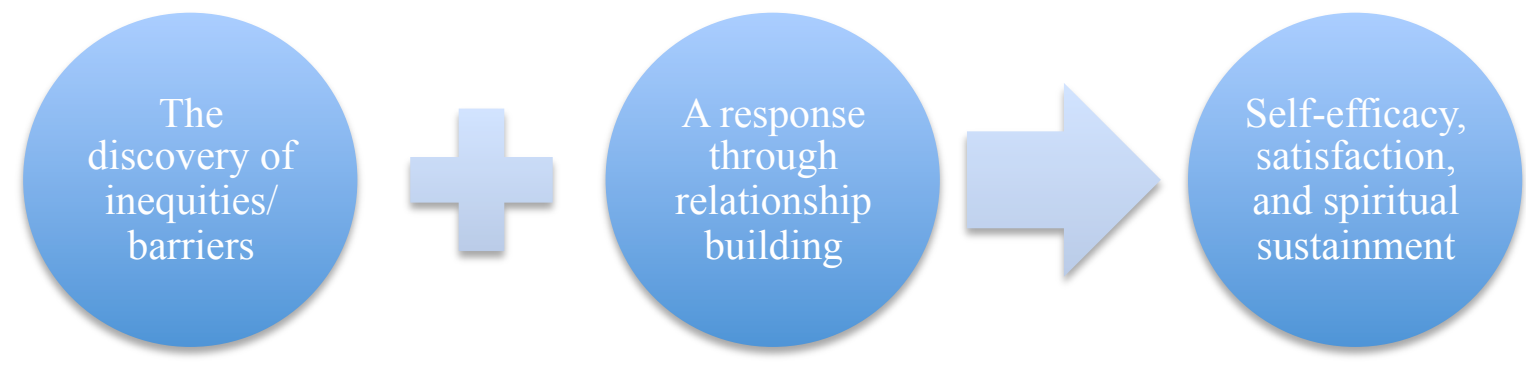

\section{SUPPPORTED BY POSITIVE WORKING CONDITIONS}

\section{Principals of Color}

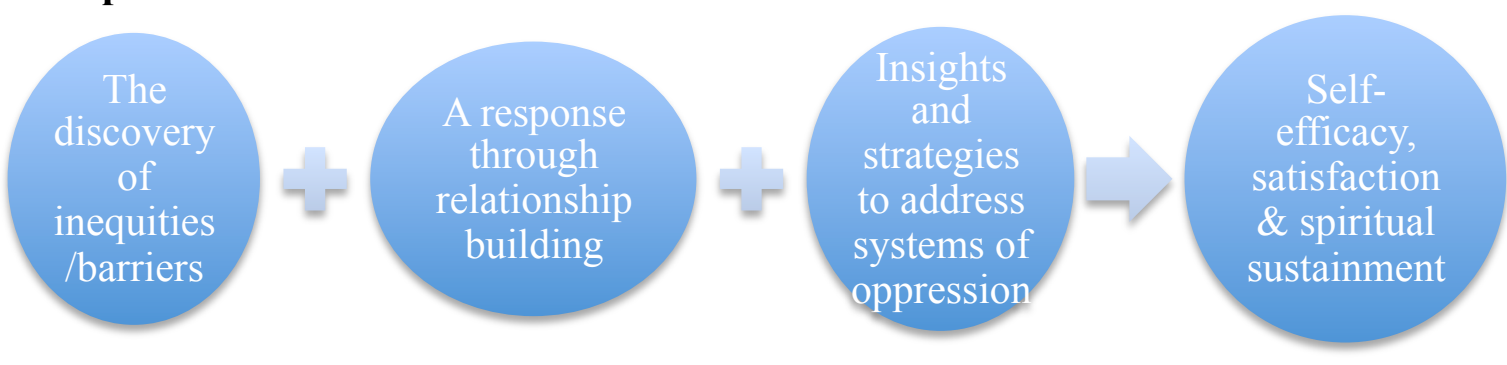

\section{SUPPPORTED BY POSITIVE WORKING CONDITIONS}

The conceptual frameworks are only applicable when positive working conditions are put in place. This study revealed that positive working conditions include reasonable 
expectations, an atmosphere of trust and respect, minimal interruptions to leaders focus of equity and relationships, and a reduction in responsibilities outside of the work day that can increase a life - work balance. As shown in the figure above, I am proposing a conceptual framework for Principals of Color that differs from the framework for a White principal. These findings have implications for future principals, district leadership, and principal preparation programs, and the findings align with the research of others who note that the experience of Leaders of Color differs dramatically from White leaders (Achinstein, Ogawa, Sexton, \& Freitas, 2010; Gordon, 2000; Johnson \& Hekman, 2016; Peterson \& Vergara, 2016; Theoharis, 2007; Whitaker, 1996).

\section{Synthesis of Findings}

This study asked 13 questions of 10 principals successful with Latina/o students. Responses revealed two categories that all participants had in common: a strong focus on equity and a clear connection to relationships. The responses of the Principals of Color revealed an additional characteristic related to their success: thick skin and grit, or their passion and perseverance as it connects to a long-term goal (Duckworth et al., 2007). Their White colleagues did not reveal this concept. These findings are supported by previous research that highlighted that Principals of Color and Educators of Color face more obstacles, especially when leading for equity, (Johnson \& Hekman, 2016; Peterson \& Vergara, 2016; Theoharis, 2007) to their personal and professional success leading to increase turnover and burnout (Achinstein, Ogawa, Sexton, \& Freitas, 2010; Gordon, 2000; Whitaker, 1996). Every participant involved in the study described feelings of satisfaction (Federici \& Skaalvik, 2012), self-efficacy (Bandura, 2006), or enjoyment of 
their job. Satisfaction, self-efficacy, and enjoyment are concepts connected to the human spirit (Jones, 2005; Federici \& Skaalvik, 2012; Miller, 2006; Peterson, 2014).

The fact that there are so few Leaders of Color in Oregon schools create precarious conditions for success. The state of Oregon has only $11 \%$ of its leaders identifying as Leaders of Color (ODE, 2016). It should be no surprise that these leaders placed an additional layer of expectations on themselves as they strive to succeed as a member of a small, under-represented group, often working in isolation. As one Principal of Color stated, "When one of us fails, it impacts all of us." Every Principal of Color had experienced micro-aggressions, feelings of doubt from others or of themselves, and pressure. White colleagues did not report feeling those pressures.

There is ample evidence that Students of Color thrive when our teachers and administrators reflect the diversity of the schools they work in (Boser, 2011; ODE, 2016). In 2005 the state of Oregon's administrator workforce was 4.8\% Administrators of Color. After 10 years that number is still under $10 \%(\mathrm{ODE}, 2016)$ revealing that movement is slow and confirms research from other fields that when leadership is comprised of White leaders, they often continue to hire White leaders (Johnson \& Hekman, 2016). Given the increased barriers to success for Leaders of Color, specifically that they are working within a system of oppression that requires an additional characteristic of "thick skin" or "grit," it is not surprising that there is such a significant shortage of Principals of Color in Oregon. Because $90 \%$ of Oregon's leaders are White (ODE, 2016), the burden to improve schools cannot fall solely on our Leaders of Color. White leaders must also 
engage in concerted efforts to end the system of oppression that prevent Leaders of Color from serving in and succeeding in high school leadership roles.

Despite very complex working conditions, the principals in this study reported the importance of relationships as a key contributor to the success and their ability to sustain their spirit while creating the conditions for the success of their Latina/o students. This is not surprising, given that many researchers have revealed the importance of interconnected to others as it pertains to the human spirit (Miller, 2006; Palmer, 1997; Tisdell, 2001). Themes connected to relationships were brought up more than any other category in the study.

\section{Implications}

The findings of this study have implications for a variety of stakeholders: all principals, White principals, Principals of Color, district leaders, principal preparation programs, and policy makers. Implications include hiring practices, retention of strong leaders, advancement of Leaders of Color into administrative roles, professional development for principals, and the working conditions for principals.

All Principals. One of the key findings of this study was that the principals were sustained when they could enact their focus on equity. This is a finding potentially unique to this study due to the success these leaders had in eliminating achievement gaps, in this case, for Latina/o students. Equity was embedded into every aspect of their leadership. What sustained them through challenging moments was making a difference in the lives of students and their families, especially students that were traditionally underserved. They spoke often about reducing barriers for Students of Color and included discussions 
of equity in staff meetings, on data teams, in student management, during observation debriefs with teachers, and in community building. Thus, while the work was daunting due to the complexities of school leadership, the principals were sustained, a finding also revealed in Peterson $(2013,2014)$.

In addition, principals acted upon inequities through relationship building (Noddings, 1992). Principals were sustained by their interactions with students and staff. Many of these principals had strategies to ensure more visibility and accessibility to students, staff, and families. While not always easy, it was through relationships that added to the principals' self-efficacy and satisfaction of knowing it was their interactions that were making a difference for others.

The respondents in this study noted the importance of creating systems for building relationships, which helped overcome the many barriers that often impede working directly with the people they serve. They all cited difficult working conditions that included mandates that seemed unnecessary and bureaucratic in nature. To offset these frustrations, principals were deliberate in creating systems for relationship building such as creating Professional Learning Communities (PLCs), working in the halls where they can easily be found, inviting community members to meetings where they can be heard, connecting systematically with students they serve, and being highly visible in the school and the community.

It was not simply a need for relationships on the leaders behalf, but also recognition of the importance that relationships were to students that were traditionally underserved (Gay, 2010). There was a desire to support, what some in the study called, 
"the underdog." Principals in this study were deliberate in making sure that students that were traditionally underserved were known and valued (Gay, 2010). This not only helped these students succeed, but also connected back to these principals' purpose for coming to work each day. Thus, any work that detracts from the school leaders' ability to focus on equity and develop relationships with students, their families, and the teachers, may detract from sustaining their spirit and ability to persist in their work eliminating disparities for their Latina/o students (Sergiovanni, 1984).

These principals recognized the need to comply with the demands that are asked of them through policy at the district, state, and federal level, but none of these principals connected the technical side of their work to their sense of meaning and purpose, or human spirit (Jones, 2005; Miller, 2006; Palmer, 2003; Tisdell, 2001). Thus, it is important for principals to develop strategies to effectively and efficiently complete duties that may detract from their sense of meaning and purpose in order to focus on what is truly important to principals working to end educational disparities: equity and relationship building. Technical management tasks should not be prioritized over the moral imperative (Fullan et al., 2005) of addressing issues of equity.

Administrators Working With Principals of Color. This study also has implications for administrators working alongside and supervising Principals of Color. Our Principals of Color are facing barriers that White principals are not. Microaggressions, negative first impressions, and often, aggressive resistance are being experienced by Principals of Color while White male principals are not reporting these at all. Similar resistance was reported by two women in this study, but not at the same 
frequency as Principals of Color. Principals of Color and the women in this study persisted in their work despite barriers and active resistance that can wear one down and negatively impact their human spirit and impact their ability to persist in their role (Theoharis, 2007). These personal experiences with barriers may make Leaders of Color and women more likely to recognize resistance and micro-aggressions when they occur amongst staff and students; this recognition may cause them to be more likely to speak out against and interrupt microagressions, negative biases, and systems that disadvantage women and students of color as they occur (Bargh, Chen, \& Burrows, 1996).

Four of the Five Principals of Color in our study talked about being unafraid of having difficult conversations connected to equity. It is critical that principals work in environments where colleagues and supervisors that oversee them will support interruptions of micro-aggressions and working for equity. This is often not the case for women and people of color who report that they have experienced negative responses in the work place for engaging in equity work (Johnson \& Hekman, 2016). Administrators working with Principals of Color must recognize their moral obligation to react and respond to micro-aggressions so that our Principals of Color do not have to do so in isolation and have allies to support them.

It is critically important that all administrators see their role as allies for Students of Color, Staff of Color, and Principals of Color, and this focus has to be clearly identified as an expected part of their work. Two of the five White administrators shared that they found their sense of meaning and purpose when they were able to remove barriers for People of Color. In addition, White administrators must be diligent in 
identifying barriers that impact their colleagues (Lawrence \& Tatum, 1997), speak up as an ally, and proactively identify and support the development of Leaders of Color. While no White leaders in this study stated they were unafraid of having equity conversations, it is critical that they have the support to do so. Recognizing that every Principal of Color experienced micro-aggressions, White leaders need explicit practice in noticing and interrupting micro-aggressions that ideally would start in teacher preparation programs and certainly be addressed in principal preparation programs (Gay \& Howard, 2000). This can support Principals of Color in two ways. First, Principals of Color need White allies to stand up when micro-aggressions are committed against them (Boutte \& Jackson, 2014). Second, Principals of Color cannot be the sole interrupter in a school setting (Senyonga, 2011). Constantly being the sole equity champion can be exhausting and puts an unfair burden on People of Color (Boutte \& Jackson, 2014). It is imperative that White allies not just support equity related work, they must lead the charge for equitable practices for all of our students.

Given the research on the impact of White women when leading equity work (Johnson \& Hekman, 2016), it is equally important that men understand their privilege and are strong allies for women in leadership roles. In order to shift the culture of White male privilege, White males must recognize their role in the system in which they work.

Principals of Color. This study revealed that successful leaders were sustained by their equity focus and relationships. Because the Principals of Color experienced far more resistance than their White colleagues, it is important to create the conditions for Leaders of Color to remain connected to what is important to them during difficult times, 
which for the leaders in our study, was equity and relationships. Therefore, it is important for Principals of Color to be placed in schools where their sense of meaning and purpose is fulfilled. It may not be fulfilling for a Principal of Color to be placed in a primarily upper class, White school; district leaders must ask and respect the desires of the principals when making placement decisions. One Principal of Color revealed how fulfilling it was when kids sought her out when they experienced unjust treatment: "When kids aren't being treated fair, they will call me and they will find me." When asked what will get in the way of her meaning and purpose, she smiled as she emphatically shook her head and said, "Nothing. Nothing will ever get in the way of my sense of meaning and purpose.” This short and powerful response was especially inspiring given that this is the same leader who shared multiple, extreme experiences of micro-aggressions from all levels of her organization. Her sense of meaning and purpose clearly sustained her through extremely challenging times.

Microagressions are impacting Principals of Color dramatically, with criticism subtle and overt. As one Principal of Color remembered being asked, "How the hell did you become principal?" Principals of Color revealed feeling pressure to succeed, with microaggressions such as the one above highlighting why Principals of Color experience extra pressure and stress that their White colleagues do not experience. Unfortunately, Principals of Color must be prepared for heightened levels of questioning and judgment from others so as to not feel isolated (Peterson \& Vergara, 2016) and to discover ways that others have developed "grit," or a perseverance and passion towards a long-term goal (Duckworth et al., 2007), to make it through microagressions and resistance to their 
leadership. All principals, but especially Principals of Color should have a clear, long term goal in mind that can contribute to perseverance and passion and help them meet the expectations that are greater than those of White principals.

In addition to staying connected to students, four of the five Principals of Color spoke about the importance of networking or creating a support system. One that didn't speak explicitly about a support system did speak to being in many professional settings and feeling attacked by other staff or community members. One spoke about going for weeks at a time without seeing "someone that looked like me." There is a need for affinity groups, and professional organizations and districts must provide ways for Principals of Color to connect. Just as schools want Students of Color to have their identity affirmed in our schools, organizations should provide the same support to Principals of Color.

Implications for District Leadership. The ten successful leaders in this study were all equity driven and effectively reduced educational disparities for Latina/o students, finding their human spirit sustained through their focus. District leadership would benefit from finding more leaders who are equity driven, meaning that the hiring of Principals of Color and White allies should be a focus for district leadership. This is especially challenging, in particular for women and minority leaders looking to break systems of oppression or bias in which White leaders may inadvertently perpetuate the status quo by hiring those who look like them (Johnson \& Hekman, 2016).

When it comes to promoting leaders for equity to the principalship, it is also important to note that this study revealed that every Principal of Color was promoted to 
their principalship by a central office administrator without going through a committee interview process, processes that are often White-normed and may advantage White applicants. While the leaders worked hard to be appointed to their initial administrator position, they all were advanced to the principalship based on a superintendent's belief in their leadership abilities. The implication may be that district leadership and superintendents across the state of Oregon and across the nation need to be prepared to promote Principals of Color to the principalship, rather than going through the standard hiring process with committees of teachers, family members, and central office administrators who often represent the White dominant culture (Razack, 1998) and may unintentionally design systems that advantage White applicants.

In addition to the recruitment implications of this study are the implications of retention. All of the administrators made it abundantly clear that the work conditions are a key factor that detract from the sustainability of their work and sustaining their spirit. They cited long hours, unnecessary initiatives, and mandates from local and state levels that were a drain to their core mission. This study indicates that district leadership must focus their initiatives that improve equity and relationships while protecting administrators from tasks that may distract from this focus. Principals compared the work to "swimming in the deep end," "juggling too many balls," "getting through red tape," and "being on 24/7." District leadership must consider the mandates that they are placing on principals and ask themselves two questions. First, is this mandate or strategic plan connected to equity or relationships? Two, is this necessary for the safe operation of schools in our district? A clear focus that allowed for autonomy was important for the 
participants in this study. Any attempt to improve working conditions in a district will only help principals stay in their roles longer, attract qualified candidates to the work of leadership in schools and allow them to focus on reducing educational disparities. Time for principals spent outside of their buildings must be thoughtful and align a focus on equity and support relationship building amongst colleagues.

Districts may also consider encouraging and implementing leadership curriculum devoted to reflective and authentic connection to one's purpose for leading. Parker Palmer's organization, Center for Courage and Renewal's, Courage to Lead (2017) and Heifetz \& Linsky's Leadership on the Line (2002) are two examples of resources that support meaningful curriculum that can help leaders sustain their spirits in the midst of complex organizations.

Principals of Color also reported that they are more likely to follow expectations rather than challenge expectations that do not align with their goals. Four of the five Principals of Color reported that they are likely to follow the chain of command. No White leaders made the same statements. In fact, one White leader noted that he is likely to challenge expectations. This means that district leaders must recognize that the system of oppression that we work within has set up a hierarchy that inhibits the full participation of Principals of Color. The system may explicitly or implicitly signal the expectation that Principals of Color must follow directives while privileging the input or pushback of White principals.

As mentioned in the previous section for Principals of Color, it is important for district leadership to create and support the conditions for affinity groups, especially for 
Administrators of Color. This can also serve the purpose of allowing White administrators the opportunities to discuss what it means to be an ally and practice interrupting micro-aggressions, which was a key implication for administrators working with Principals of Color.

Lastly, while higher education works to improve preparation programs for future education leaders (further discussion to follow), district leadership must continue to provide adequate equity training for future administrators. They must be deliberate about supporting leaders with relevant equity training. Recently, North Clackamas School District Superintendent Matt Utterback won the award for National Superintendent of the Year. North Clackamas, is a suburban district that neighbors the Portland School District in Portland, Oregon. His award came for his deliberate work on equity that has made a significant difference for the students he serves. As a White male, he is privileged in doing the equity work (McIntosh, 2010) and he has the responsibility and moral obligation to pursue equal outcomes for his students. Each employee in the district participates in a two-day training on equity that helps participants recognize the system of oppression in the context of Oregon. Additionally, the district funds a four-day, threenight training for each of their administrators to support equity work by helping their administrators create their own equity platform. In addition, they recently created an equity policy and equity lens that is embedded in decision making at all levels of the district. This is an example of how district leaders can support the work of equity rather than waiting for preparation programs to do so. 


\section{Implications for Higher Education Principal Preparation Programs. All ten}

leaders went through their principal preparation programs over six years ago and some went through a program over 20 years ago. Only one principal in our entire study shared that his preparation program supported his role as a leader in a school with a significant amount of Latina/o students. In fact, four of the five Principals of Color shared that their experience didn't help prepare for leading Latina/o students and was actually a negative experience. Principal preparation programs need to support future administrators in recognizing inequities and building relationships. Principal preparation programs must support future principals in recognizing the importance of equitable practices and help future principals be called to action through the discovery of inequities.

Therefore, programs need to highlight disparities that exist for our students and create a sense of urgency for future leaders to ensure all children succeed in our schools. This could be an opportunity for preparation programs to become hyper focused on the problem of inequity. If our future leaders can connect their own sense of meaning and purpose to eliminating achievement gaps for traditionally underserved students, this will likely lead to principals feeling satisfied and fulfilled even in the midst of challenges and resistance from others.

This study also found that Principals found relationships to be both fulfilling and serve as a conduit towards serving traditionally underserved students. Higher education programs must support this work by help future principals create systems for creating relationships and prioritize the importance of relationship building amongst students, 
staff, and families (Noddings, 2005). The relationships that principals model for their students and staff are likely to be mirrored by the teachers.

In addition to recognizing barriers for others, it was also prevalent that White principals recognized their own White privilege. This was a critical part of recognizing barriers for others. Preparation programs must support White leaders in understanding and recognizing their own privilege and biases. It is not until White leaders recognize privilege that they will be able to recognize barriers, especially in the form of microaggressions (McIntosh, 2010).

Higher education programs can also support future Principals of Color by preparing them for the system of oppression that they are about to lead. Principals of Color in this study were quick to offer advice to future leaders that looked more like warnings of what to expect. Programs need to support Leaders of Color by helping them create support systems and seek out White allies that can come along side them as they lead what is likely to be a largely White organization.

Some say that principals make hundreds of decisions every day (Weaver, 2007). Administrator preparation programs need to prepare leaders to make decisions for equity while recognizing their moral obligation to do so. The connection between equity, and morality is imperative in a culture of quick decision-making and the need to support many components in a complex system.

Implications for Policy. All principals in this study spoke about distractions from the big picture, managerial work, and bureaucracy as barriers to their success. Policy makers must recognize the impact of well-intentioned decisions. Recently Oregon passed 
Measure 98, a measure intended to support drop out reduction, and career and college readiness programs. The bill was unfunded and simply reallocated $\$ 800$ per student for districts that could show new programs to support the bills purpose. Meanwhile, Measure 97 failed. Measure 97 would have increased taxes on business with gross sales of 25 million dollars or more by 2.5 percent. As the new budget for Oregon has been proposed, schools are facing budget cuts and reductions and at the same time, adding programs that support drop out prevention and career and college readiness in an effort to collect the 800 dollars promised by Measure 98 . This is an example of the unintended consequences of policy that add to the bureaucracy of the work. These two Measures are a perfect example of the high accountability and low trust society that Blackmore (2001) describes that creates challenging working environments for principals and others.

In December of 2015 ESSA was passed giving states an opportunity to create their own measurements of accountability. In the state of Oregon, and in many states across the nation, the ramifications of this are still unknown. One implication of this study is the need to be cautious of creating systems that add additional unfunded work for teachers and leaders while recognizing the importance of accountability and data gathering for recognizing and working to eliminate educational disparities. Impacting policy is an opportunity for policy makers to work in collaboration with educators to ensure that educators are not so consumed with compliance reporting that they cannot engage in practices that reduce educational disparities in schools. 


\section{Conclusion}

Few studies examine how principals successful with reducing educational disparities with Latina/o students are able to sustain themselves while leading for equity. Marshall (2009) revealed that teachers getting into the profession of education are doing so to fulfill a sense of calling or mission to help others. Palmer (1997) describes the human spirit as a deep yearning to be connected to something larger than oneself, further confirming the connection between the human spirit and education. Principals in this study affirmed Marshall's findings: that educators seem to have an internalized spiritual framework but some may lack the language or intentionality to talk about it.

Interestingly, the successful principals in our study, principals who have served for one to three decades, shared the same idealistic answers that the newly-seated teachers in Marshall's study shared: They entered our profession to help others and to see students succeed. What sustains them in their complex work is their sense of meaning when reducing barriers for underserved students and the relationships they develop with students and staff, relationships that are identified to be key to helping students succeed. The strong desire for relationships and relationship building is a key construct in the research of the human spirit (Jones, 2005; Miller, 2006; Noddings, 2005; Palmer, 1997; Peterson, 2014).

As principals engage in complex, challenging work, our educational system needs to identify which leaders are reducing educational disparities and ensure that superintendents sustain their human spirit by nurturing those who work as change agents and equity champions (Peterson, 2014). Barriers to principals' work included negative 
working conditions that did not allow principals to focus on equity and student success. While some may call for a work-life balance as the answer (Wilmore, 2004; Whitaker, 1996), these principals found that despite the job feeling overwhelming, they were still able to sustain their human spirit by remaining focused on equity and relationships. This study confirmed that being a leader for equity and reducing educational disparities is challenging work that takes a toll on the principal leaders. However, the ten principals in this study showed that through engagement in equity-focused leadership and relationship building, it is possible to sustain one's spirit and thrive. 


\section{REFERENCES:}

Achinstein, B., Ogawa, R. T., Sexton, D., \& Freitas, C. (2010). Retaining teachers of color: A pressing problem and a potential strategy for "hard-to-staff"

schools. Review of Educational Research, 80(1), 71-107.

American Association of School Administrators. (2007). AASA Releases Study of the American School Superintendency. Retrieved from

http://www.aasa.org/content.aspx?id=8392

Allison, D. G. (1997). Coping with stress in the principalship. Journal of Educational Administration, 35(1), 39-55.

Alt, M. N., \& Henke, R. (2007). To Teach or Not to Teach? Teaching Experience and Preparation among 1992-93 Bachelor's Degree Recipients 10 Years after College. Statistical Analysis Report. NCES 2007-163. National Center for Education Statistics.

Angelo, J. M., (2002). Education bill finally passes; draws fire from national associations. Retrieved from http://www.districtadministration.com/article/government-spotlight

Anguiano, C., Milstein, T., De Larkin, I., Chen, Y. W., \& Sandoval, J. (2012). Connecting community voices: Using a Latino/a critical race theory lens on environmental justice advocacy. Journal of International and Intercultural Communication, 5(2), 124-143.

Bandura, A. (1986). Social foundations of thought and action: A social cognitive theory. Prentice-Hall, Inc.

Bandura, A. (2006). Guide for constructing self-efficacy scales. Self-efficacy beliefs of adolescents, 5(307-337).

Bargh, J. A., Chen, M., \& Burrows, L. (1996). Automaticity of social behavior: Direct effects of trait construct and stereotype activation on action. Journal of personality and social psychology, 71(2), 230.

Barnes, R. D. (1989). Race consciousness: The thematic content of racial distinctiveness in critical race scholarship. Harv. L. Rev., 103, 1864.

Barr, R. B., \& Tagg, J. (1995). From teaching to learning-A new paradigm for undergraduate education. Change: The magazine of higher learning, 27(6), 12-26. 
Barth, R. S. (2006). Improving relationships within the schoolhouse. Educational Leadership, 63(6), 8.

Bass, B. M. (1996). A New Paradigm for Leadership: An Inquiry into Transformational Leadership. STATE UNIV OF NEW YORK AT BINGHAMTON.

Bell, D. A. (1995). Who's afraid of critical race theory. U. Ill. L. Rev., 893.

Bernard, H. R. (1988). Research methods in cultural anthropology (p. 117). Newbury Park, CA: Sage.

Béteille, T., Kalogrides, D., \& Loeb, S. (2012). Stepping stones: Principal career paths and school outcomes. Social Science Research, 41(4), 904-919.

Bitterman, A., Goldring, R., \& Gray, L. (2013). Characteristics of Public and Private Elementary and Secondary School Principals in the United States: Results from the 2011-12 Schools and Staffing Survey. First Look. NCES 2013-313. National Center for Education Statistics.

Blackmore, J. (2001). Leadership for socially just schooling: More substance and less style in high-risk, low-trust times?. Vol 12-N2, 12, 198.

Bogdan, R., \& Biklen, S. (2007). Qualitative research for education: An introduction to theory and practice.

Bolman, L. G., \& Deal, T. E. (2011). Reframing organizations: Artistry, choice and leadership. John Wiley \& Sons.

Boser, U. (2011). Teacher diversity matters: A state by state analysis of teachers of color. Retrieved from https://cdn.americanprogress.org/wpcontent/uploads/issues/2011/11/pdf/ teacher_diversity.pdf

Boutte, G. S., \& Jackson, T. O. (2014). Advice to white allies: Insights from faculty of color. Race Ethnicity and Education, 17(5), 623-642.

Bridges, E. M. (1977). The Changing Nature of Leadership. In Cunnignham, R., Hack, W. \& Nystrand, R. (Eds.), Educational Administration: The Developing Decades (Pp 202-230). Berkely, CA: McCutchan Publishing.

Browne-Ferrigno, T. (2003). Becoming a principal: Role conception, initial socialization, role-identity transformation, purposeful engagement. Educational administration quarterly, 39(4), 468-503. 
Burkhauser, S., Gates, S. M., Hamilton, L. S., \& Ikemoto, G. S. (2012). First-Year Principals in Urban School Districts: How Actions and Working Conditions Relate to Outcomes. Technical Report. Rand Corporation.

The Carnegie Project on the Educational Doctorate. (2017). A Knowledge Forum on the EdD. Retrieved from www.cpedinitiative.org

Center for Courage \& Renewal. (2017). Courage to Lead Programs. Retrieved from: http://www.couragerenewal.org/courage-to-lead/

Center for Public Education. (2012). The Principal Perspective: At a Glance. Retrieved From

http://www.centerforpubliceducation.org/Main-Menu/Staffingstudents/ThePrincipal- Perspective-at-a-glance.

Center for Public Education. (2016). Educational Equity. What do we know about it? How do we know when we've reached it? Retrieved from http://www.centerforpubliceducation.org/educationalequity.

Childress, S. M., Doyle, D. P., \& Thomas, D. A. (2009). Leading for Equity: The Pursuit of Excellence in the Montgomery County Public Schools. Harvard Education Press. 8 Story Street First Floor, Cambridge, MA 02138.

Clegg, S. R. (1990). Modern organizations: Organization studies in the postmodern world. London: Sage Publications.

Cohen, D. \& Crabtree, B. (2006). Qualitative research guidelines project.

Copland, M. (2001). The myth of the superprincipal. Phi Delta Kappan, 82(7), 528-533.

Corbin, J., \& Morse, J. M. (2003). The unstructured interactive interview: Issues of reciprocity and risks when dealing with sensitive topics. Qualitative inquiry, 9(3), 335-354.

Creswell, J. W. (2009). Research design: Qualitative, quantitative, and mixed methods approaches (3rd edition). Thousand Oaks, CA: Sage Publications.

Creswell, J. W. (2013). Research design: Qualitative, quantitative, and mixed methods approaches (3rd edition). Thousand Oaks, CA: Sage Publications. (Chapter 1)

Cross, C.T. (2014). Political Education: Setting the Course for State and Federal Policy, Second Edition. New York, NY: Teachers College Press. 
Crowell, S. (2003). Attributes of the Heart That Reenchant Learning. Paths of Learning. 16,6 .

Cummins, J. (2005). Affirming Identity in Multilingual Classrooms. Educational Leadership, 63 (1), 38.

Curry-Stevens, A., \& Cross-Hemmer, A. (2010). Coalition of Communities of Color (2010). Communities of color in Multnomah County: An unsettling profile.

Deal, T., \& Peterson, K. (2009). Shaping School Culture: Pitfalls, Paradoxes, \& Promises. San Francisco, CA: Jossey-Bass.

Delpit, L. D. (2012). "Multiplication is for White People": Raising Expectations for Other People's Children. The New Press.

Diamond, J. B. (2013). Distributed leadership: Examining issues of race, power and inequality. In Tillman, L. C., \& Scheurich, J. J. (Eds.). Handbook of research on educational leadership for equity and diversity (pp. 83-104). New York, NY: Routledge.

DiAngelo, R. (2011). White fragility. The International Journal of Critical Pedagogy, 3(3).

Drago-Severson, E. (2012). The need for principal renewal: The promise of sustaining principals through principal-to-principal reflective practice. Teachers College Record, 114(12), 1-56.

Duckworth, A. L., Peterson, C., Matthews, M. D., \& Kelly, D. R. (2007). Grit: perseverance and passion for long-term goals. Journal of personality and social psychology, 92(6), 1087.

DuFour, R., DuFour, R., Eaker, R., \& Many, T. (2006). Learning by doing. Bloomington, IN: Solution Tree.

Dworkin, A. G., Haney, C. A., Dworkin, R. J., \& Telschow, R. L. (1990). Stress and illness behavior among urban public school teachers. Educational Administration Quarterly, 26(1), 60-72.

Elias, J. L., \& Merriam, S. B. (2005). Philosophical foundations of adult education. Kueger. Malabar Florida.

Farkas, S., Johnson, J., Foleno, T., Duffett, A., \& Foley, P. (2000). A sense of calling: Who teaches and why. New York: Public Agenda. 
Federici, R. A., \& Skaalvik, E. M. (2012). Principal self-efficacy: Relations with burnout, job satisfaction and motivation to quit. Social Psychology of Education,15(3), 295-320.

Ferrer, J. N. (2003). Dialogical inquiry as spiritual practice. Tikkun, 18(1), 29-32.

Fowler, Frances C. (2013). Policy Studies for Educational Leaders: An Introduction, 4th edition. Boston, MA: Pearson Press.

Freire, P. (2000). Pedagogy of the oppressed. Bloomsbury Publishing.

Fullan, M. (1993). Change forces: Probing the depths of educational reform(Vol. 10). Psychology Press.

Fullan, M. (1999). Change forces: The sequel. Psychology Press.

Fullan, M. (2002). Leadership and sustainability. Principal leadership, 3(4), 14-17.

Fullan, M., Cuttress, C., \& Kilcher, A. (2005). Eight forces for leaders of change. Journal of Staff Development, 26(4), 54.

Furman, G. C., \& Gruenewald, D. A. (2004). Expanding the landscape of social justice: A critical ecological analysis. Educational administration quarterly, 40(1), 47-76.

Gates, S. M., Ringel, J. S., Santibanez, L., Guarino, C., Ghosh-Dastidar, B., \& Brown, A. (2006). Mobility and turnover among school principals. Economics of Education Review, 25(3), 289- 302.

Gay, G., \& Howard, T. C. (2000). Multicultural teacher education for the $21 \mathrm{st}$ century. The Teacher Educator, 36(1), 1-16.

Gay, G. (2010). Culturally responsive teaching: Theory, research, and practice. Teachers College Press.

Glaser, B., \& Strauss, A. (1967). The discovery of grounded theory. London: Weidenfeld and Nicholson.

Gordon, J. A. (2000). The color of teaching. Taylor \& Francis.

Guarino, C. M., Santibanez, L., \& Daley, G. A. (2006). Teacher recruitment and retention: A review of the recent empirical literature. Review of educational research, 76(2), 173-208. 
Hartfiel, N., Havenhand, J., Khalsa, S. B., Clarke, G., \& Krayer, A. (2011). The effectiveness of yoga for the improvement of well-being and resilience to stress in the workplace. Scandinavian journal of work, environment \& health, 70-76.

Hattie, J. (2009). Visible Learning: A Synthesis of Over 800 Meta-Analyses Relating to Achievement. New York, NY: Routledge.

Heifetz, R. A., \& Laurie, D. L. (1997). The work of leadership. Harvard business review, 75, 24-134.

Heifetz, R. A., \& Linsky, M. (2002). Leadership on the line.

Heifetz, R. A., \& Linsky, M. (2004). When leadership spells danger. Educational Leadership, 61(7), 33-37.

Hitt, D. H., Tucker, P. D., \& Young, M. D. (2012). The Professional Pipeline for Educational Leadership. A White Paper Developed to Inform the Work of the National Policy Board for Educational Administration. University Council for Educational Administration.

Jackson, D., Firtko, A., \& Edenborough, M. (2007). Personal resilience as a strategy for surviving and thriving in the face of workplace adversity: a literature review. Journal of advanced nursing, 60(1), 1-9.

Jenkins, B. (2009). What It Takes to Be an Instructional Leader. Principal,88(3), 34-37.

Jinpa, T. (2015). A fearless heart: How the courage to be compassionate can transform our lives. New York, NY: Hudson Street Press.

Jones, L. (2005). What does spirituality in education mean? Stumbling toward wholeness. Journal of College and Character, 6(7). 1-7.

Johnson, S. K., \& Hekman, D. R. (2016). Women and Minorities are Penalized for Promoting Diversity. Harvard Business Review, 60(2), 771-797.

Ladson-Billings, G., \& Tate IV, W. (1995). Toward a critical race theory of education. The Teachers College Record, 97(1), 47-68.

Lambert, L. (2002). The constructivist leader. Teachers College Press.

Lawrence, S. M., \& Tatum, B. D. (1997). Teachers in Transition: The Impact of Antiracist Professional Development on Classroom Practice. Teachers College Record, 99(1), 162-78. 
Leana, C. R. (2011). The missing link in school reform. Stanford Social Innovation Review, 9(4), 30-35.

Leithwood, K. A., \& Poplin, M. S. (1992). Transformational Leadership. Educational leadership, 49, 5.

Leithwood, K., Day, C., Sammons, P., Harris, A., \& Hopkins, D. D.(2006).Seven strong claims about successful school leadership.

Leithwood, K., Louis, K. S., Anderson, S., \& Wahlstrom, K. (2004). Executive summary How leadership influences student learning.

Lincoln, Y. S., Lynham, S. A., \& Guba, E. G. (2011). Paradigmatic controversies, contradictions, and emerging confluences, revisited. The Sage handbook of qualitative research, 4, 97-128.

Louis, K. S., Leithwood, K., Wahlstrom, K. L., \& Anderson, S. E. (2010, July). Learning from leadership: Investigating the links to improved student learning (Final Report of Research to the Wallace Foundation). St. Paul, MN: Center for Applied Research and Educational Improvement, University of Minnesota.

Markow, D., \& Pieters, A. (2012). The Metlife survey of the American teacher: teachers, parents and the economy. New York: Metlife.

Marshall, C. (2004). Social justice challenges to educational administration: Introduction to a special issue. Educational Administration Quarterly, 40(1), 3-13.

Marshall, J. M. (2009). Describing the elephant: Preservice teachers talk about spiritual reasons for becoming a teacher. Teacher Education Quarterly, 25-44.

Marzano, R. J. (2015). Designing \& teaching learning goals \& objectives. Solution Tree Press.

Maslach, C., Schaufeli, W. B., \& Leiter, M. P. (2001). Job burnout. Annual review of psychology, 52(1), 397-422.

Mathis, W. J., \& Trujillo, T. M. (2016). EVERY STUDENT SUCCEEDS ACT.

Maxwell, J. A. (2012). Qualitative research design: An interactive approach: An interactive approach. Sage.

May, D. R., Gilson, R. L., \& Harter, L. M. (2004). The psychological conditions of meaningfulness, safety and availability and the engagement of the human spirit at work. Journal of occupational and organizational psychology, 77(1), 11-37. 
Mayes, C., Mayes, P. B., \& Sagmiller, K. (2003). The sense of spiritual calling among teacher education program students. Religion and Education, 30(2), 84-109.

McIntosh, P. (2010). White privilege and male privilege. The Teacher in American Society: A Critical Anthology, 121.

McLaren, P. (2003). Critical pedagogy: A look at the major concepts. The critical pedagogy reader, 69-96.

Merriam, S. B., \& Cafarella, R. (1991). Learning in Adulthood: A Comprehensive Guide Jossey Bass Publishers, Inc. Reprinted:(1998) "Toward Comprehensive Theories of Adult Learning” Needham Heights, MA: Simon and Schuster.

Miller, R. (2006). Reflecting on spirituality in education. Encounter: Education for Meaning and Social Justice, 19(2), 6-9.

Morgan, G. (1980). Paradigms, metaphors, and puzzle solving in organization theory. Administrative science quarterly, 605-622.

National Education Association. (2013). 2012-2013 Average Starting Teacher Salaries by State. Retrieved from http://www.nea.org/home/2012-2013-average-starting-teacher-salary.html

National Center for Education Statistics, (2014). Public High School Four-Year OnTime Graduation Rates and Event Dropout Rates: School Years 2010-11 and 2011-12. Retrieved from http://nces.ed.gov/pubs2014/2014391.pdf

National Center for Education Statistics, (2014). Public High School Four-Year Adjusted Cohort Graduation Rates: School Year 2013-14. Retrieved from http://nces.ed.gov/ccd/tables/ACGR_RE_and_characteristics_2013-14.asp

National Center for Educational Statistics. (2014). School and Staffing Statistics. Retrieved from https://nces.ed.gov/surveys/sass/tables list.asp\#2012.

National Center for Educational Statistics. (2015). NAEP Data Explorer. Retrieved from http://nces.ed.gov/nationsreportcard/lttdata/

National Center for Educational Statistics. (2015). Racial/Ethnic Enrollment in Public Schools. Retrieved from http://nces.ed.gov/programs/coe/indicator_cge.asp

National Urban League. (2015). State of Black America: Save our Cities. New York, NY: NUL 
Nieto, S. (2009). Multicultural education in the United States. The Routledge international companion to multicultural education, 79.

Noddings, N. (1992). The challenge to care in schools. New York, NY: Teachers College Press.

Noguera, P. A. (2008). Creating schools where race does not predict achievement: The role and significance of race in the racial achievement gap. The Journal of Negro Education, 90-103.

Noddings, N. (2005). Caring. In The Challenge to Care in Schools (pp. 15-27). New York \& London: Teachers College Press.

Oregon Center for Educational Equity. (2014, January). Looking back in order to move forward: An often history affecting Oregon's past, present and future.

Oregon Department of Education, (2016). 2016 Oregon Educator Equity Report. Retrieved from http://tspc.oregon.gov/publications/EducatorEquityReport_CEdO_July_2016.pdf

Oregon Department of Education, (2011). Oregon Framework for Teacher and Administrator Evaluation and Support Systems: Revised 2014-2015 State Guidelines for ESEA Waiver and SB 290. retrieved from http://www.ode.state.or.us/wma/teachlearn/educatoreffectiveness/oregonframework--for-eval-and-support-systems.pdf

Oregon Department of Education, (2016), An Annual Report to the Legislature on Oregon Public Schools: Statewide Report Card 2015 - 2016. retrieved from http://www.ode.state.or.us/data/annreportcard/rptcard2016.pdf

Oregon Health and Science University, (2016), List of Cities and Towns in Oregon by ORH Urban/Rural Definition: 10 Mile Radius from a City of 40,000 or More. Retrieved from: http://www.ohsu.edu/xd/outreach/oregon-rural-health/data/ruraldefinitions/upload/List-of-Towns-and-Cities-in-Oregon-by-ORH-Urban.pdf

Oregon Tell Survey. (2016). Retrieved from https://telloregon.org/results

Palmer, P. (1997) The Courage to Teach: Exploring the Inner Landscape of a Teacher's Life. San Francisco, CA: Jossey-Bass Publishers.

Palmer, P. J. (2003). Teaching with heart and soul reflections on spirituality in teacher education. Journal of Teacher Education, 54(5), 376-385. 
Palmer, P. J. (2011). Healing the heart of democracy: The courage to create a politics worthy of the human spirit. John Wiley \& Sons.

Patton, M. Q. (2002). Two decades of developments in qualitative inquiry a personal, experiential perspective. Qualitative social work, 1(3), 261-283.

Pavlov, I. P., \& Anrep, G. V. (2003). Conditioned reflexes. Courier Corporation.

Peterson, D.S. (2013). Drafted! An urban principal's tale. Educational Leadership, 70(7): 74-77.

Peterson, D.S. (2014). A Missing Piece in the Sustainability Movement: The Human Spirit. Sustainability: The Journal of Record, 7(2), 74-77.

Peterson, D.S. \& Vergara, V. (2016). Thriving in school leadership: Latina/o leaders speak out. National Forum of Educational Administration and Supervision Journal, 34(4): 2-15. http://www.nationalforum.com/Journals/NFEASJSI/NFEASJ-SI.htm

Piaget, J. (1969). Science of education and the psychology of the child. (D. Coltman, Trans., 1970). New York, NY: Orion Press.

Ramsey, C. P. (1962). Leadership preparation. Educational Leadership, 20, 151-154.

Razack, S. (1998). Looking white people in the eye: Gender, race, and culture in courtrooms and classrooms. University of Toronto Press.

Roeser, R. W., Skinner, E., Beers, J., \& Jennings, P. A. (2012). Mindfulness training and teachers' professional development: An emerging area of research and practice. Child Development Perspectives, 6(2), 167-173.

Roeser, R. W. (2014). The Emergence of Mindfulness-Based Interventions in Educational Settings. In Motivational Interventions (pp. 379-419). Emerald Group Publishing Limited.

Saldaña, J. (2016). The coding manual for qualitative researchers. Sage.

Senyonga, M. (2011). The Impact of Intergroup Dialogue Program on Students' Recognition and Interruption of Microaggressions.

Serow, R. C. (1994). Called to teach: A study of highly motivated preservice teachers. Journal of Research \& Development in Education.

Scheurich, J. J., \& Skrla, L. (2003). Leadership for equity and excellence: Creating high- 
achievement classrooms, schools, and districts. Corwin Press.

Sergiovanni, T.J. (1984). Leadership and Excellence in Schooling: Excellent Schools Need Freedom Within Boundaries. Educational Leadership. 41(2), 4-13.

Sergiovanni, T. (1990). Value-added leadership: How to get extraordinary performance in schools. San Diego, CA: Harcourt Brace Jovanovich, Publishers.

Shapiro, D. A. N. I. E. L. (2009). Why repressing emotions is bad for business. Harvard business review, 87(11), 30-130.

Sjøberg, S. (2007). Constructivism and learning. International Encyclopaedia of Education. Oxford: Elsevier.[On-line]. Disponivel: http://folk. uio. no/sveinsj/Constructivism_and_learning_Sjoberg. pdf. Recuperado, 10.

Skinner, B. F. (1938). The behavior of organisms: An experimental analysis.

Skinner, B. F. (1974). About behaviorism. Alfred A.

Smith, G., \& Williams, D. (Eds.). (1999). Ecological Education in Action: On Weaving Education, Culture, and the Environment. Albany, NY: State University of New York Press.

Sprick, R. (2009). Doing Discipline Differently. Principal Leadership, 9(5), 18-22.

Steinar, K. (1996). Interviews: An introduction to qualitative research interviewing. Studentlitteratur, Lund, 8.

Strauss, A., \& Corbin, J. (1994). Grounded theory methodology. Handbook of qualitative research, 273-285.

Strauss, A., \& Corbin, J. (1998). Basics of qualitative research: Techniques and procedures for developing grounded theory $\left(2^{\text {nd }}\right.$ ed.). Thousand Oaks, CA: Sage.

Swedberg, R., \& Agevall, O. (2005). The Max Weber dictionary: key words and central concepts. Stanford University Press.

Tapia, A. H., \& Kvasny, L. (2004, April). Recruitment is never enough: retention of women and minorities in the IT workplace. In Proceedings of the 2004 SIGMIS conference on Computer personnel research: Careers, culture, and ethics in a networked environment (pp. 84-91). ACM.

Tatum, B. D. (2007). Can we talk about race?: And other conversations in an era of School resegregation. Beacon Press. 
Theoharis, G. (2007). Social Justice Educational Leaders and Resistance: Toward a Theory of Social Justice Leadership. Education Administration Quarterly, 43(2). 221-258.

Tisdell, E. J. (2001). Spirituality in Adult and Higher Education. ERIC Digest.

Tschannen-Moran, M., \& Gareis, C. R. (2004). Principals' sense of efficacy: Assessing a promising construct. Journal of Educational Administration, 42(5), 573-585.

UCEA University Council for Educational Administration. (2012). The professional pipeline for educational leadership: a white paper developed to inform the national policy board of educational administration [White paper]. Retrieved from http://3f17112qoj413y6ep2tqpwra.wpengine.netdna-cdn.com/wpcontent/uploads/2014/08/PipelineWhitePaper_web.pdf

United States Census Bureau. Projections Show a Slower Growing, Older, More Diverse Nation a Half Century from Now. Retrieved from: https://www.census.gov/newsroom/releases/archives/population/cb12-243.html

United States Census Bureau. Supplemental measure of poverty remains unchanged. Retrieved on November 6, 2013 from http://www.census.gov/newsroom/releases/archives/poverty/cb13-183.html

United States Department of Education. (2010). A blueprint of reform: The reauthorization of the elementary and secondary education act. Retrieved from https://www2.ed.gov/policy/elsec/leg/blueprint/blueprint.pdf

United States Department of Education. (2015). Every student succeeds Act. Retrieved from http://www.ed.gov/essa

Villalpando, O. (2004). Practical considerations of critical race theory and Latino critical Theory for Latino college students. New Directions for Student Services, 2004(105), 41-50.

The Wallace Foundation. (2007). Educational Leadership. A Bridge to School Reform. National Conference. Retrieved from: http://www.wallacefoundation.org/knowledgecenter/school-leadership/key-research/Documents/Bridge-to-School-Reform.pdf

Weaver, R. L. (2007). What principals need to know about ethics.

Whitaker, K. (1996). Exploring Causes of Principal Burnout. Journal of Educational Administration, 34(1). 60-71. 
Wilmore, E.L. (2004). Principal induction: A standards-based model for administrator development. Thousand Oaks, CA: Corwin Press. 
Date:

Dear

Our names are Ryan Richardson, Assistant Principal at Rex Putnam High School in North Clackamas, and Victor Vergara, High School Principal at the Academy of International Studies, Woodburn High School in Woodburn. We are also Education Doctorate candidates at Portland State University, and it is for this purpose that we are reaching out to you. Our dissertation topic is about the sustainability and characteristics of successful school leaders. The aggregate results of this study will be published in our final dissertations.

We are writing you to request your participation in our study. You are being asked to participate in this study because the school you lead has shown to have successful academic results for your students. We will use this data to identify characteristics of successful school leaders and how they sustain themselves in the midst of complex organizations.

All your answers would be confidential, and there will be no way to tie the responses to you or to your schools/districts. We will confirm with you, prior to publishing our study, that we have protected your confidentiality. We are contacting high school principals from different districts across Oregon to participate in this study.

Your participation is voluntary. If you choose to participate, then let us thank you in advance for your assistance in our research. In addition, you may choose to stop your participation at any time during this study. If you have any questions whatsoever about this request or the research itself, please feel free to contact us, Ryan Richardson, at 503353-5864, richardsonr@nclack.k12.or.us, Victor Vergara at 503-980-6100, vvergara@woodburnsd.org or our Portland State University doctoral candidate 
supervisor, Deborah Peterson, at (503) 490 5504,dpeterson@pdx.edu.

If you are interested in participating in this study of successful leadership in Oregon please respond to this email and we will follow up.

Sincerely,

Ryan Richardson \& Victor Vergara

Ed.D. Candidates

Portland State University 
Appendix B Letter to Superintendents to Request Permission to Study

Date:

Dear

Our names are Ryan Richardson, Assistant Principal at Rex Putnam High School in North Clackamas, and Victor Vergara, High School Principal at the Academy of International Studies, Woodburn High School in Woodburn. We are also Education Doctorate candidates at Portland State University, and it is for this purpose that we are reaching out to you. Our dissertation topic is about the sustainability of the human spirit of successful high school principals and how culturally responsive high school leaders successfully work with Latina/o students. The aggregate results will be published in our final dissertations.

We are writing you to request permission to contact in order to ask him/her to participate in our study. We have chosen ___ because they has demonstrated successful leadership in a school with higher graduation rates of Latina/o students than what is expected according to state data. The participants will all be confidential, and there will be no way to tie the responses to individuals or to schools/districts included in the study.

We thank you for your assistance in our research and if allowable, the permission to contact your administrator about his/her participation. If you have any questions whatsoever about this request or the research itself, please feel free to contact us, Ryan Richardson, at 503-353-5864, richardsonr@nclack.k12.or.us, Victor Vergara at 503-9806100,vvergara@woodburnsd.org or our Portland State University doctoral candidate supervisor, Deborah Peterson, at (503) 490 5504,dpeterson@pdx.edu.

We would appreciate your approval to include your successful principal's in our study. 
Please respond to this email with your approval by September $30^{\text {th }}, 2016$.

Sincerely,

Ryan Richardson \& Victor Vergara

Ed.D. Candidates

Portland State University 


\section{Appendix C Interview Questions}

1. Describe your career pathway (role, what part of the country, how long): e.g., first I was an educational assistant for 3 years in California, then for 6 years a teacher in Portland, then a dean for one year in Portland, next a vice principal for 8 years in Hillsboro, and then a principal in Hillsboro for 3 years, etc.

2. Who helped you, inspired you, and motivated you along the way as a leader and how did they do so?

a. Was this person from a non-dominant or dominant culture (Gender, race, sexual orientation, able-bodied)?

3. As you decided to become a leader in education, were you met with any resistance from anyone or anything? a. If yes: Who (in what role, group, or culture) or what held you back or tried to hold you back as you became a leader?

4. We noted that your school has a higher population of Latina/o students than state averages. How did your formal training for administration prepare you to become a leader in schools with a high population of Latina/o students?

5. What was the best advice and support you received, as you became a leader in schools with a high population of Latina/o students?

6. What are your unique leadership characteristics that help Latina/o students be successful?

7. What are your most important priorities and/or initiatives as a school leader? a. Why are these the most important?

8. To what do you attribute your success with Latina/o students graduating high school or performing well on assessments?

9. What leadership expectations does your superintendent and school board have of you?

a. What expectations do you think they should have for you?

10. What messages do you give teachers about their work? What about students and families? 
11. As a member of the White/Latina/o/__ culture, what else should future White/Latina/o/__ leaders know about becoming a leader in schools with high populations of Latina/o students?

12. As a high school principal, what gives you a sense of meaning and purpose? In other words, what motivates you to do the work that you're doing?

13. As a high school principal, what, if anything, gets in the way of you connecting to your sense of meaning and purpose? 
Appendix D Consent for Participation in Research

\section{Principal Investigators: Ryan Richardson \& Victor Vergara}

Introduction:

You are being asked to participate in a research study conducted by Ryan Richardson and Victor Vergara, Doctoral Students, at Portland State University in Portland, Oregon. This study is examining culturally responsive school leadership and the sustaining of the human spirit of these educational leaders for social justice from the dominant and the non-dominant culture.

You are being asked to participate in this study because the school you lead has a successful Latino/a student population as measured by higher than expected Latina/o graduation rates as compared to state averages. We will use interview data to identify conditions that support the retention of school leaders from the dominant and nondominant culture and their work with Latina/o students.

We will protect your confidentiality, ensuring that no information you share can be attributed to you in any way. All information that could link you to this study will be deidentified and will remain confidential. We will confirm our findings with you prior to sharing our findings with others.

The information below explains the research study, the possible risks, and possible benefits to you. If you have any questions, please contact Ryan Richardson at 503.353.5864 and/or Victor Vergara at 503.980.6100 or at vvergara@woodburnsd.org Your participation is voluntary. Your participation in this study includes at the maximum, a two-hour interview about your career and what motivates you to be a school leader who successfully ensures Latina/o student success.

The benefit of your participation is that you will contribute to the body of research regarding how to recruit, prepare, and retain school leaders to work successfully with Latina/o students. The benefit of participation in this study is high, as the study could potentially provide an evidence-informed method of determining strategies to prepare and retain school leaders from the dominant and non-dominant cultures. The study could make a significant contribution to the literature on how to help with the recruitment of school leaders that are ready to work with Latina/o students.

The research presents minimal risk of harm to participants. The researchers, Doctoral students Ryan Richardson and Victor Vergara will de-identify all information that could link you to the data. While there is little risk of stress, emotional distress, inconvenience or loss of privacy and confidentiality associated with participating in this study, if you should experience any of these, please contact Ryan Richardson at richardsons@nclack.k12.or.us and/or Victor Vergara at vvergara@woodburnsd.org 
immediately and they will assist you with finding appropriate support and will discontinue your participation in the study. In addition, if at any time you would like to withdraw from the study, you may contact Doctoral students Ryan Richardson and/or Victor Vergara and they will withdraw your data from the study.

How will my information be kept confidential?

We will take measures to protect the security of all your personal information. Confidentiality is guaranteed for all study participants and data collected. Pseudonyms will be used for all participants. All names or identifying characteristics which could potentially compromise confidentiality will be de-identified. All information you share is confidential. All notes, transcripts, and materials collected in the course of this study will be stored in a locked office of the researcher. Materials stored digitally are accessible by the researcher on a password-protected computer in a locked office. The records will be stored in the researcher's locked office for a period of three years from the time of completion of the study.

Information contained in our study records will be used by study staff only. The Portland State University Institutional Review Board (IRB) that oversees human subject research and/or other entities may be permitted to access your records. There may be times when we are required by law to share your information, for example, it is the investigator's legal obligation to report child abuse, child neglect, elder abuse, harm to self or others or any life-threatening situation to the appropriate authorities; in those cases, therefore, your confidentiality would not be maintained. Your name will not be used in any published reports about this study.

There is no compensation for participating in this study. Your participation in this study is completely voluntary. You have the right to choose not to participate or to withdraw your participation at any point in this study without penalty or loss of benefits to which you are otherwise entitled.

If you have any questions, concerns or complaints at any time about the research study, please contact Doctoral students Ryan Richardson at richardsonr@nclack.k12.or.us and/or Victor Vergara at vvergara@woodburnsd.org

If you have questions regarding your rights as a research participant, you may call the PSU Office for Research Integrity at (503) 725-2227 or 1(877) 480-4400. The ORI is the office that supports the PSU Institutional Review Board (IRB). The IRB is a group of people from PSU and the community who provide independent oversight of safety and ethical issues related to research involving human participants. For more information, you may also access the IRB website at https://sites.google.com/a/pdx.edu/research/integrity. 


\section{CONSENT}

You are making a decision whether to participate in this study. Your signature below indicates that you have read the information provided (or the information was read to you). By signing this consent form, you are not waiving any of your legal rights as a research participant.

You have had an opportunity to ask questions and all questions have been answered to your satisfaction. By signing this consent form, you agree to participate in this study. A copy of this consent form will be provided to you.

$\overline{\text { Name of Adult Subject (print) }} \overline{\text { Signature of Adult Subject }}$ Date

\section{INVESTIGATORS SIGNATURE}

This research study has been explained to the participant and all of his/her questions have been answered. The participant understands the information described in this consent form and freely consents to participate.

Ryan Richardson/ Victor Vergara

Name of Investigators/ Research Team Members (type or print)

(Signature of Investigator/ Research Team Member)

Date 
Appendix E SPSS Results: Shared Vision

Table A1

One-Sample Statistics

\begin{tabular}{lr|r|r|r} 
& $N$ & Mean & Std. Deviation & Std. Error Mean \\
\hline Q71a2016 & 7 & 66.086 & 21.8977 & 8.2765 \\
\hline
\end{tabular}

Table A2

\section{One-Sample Test}

\begin{tabular}{|c|c|c|c|c|c|c|}
\hline & & & Test & Value $=70.8$ & & \\
\hline & & & Sig. (2- & Mean & $\begin{array}{r}95 \% \text { Co } \\
\text { Interva } \\
\text { Diffe }\end{array}$ & $\begin{array}{l}\text { dence } \\
\text { f the } \\
\text { ice }\end{array}$ \\
\hline & $\mathrm{t}$ & $\mathrm{df}$ & tailed) & Difference & Lower & Upper \\
\hline $\begin{array}{l}\text { Q71a201 } \\
6\end{array}$ & -.570 & 6 & .590 & -4.7143 & -24.966 & 15.538 \\
\hline
\end{tabular}


Appendix F SPSS Results: Trust, Mutual Respect

Table A3

\section{One-Sample Statistics}

\begin{tabular}{lr|c|r|r} 
& N & Mean & Std. Deviation & Std. Error Mean \\
\hline Q71b2016 & 7 & 69.429 & 18.2148 & 6.8845 \\
\hline
\end{tabular}

Table A4

\section{One-Sample Test}

\begin{tabular}{|c|c|c|c|c|c|c|}
\hline & \multicolumn{6}{|c|}{ Test Value $=71.7$} \\
\hline & \multirow[b]{2}{*}{$t$} & \multirow[b]{2}{*}{$\mathrm{df}$} & \multirow{2}{*}{$\begin{array}{l}\text { Sig. (2- } \\
\text { tailed) }\end{array}$} & \multirow{2}{*}{$\begin{array}{c}\text { Mean } \\
\text { Difference }\end{array}$} & \multicolumn{2}{|c|}{$\begin{array}{c}95 \% \text { Confidence } \\
\text { Interval of the } \\
\text { Difference }\end{array}$} \\
\hline & & & & & Lower & Upper \\
\hline $\begin{array}{l}\text { Q71b20 } \\
16\end{array}$ & -.330 & 6 & .753 & -2.2714 & -19.117 & 14.574 \\
\hline
\end{tabular}


Appendix G SPSS Results: Staff Can Raise Concerns

Table A5

\section{One-Sample Statistics}

\begin{tabular}{lr|r|r|r} 
& $\mathrm{N}$ & Mean & Std. Deviation & Std. Error Mean \\
\hline Q71c2016 & 7 & 68.700 & 15.4904 & 5.8548 \\
\hline
\end{tabular}

Table A6

One-Sample Test

\begin{tabular}{|c|c|c|c|c|c|c|}
\hline & \multicolumn{6}{|c|}{ Test Value $=72$} \\
\hline & & & Sig. (2- & & $\begin{array}{l}95 \% \text { Co } \\
\text { Interva } \\
\text { Diffe }\end{array}$ & $\begin{array}{l}\text { dence } \\
\text { of the } \\
\text { nce }\end{array}$ \\
\hline & $\mathrm{t}$ & df & tailed) & Difference & Lower & Upper \\
\hline $\begin{array}{l}\text { Q71c20 } \\
16\end{array}$ & -.564 & 6 & .593 & -3.3000 & -17.626 & $26^{11.0}$ \\
\hline
\end{tabular}


Appendix H SPSS Results: Leadership Supports Teachers

Table A7

\section{One-Sample Statistics}

\begin{tabular}{lr|r|r|r} 
& $N$ & Mean & Std. Deviation & Std. Error Mean \\
\hline Q71d2016 & 7 & 75.800 & 17.2477 & 6.5190 \\
\hline
\end{tabular}

Table A8

One-Sample Test

\begin{tabular}{|c|c|c|c|c|c|c|}
\hline & & & Test 1 & Value $=75$. & & \\
\hline & & & Sig. (2- & $\begin{array}{c}\text { Mean } \\
\text { Differenc }\end{array}$ & $\begin{array}{r}95 \% \text { Co } \\
\text { Interva } \\
\text { Differ }\end{array}$ & $\begin{array}{l}\text { fidence } \\
\text { of the } \\
\text { nce }\end{array}$ \\
\hline & $\mathrm{t}$ & $\mathrm{df}$ & tailed) & $\mathrm{e}$ & Lower & Upper \\
\hline $\begin{array}{l}\text { Q71d20 } \\
16\end{array}$ & .031 & 6 & .977 & .2000 & -15.751 & 16.151 \\
\hline
\end{tabular}


Appendix I SPSS Results: High Professional Standards

Table A9

\section{One-Sample Statistics}

\begin{tabular}{lr|c|r|r} 
& N & Mean & Std. Deviation & Std. Error Mean \\
\hline $\mathrm{Q} 71 \mathrm{e} 2016$ & 7 & 87.414 & 16.0825 & 6.0786 \\
\hline
\end{tabular}

Table A10

\section{One-Sample Test}

\begin{tabular}{|c|c|c|c|c|c|c|}
\hline & & & Test & Value $=88$ & & \\
\hline & & & Sig. (2- & $\begin{array}{c}\text { Mean } \\
\text { Differenc }\end{array}$ & $\begin{array}{r}95 \% \text { Co } \\
\text { Interva } \\
\text { Diffe }\end{array}$ & $\begin{array}{l}\text { idence } \\
\text { of the } \\
\text { nce }\end{array}$ \\
\hline & $\mathrm{t}$ & $\mathrm{df}$ & tailed) & $\mathrm{e}$ & Lower & Upper \\
\hline $\begin{array}{l}\text { Q71e20 } \\
16\end{array}$ & -.096 & 6 & .926 & -.5857 & -15.460 & 14.288 \\
\hline
\end{tabular}


Table A11

\section{One-Sample Statistics}

\begin{tabular}{ll|r|r|r} 
& $N$ & Mean & Std. Deviation & Std. Error Mean \\
\hline Q71f2016 & 7 & 85.771 & 8.7838 & 3.3200 \\
\hline
\end{tabular}

Table A12

\section{One-Sample Test}

\begin{tabular}{|c|c|c|c|c|c|c|}
\hline & \multicolumn{6}{|c|}{ Test Value $=84.1$} \\
\hline & \multirow[b]{2}{*}{$t$} & \multirow[b]{2}{*}{ df } & \multirow{2}{*}{$\begin{array}{l}\text { Sig. (2- } \\
\text { tailed) }\end{array}$} & \multirow{2}{*}{$\begin{array}{c}\text { Mean } \\
\text { Differenc } \\
\mathrm{e}\end{array}$} & \multicolumn{2}{|c|}{$\begin{array}{l}95 \% \text { Confidence } \\
\text { Interval of the } \\
\text { Difference }\end{array}$} \\
\hline & & & & & Lower & Upper \\
\hline $\begin{array}{l}\text { Q71f20 } \\
16\end{array}$ & .503 & 6 & .633 & 1.6714 & -6.452 & 9.795 \\
\hline
\end{tabular}


Appendix K SPSS Results: Teacher Performance Assessed Objectively

Table A13

One-Sample Statistics

\begin{tabular}{lr|r|r|r} 
& $N$ & Mean & Std. Deviation & Std. Error Mean \\
\hline Q71g2016 & 7 & 83.229 & 7.7783 & 2.9399 \\
\hline
\end{tabular}

Table A14

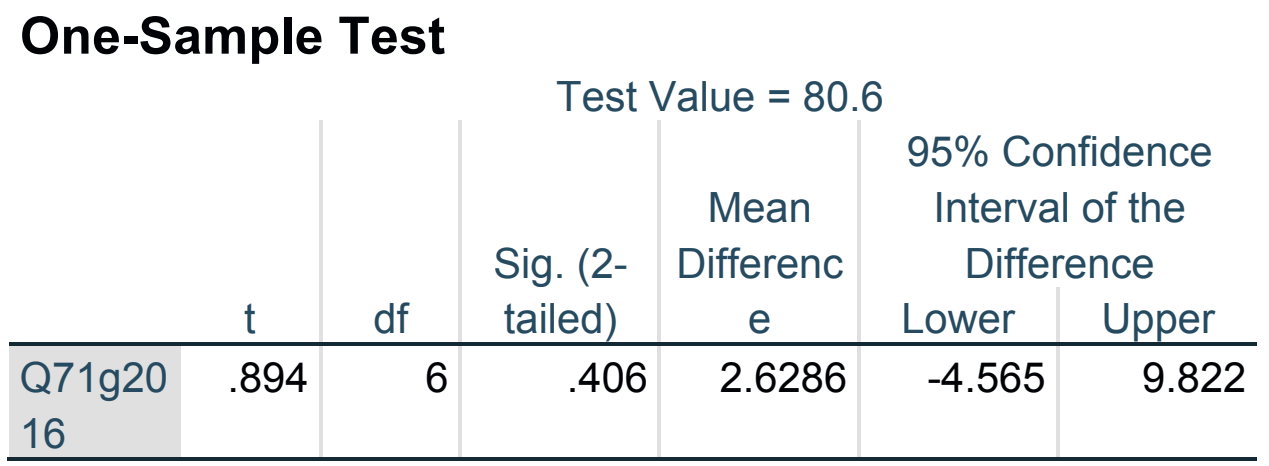


Appendix L SPSS Results: Helpful Feedback for Improvement

Table A15

\section{One-Sample Statistics}

\begin{tabular}{lr|r|r|r} 
& N & Mean & Std. Deviation & Std. Error Mean \\
\hline Q71h2016 & 7 & 77.257 & 14.9076 & 5.6345 \\
\hline
\end{tabular}

Table A16

\section{One-Sample Test}

\begin{tabular}{|c|c|c|c|c|c|c|}
\hline & \multicolumn{6}{|c|}{ Test Value $=74.4$} \\
\hline & & & Sig. (2- & $\begin{array}{c}\text { Mean } \\
\text { Differenc }\end{array}$ & $\begin{array}{l}95 \% \text { Co } \\
\text { Interva } \\
\text { Diffe }\end{array}$ & $\begin{array}{l}\text { fidence } \\
\text { of the } \\
\text { nce }\end{array}$ \\
\hline & $\mathrm{t}$ & df & tailed) & $\mathrm{e}$ & Lower & Upper \\
\hline $\begin{array}{l}\text { Q71h20 } \\
16\end{array}$ & .50 & t & .63 & 2.8571 & -10.930 & 16.644 \\
\hline
\end{tabular}


Appendix M SPSS Results: Ongoing Teacher Feedback

Table A17

\section{One-Sample Statistics}

\begin{tabular}{lrrrrr} 
& $\mathrm{N}$ & Mean & Std. Deviation & Std. Error Mean \\
\hline Q71i2016 & 7 & 58.186 & 23.8725 & 9.0230 \\
\hline
\end{tabular}

Table A18

One-Sample Test

\begin{tabular}{|c|c|c|c|c|c|c|}
\hline & \multicolumn{6}{|c|}{ Test Value $=62.7$} \\
\hline & \multirow[b]{2}{*}{$\mathrm{t}$} & \multirow[b]{2}{*}{$\mathrm{df}$} & \multirow{2}{*}{$\begin{array}{l}\text { Sig. (2- } \\
\text { tailed) }\end{array}$} & \multirow{2}{*}{$\begin{array}{c}\text { Mean } \\
\text { Differenc } \\
e\end{array}$} & \multicolumn{2}{|c|}{$\begin{array}{l}95 \% \text { Confidence } \\
\text { Interval of the } \\
\text { Difference }\end{array}$} \\
\hline & & & & & Lower & Upper \\
\hline $\begin{array}{l}\text { Q71i20 } \\
16\end{array}$ & -.500 & 6 & .635 & -4.5143 & -26.593 & 17.564 \\
\hline
\end{tabular}


Appendix N SPSS Results: Evaluations Consistent

Table A19

\section{One-Sample Statistics}

\begin{tabular}{ll|l|r|r} 
& $\mathrm{N}$ & Mean & Std. Deviation & Std. Error Mean \\
\hline Q71j2016 & 7 & 75.771 & 10.2972 & 3.8920 \\
\hline
\end{tabular}

Table A20

One-Sample Test

\begin{tabular}{|c|c|c|c|c|c|c|}
\hline & & & Test & Value $=74$ & & \\
\hline & & & Sig. (2- & Mean & $\begin{array}{r}95 \% \text { Co } \\
\text { Interva } \\
\text { Diffe }\end{array}$ & $\begin{array}{l}\text { idence } \\
\text { of the } \\
\text { nce }\end{array}$ \\
\hline & $\mathrm{t}$ & $\mathrm{df}$ & tailed) & Difference & Lower & Upper \\
\hline $\begin{array}{l}\text { Q71j201 } \\
6\end{array}$ & .455 & 6 & .665 & 1.7714 & -7.752 & 11.295 \\
\hline
\end{tabular}


Appendix O SPSS Results: Admin Uses Evaluation Tool Well

Table A21

\section{One-Sample Statistics}

\begin{tabular}{lr|r|r|r} 
& $\mathrm{N}$ & Mean & Std. Deviation & Std. Error Mean \\
\hline Q71k2016 & 7 & 80.271 & 15.0443 & 5.6862 \\
\hline
\end{tabular}

Table A22

\section{One-Sample Test}

\begin{tabular}{|c|c|c|c|c|c|c|}
\hline & & & Test & /alue $=78$ & & \\
\hline & & & Sig. (2- & $\begin{array}{c}\text { Mean } \\
\text { Differenc }\end{array}$ & $\begin{array}{r}95 \% \text { Co } \\
\text { Interva } \\
\text { Diffe }\end{array}$ & $\begin{array}{l}\text { idence } \\
\text { of the } \\
\text { nce }\end{array}$ \\
\hline & $\mathrm{t}$ & $\mathrm{df}$ & tailed) & $\mathrm{e}$ & Lower & Upper \\
\hline $\begin{array}{l}\text { Q71k20 } \\
16\end{array}$ & .294 & 6 & .779 & 1.6714 & -12.242 & 15.585 \\
\hline
\end{tabular}


Appendix P SPSS Results: School Improvement Team Leads

Table A23

\section{One-Sample Statistics}

\begin{tabular}{lr|r|r|r} 
& $\mathrm{N}$ & Mean & Std. Deviation & Std. Error Mean \\
\hline $\mathrm{Q} 71 / 2016$ & 7 & 70.171 & 26.3231 & 9.9492 \\
\hline
\end{tabular}

Table A24

One-Sample Test

\begin{tabular}{|c|c|c|c|c|c|c|}
\hline & & & Test & /alue $=69$. & & \\
\hline & & & Sig. (2- & $\begin{array}{c}\text { Mean } \\
\text { Differenc }\end{array}$ & $\begin{array}{r}95 \% \text { Co } \\
\text { Interva } \\
\text { Diffe }\end{array}$ & $\begin{array}{l}\text { idence } \\
\text { of the } \\
\text { nce }\end{array}$ \\
\hline & $\mathrm{t}$ & $\mathrm{df}$ & tailed) & $\mathrm{e}$ & Lower & Upper \\
\hline $\begin{array}{l}\text { Q71/20 } \\
16\end{array}$ & .027 & 6 & .979 & .2714 & -24.073 & 24.616 \\
\hline
\end{tabular}


Appendix Q SPSS Results: Recognition of Accomplishments

Table A25

One-Sample Statistics

\begin{tabular}{lr|r|r|r} 
& N & Mean & Std. Deviation & Std. Error Mean \\
\hline Q71m2016 & 7 & 78.443 & 10.6075 & 4.0093 \\
\hline
\end{tabular}

Table A26

\section{One-Sample Test}

\begin{tabular}{|c|c|c|c|c|c|c|}
\hline & & & Test & /alue $=78$ & & \\
\hline & & & Sig. (2- & $\begin{array}{c}\text { Mean } \\
\text { Differenc }\end{array}$ & $\begin{array}{r}95 \% \text { Co } \\
\text { Interva } \\
\text { Diffe }\end{array}$ & $\begin{array}{l}\text { idence } \\
\text { of the } \\
\text { nce }\end{array}$ \\
\hline & $\mathrm{t}$ & $\mathrm{df}$ & tailed) & $\mathrm{e}$ & Lower & Upper \\
\hline $\begin{array}{l}\text { Q71m20 } \\
16\end{array}$ & -.114 & 6 & .913 & -.4571 & -10.267 & 9.353 \\
\hline
\end{tabular}


Appendix R SPSS Results: Good Place to Work and Learn

Table A27

\section{One-Sample Statistics}

\begin{tabular}{lr|r|r|r} 
& N & Mean & Std. Deviation & Std. Error Mean \\
\hline Q1072016 & 7 & 86.371 & 14.0822 & 5.3226 \\
\hline
\end{tabular}

Table A28

\section{One-Sample Test}

\begin{tabular}{|c|c|c|c|c|c|c|}
\hline & & & Test & /alue $=85$ & & \\
\hline & & & Sig. (2- & $\begin{array}{c}\text { Mean } \\
\text { Differenc }\end{array}$ & $\begin{array}{r}95 \% \text { Co } \\
\text { Interva } \\
\text { Diffe }\end{array}$ & $\begin{array}{l}\text { idence } \\
\text { of the } \\
\text { nce }\end{array}$ \\
\hline & $\mathrm{t}$ & $\mathrm{df}$ & tailed) & $\mathrm{e}$ & Lower & Upper \\
\hline $\begin{array}{l}\text { Q10720 } \\
16\end{array}$ & .089 & 6 & .932 & .4714 & -12.552 & 13.495 \\
\hline
\end{tabular}




\section{Appendix S Question 1 Responses}

Question 1. Describe your career pathway (role, what part of the country, how long)?

Table three shows themes that emerged from the respondents. Themes are split apart according to the race of the respondent.

Table A29

Number of responses placed into each theme during question 1

\begin{tabular}{lcc}
\hline Themes for Question 1 & Administrators of Color & White Administrators \\
\hline Was promoted to principal without & 5 & 1 \\
an interview & 5 & 0 \\
I was encouraged by someone & 2 & 1 \\
Demanding job & 2 & 1 \\
References an intrinsic goal & 2 & 1 \\
Adverse experiences in childhood & 3 & 0 \\
Reference to equity & 2 & 0 \\
Barriers to getting licensure & 1 & 0 \\
Teaching through relationship & 1 & 1 \\
Commitment to religion &
\end{tabular}




\section{Appendix T Question 2 Responses}

Question 2. Who helped you, inspired you, and motivated you along the way as a leader and how did they do so? Was this person from a non-dominant or dominant culture?

Table A30

Number of responses placed into each theme during question 2

\begin{tabular}{lcc}
\hline Themes for Question 2 & Administrators of Color & White Administrators \\
\hline $\begin{array}{l}\text { Needed grit to make it to where } \\
\text { they are now. }\end{array}$ & 3 & 1 \\
Looking out for the underdog & 3 & 1 \\
They were a collaborative leader & 2 & 2 \\
Leaders that were deliberate & 1 & 1 \\
decision maker & 1 & 1 \\
Made me want to respond to & & \\
difficult situations that led to & 1 & 0 \\
despondence & 1 & 1 \\
Helped me overcome adverse & & 1 \\
experiences in childhood & 1 & 3 \\
Instilled a desire to impact large & & \\
groups & 1 & \\
I was surprised that someone saw & & \\
something in me & & \\
They gave me positive & & \\
encouragement & & \\
They had a focus on equity & &
\end{tabular}




\section{Appendix U Question 3 Responses}

Question 3. As you decided to become a leader in education, were you met with any resistance from anyone or anything?

Table A31

Number of responses placed into each theme during question 3

\begin{tabular}{lcc}
\hline Themes for Question 3 & Administrators of Color & White Administrators \\
\hline I had to have thick skin/grit & 5 & 0 \\
Microaggressions & 5 & 1 \\
First impression/judgments & 4 & 1 \\
Aggressive resistance & 3 & 1 \\
I needed to prove to others I can do & 3 & 0 \\
the job & & \\
None & 0 & 2 \\
Teacher resistance when I switched & 1 & 0 \\
roles & 1 & 0 \\
I wasn't sure I could do it & 1 & 0 \\
Connection to the community helped & & \\
overcome resistance & 1 & 0 \\
Institutional/Generational racism & 1 & 0 \\
I wanted to be a leader but they were & & \\
used to a manager & 1 & 0 \\
I distrusted others or myself & 0 & 1 \\
Family resistance &
\end{tabular}




\section{Appendix V Question 4 Responses}

Question 4. We noted that your school has a higher population of Latina/o students than state averages. How did your formal training for administration prepare you to become a leader in schools with a high population of Latina/o students?

Table A32

Number of responses placed into each theme during question 4

\begin{tabular}{lcc}
\hline Themes for Question 4 & Administrators of Color & White Administrators \\
\hline Informal/other training helped me & 4 & 3 \\
(ethnic studies major, doctoral & & 3 \\
program or district PD) & 5 & 0 \\
No positive formal training & 4 & 3 \\
I had one multicultural class but it & & 1 \\
was a negative experience & 2 & 3 \\
My life experiences prepared me & 0 &
\end{tabular}




\section{Appendix W Question 5 Responses}

Question 5. What was the best advice and support you received, as you became a leader in schools with a high population of Latina/o students?

Table A33

Number of responses placed into each theme during question 5

\begin{tabular}{lcc}
\hline Themes for Question 5 & Administrators of Color & White Administrators \\
\hline I received professional advice & 3 & 4 \\
I was warned about the pressures & 3 & 0 \\
connected to the job & 2 & 1 \\
I didn't receive advice & 1 & 1 \\
Be a role model & 1 & 1 \\
Be authentic (be yourself) & 1 & 0 \\
I received personal advice & &
\end{tabular}




\section{Appendix X Question 6 Responses}

Question 6. What are your unique leadership characteristics that help Latina/o students be successful?

Table A34

Number of responses placed into each theme during question 6

\begin{tabular}{lcc}
\hline Themes for Question 6 & Administrators of Color & White Administrators \\
\hline I am authentic & 4 & 3 \\
I keep students accountable & 4 & 1 \\
I give encouragement & 2 & 2 \\
I provide opportunities for Latina/o & 2 & 1 \\
students & & \\
I am a listener & 2 & 1 \\
I am a hard worker & 1 & 2 \\
I am caring & 0 & 2 \\
I promote family \& community & 2 & 0 \\
building & & 1 \\
I am a role model & 2 & 1 \\
I try to recognize barriers & 1 & 2 \\
I am accessible & 2 &
\end{tabular}




\section{Appendix Y Question 7 Responses}

Question 7. What are your most important priorities and/or initiatives as a school leader? Why are these the most important?

A35

Number of responses placed into each theme during question 7

\begin{tabular}{lcc}
\hline Themes for Question 7 & Administrators of Color & White Administrators \\
\hline Equity & 5 & 2 \\
Be culturally sensitive & 5 & 2 \\
Care for the whole child & 1 & 4 \\
Provide clear student expectations & 3 & 1 \\
Detrack students & 2 & 1 \\
Promote collaborative decision & 2 & 1 \\
making & & \\
Attendance / grades & 1 & 2 \\
Graduation rates & 2 & 1 \\
Be visible & 0 & 2
\end{tabular}




\section{Appendix Z Question 8 Responses}

Question 8. To what do you attribute your success with Latina/o students graduating high school or performing well on assessments?

Table A36

Number of responses placed into each theme during question 8

\begin{tabular}{lcc}
\hline Themes for Question 8 & Administrators of Color & White Administrators \\
\hline Create relationships & 2 & 5 \\
Provide access to resources for & 4 & 1 \\
students & 2 & 2 \\
Teachers & 4 & 0 \\
I'm not afraid of have difficult & & 2 \\
conversations about equity & 2 & 1 \\
We are data driven & 2 & 1 \\
We are connected to the community & 1 & 2 \\
ESL student support & &
\end{tabular}




\section{Appendix AA Question 9 Responses}

Question 9. What leadership expectations do your superintendent and school board have of you?

Table A37

Number of responses placed into each theme during question 9

\begin{tabular}{lcc}
\hline Themes for Question 9 & Administrators of Color & White Administrators \\
\hline They have high expectations of me & 4 & 3 \\
They expect me to work hard & 3 & 2 \\
I follow their expectations & 4 & 0 \\
Make equity a priority & 2 & 1 \\
There are no clear expectations & 1 & 3 \\
Be a leader, not just a manager & 2 & 1 \\
Be an instructional leader & 2 & 1 \\
Be a visionary leader & 1 & 0 \\
I can challenge the expectations & 0 & 1
\end{tabular}




\section{Appendix BB Question 10 Responses}

Question 10. What messages do you give teachers about their work? What about students and families?

Table A38

Number of responses placed into each theme during question 10

\begin{tabular}{lcc}
\hline Themes for Question 10 & Administrators of Color & White Administrators \\
\hline Teachers are valued and important & 4 & 4 \\
Collaboration is important & 4 & 2 \\
We need to motivate students & 3 & 2 \\
Be a data driven school & 1 & 1 \\
Relationships are important & 0 & 3 \\
Students need to work hard & 2 & 1 \\
Teachers need to take care of & 1 & 0 \\
themselves & &
\end{tabular}




\section{Appendix CC Question 11 Responses}

Question 11. As a member of the (i.e. White, Latina/o, etc...) culture, what else

should future (i.e. White, Latina/o, etc...) leaders know about becoming a leader in schools with high populations of Latina/o students?

Table A39

Number of responses placed into each theme during question 11

\begin{tabular}{lcc}
\hline Themes for Question 11 & Administrators of Color & White Administrators \\
\hline Be culturally sensitive & 2 & 5 \\
Have a support system & 3 & 2 \\
Prove yourself & 3 & 1 \\
Be prepared for judgments/first & 3 & 0 \\
impressions & & \\
Build relationships & 2 & 2 \\
This is a lonely job & 2 & 0 \\
Networking is important & 1 & 0 \\
Pick your battles & 1 & 0 \\
Be an active community member & 1 & 0
\end{tabular}

